\title{
MERCURY CONTAMINATED MATERIAL DECONTAMINATION METHODS: INVESTIGATION AND ASSESSMENT
}

Principal Investigator:

M.A. Ebadian, Ph.D.

\author{
Florida International University \\ Collaborators: \\ Marshall Allen \\ Yong Cai, Ph.D.
}

Consultant:

John F. McGahan

Prepared for:

U.S. Department of Energy Office of Environmental Management Office of Science and Technology

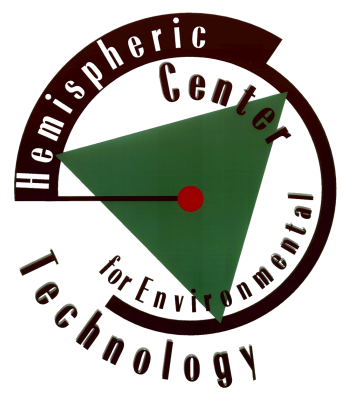




\section{DISCLAIMER}

This report was prepared as an account of work sponsored by an agency of the United States government. Neither the United States government nor any agency thereof, nor any of their employees, nor any of its contractors, subcontractors, nor their employees makes any warranty, express or implied, or assumes any legal liability or responsibility for the accuracy, completeness, or usefulness of any information, apparatus, product, or process disclosed, or represents that its use would not infringe upon privately owned rights. Reference herein to any specific commercial product, process, or service by trade name, trademark, manufacturer, or otherwise does not necessarily constitute or imply its endorsement, recommendation, or favoring by the United States government or any agency thereof. The views and opinions of authors expressed herein do not necessarily state or reflect those of the United States government or any agency thereof. 


\section{Principal Investigator}

M.A. Ebadian, Ph.D.

Hemispheric Center for Environmental Technology

Florida International University

Miami, FL 33174

\section{Florida International University Collaborators}

Marshall Allen, Yong Cai, Ph.D.

Hemispheric Center for Environmental Technology

Florida International University

Miami, FL 33174

January 2001

\section{Prepared for}

U.S. Department of Energy

Office of Environmental Management

Office of Science and Technology

U.S. Department of Energy

Under Grant No DE-FG21-95EW55094 



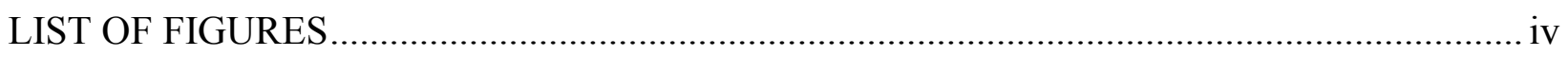

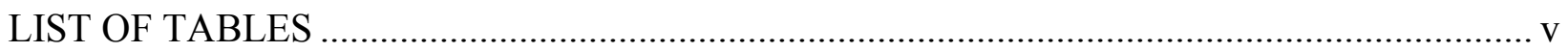

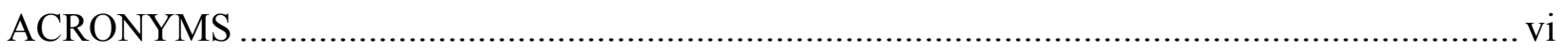

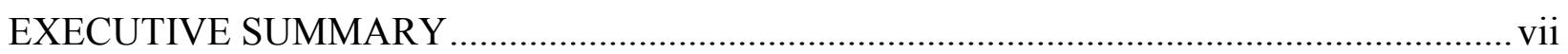

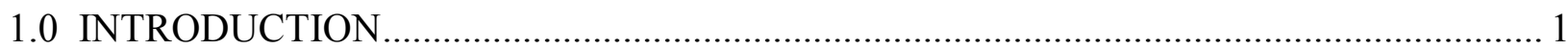

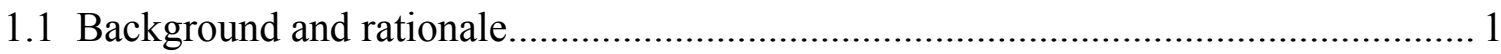

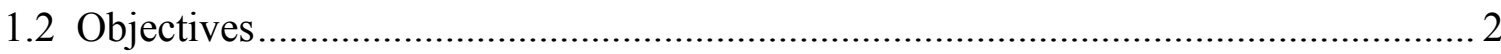

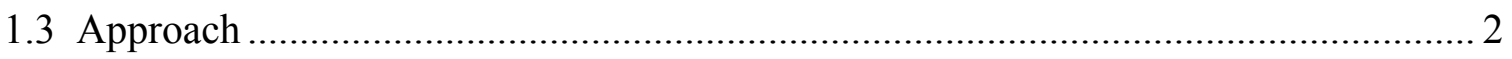

2.0 CHEMISTRY OF MERCURY AND ENVIRONMENTAL ISSUES ................................... 4

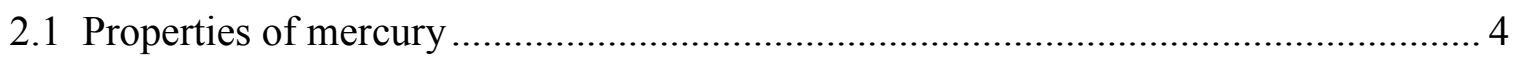

2.1.1 Properties of elemental mercury ……………...................................... 4

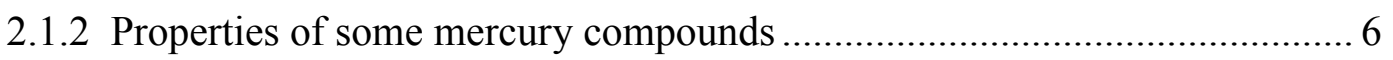

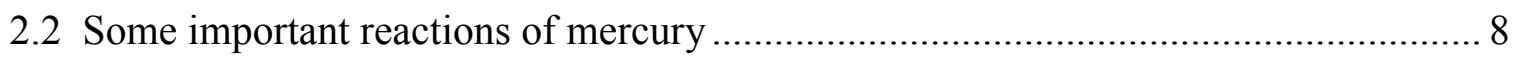

2.2.1 Reactions involving inorganic mercury ................................................. 8

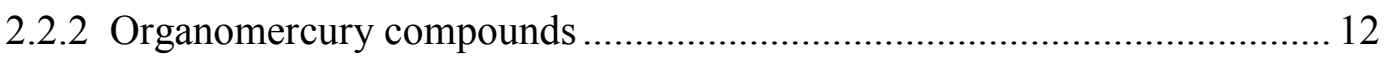

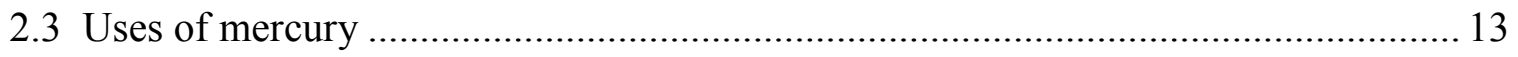

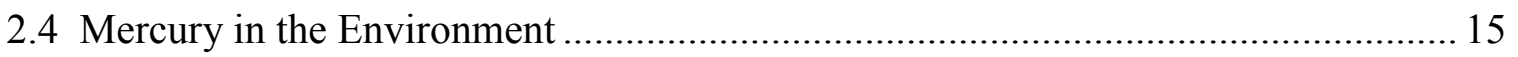

3.0 CONTROL TECHNIQUES FOR CONTAMINATED WATERS …………...................... 17

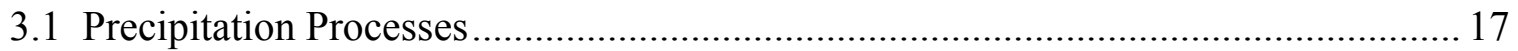

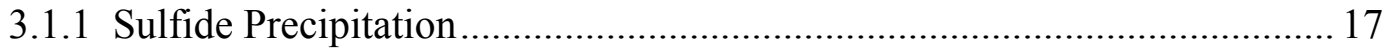

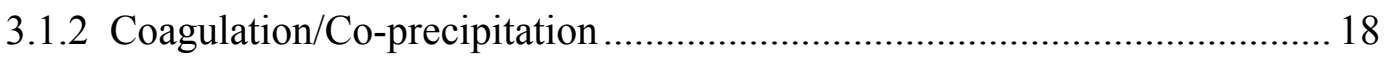

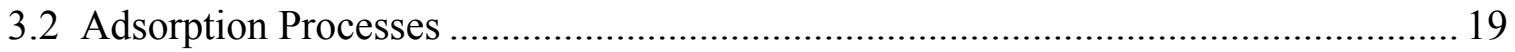

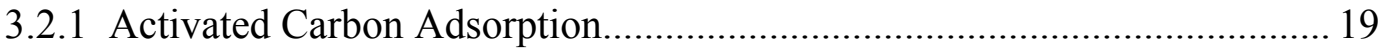

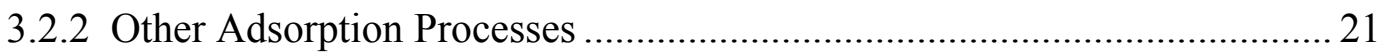

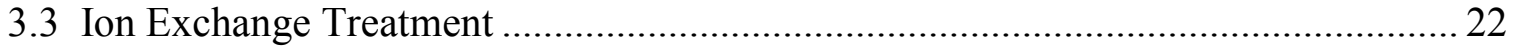

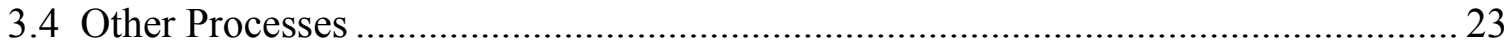

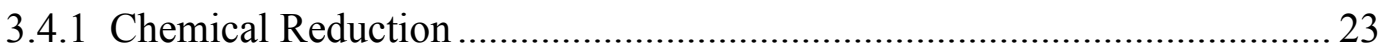

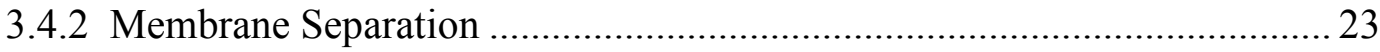

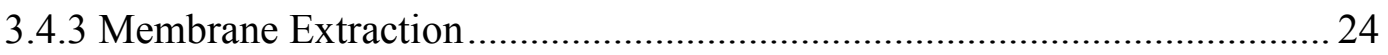

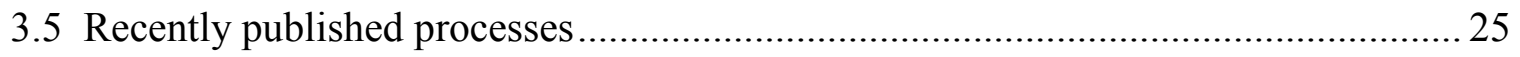

3.5.1 Self-Assembled Mercaptan on Mesoporous Silica (SAMMS) ................... 25

3.5.2 Graft Copolymer of Acrylamide onto Cellulose ........................................... 26

4.0 CONTROL TECHNIQUES FOR MIXED WASTE MATRICES ………………................. 27

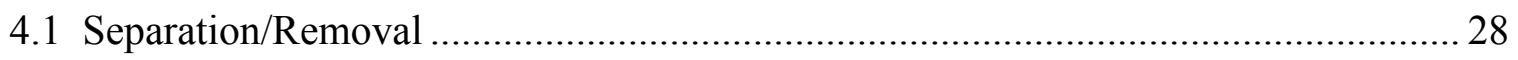

4.1.1 Thermal Treatment Processes ................................................................. 28 


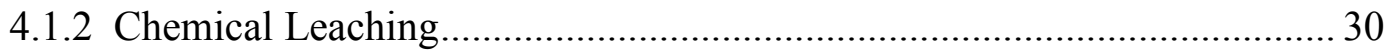

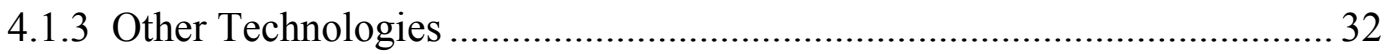

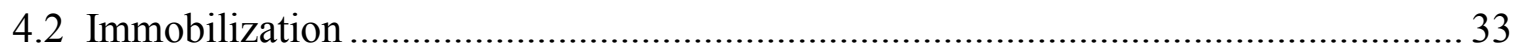

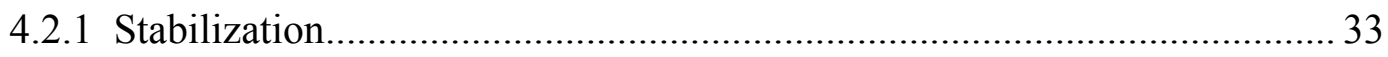

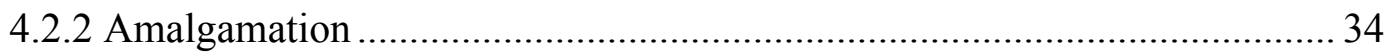

5.0 EXISTING AND POTENTIAL MERCURY

DECONTAMINATION TECHNIQUES FOR

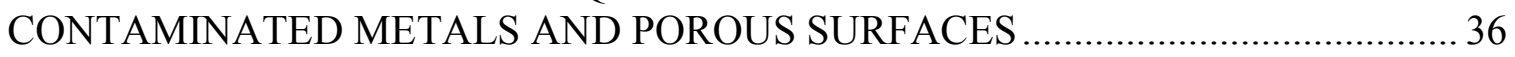

5.1 Review of current surface decontamination processes .......................................... 36

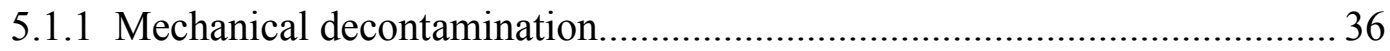

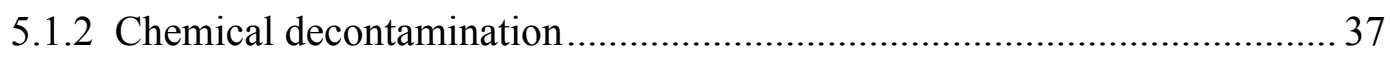

5.2 Decontamination problems specific to mercury-contaminated surfaces.................... 38

5.3 Modified decontamination process strategies of potential merit ............................... 38

5.3.1 Reactive Strippable Coatings ............................................................... 38

5.3.2 Chemical decontamination with iodine/iodide lixiviant .......................... 40

5.3.3 Chemisorbing surface wipes .............................................................. 41

5.3.4 Surface/Pore fixation through amalgamation or stabilization................... 42

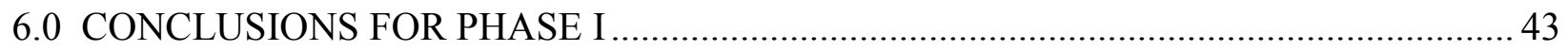

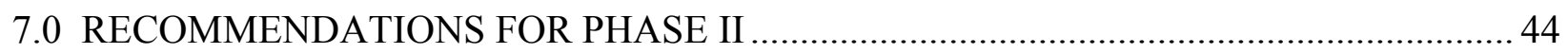

7.1 Reactive Strippable Coating: design and evaluation.......................................... 44

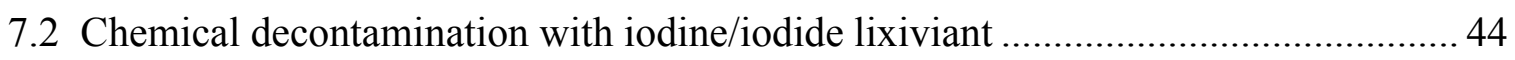

8.0 PHASE II: EVALUATION OF THE RECOMMENDED TECHNIQUES ....................... 44

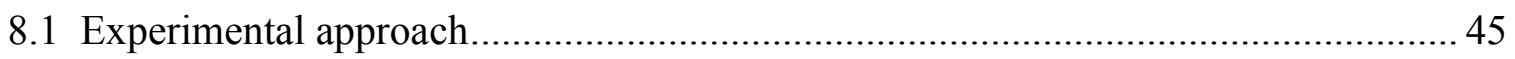

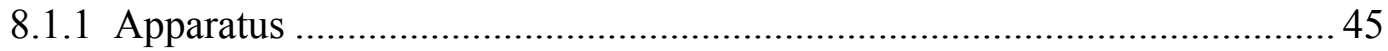

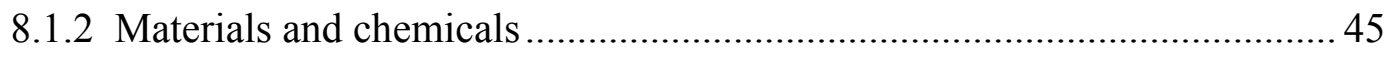

8.1.3 Experimental procedures............................................................. 47

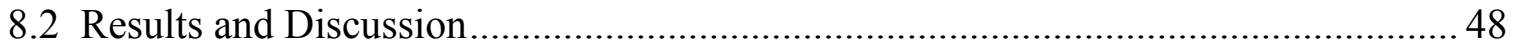

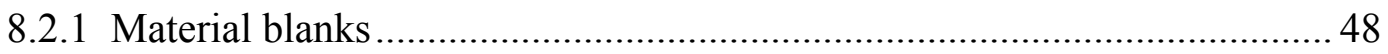

8.2.2 Contamination of the testing materials ................................................. 49

8.2.3 Mercury removal by strippable coating ............................................. 50

8.2.4 Mercury removal by iodine/iodide lixiviant......................................... 50

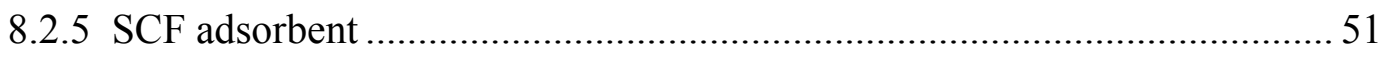

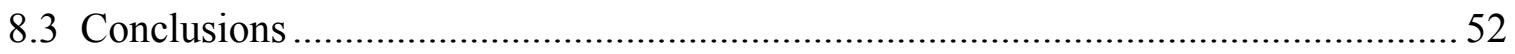

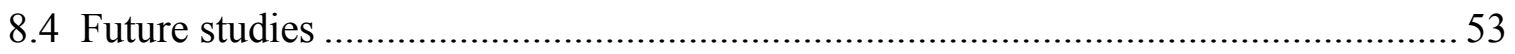

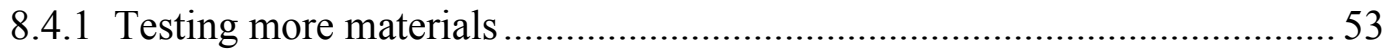

8.4.2 Further tests on iodine/iodide lixiviant................................................ 53

8.4.3 Development of more reliable contamination and strippable coating

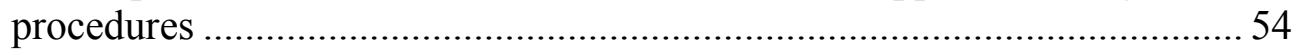

8.4.4 Development of alternative methods for evaluating mercury removal....... 54 
8.4.5 Bench testing with actual DOE site samples......................................... 54

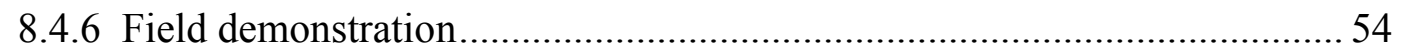

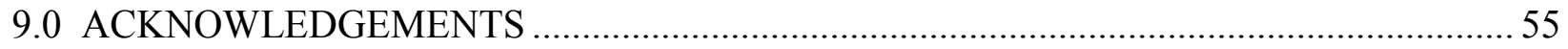

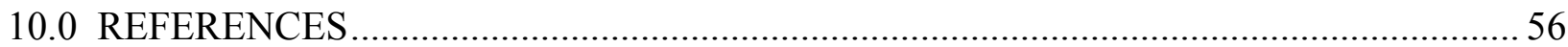




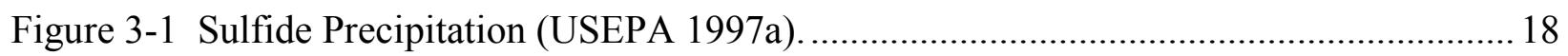

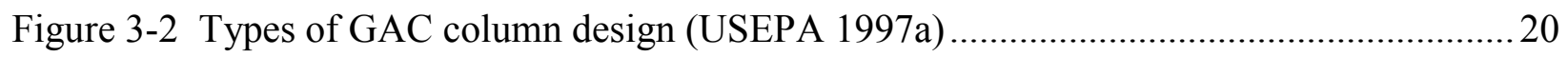

Figure 3-3 Schematic representation of mercury ion extraction with an emulsion liquid membrane (USEPA 1997a)............................2 24

Figure 3-4 Schematic representation of mercury ion extraction with an emulsion liquid membrane (USEPA 1997a) mechanisms.......... 25

Figure 4-1 PEMT/MRS PTT schematic diagram (from Stepan et al. 1995). ............................ 29

Figure 4-2 COGNIS, Inc., Mercury Remediation Process Schematic ..................................... 31

Figure 8-1 Decontamination strategy for mercury removal

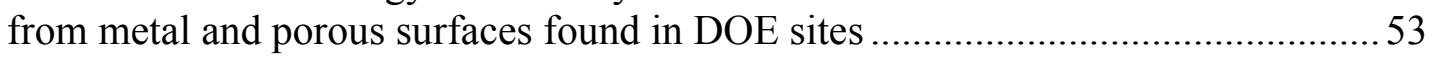


Table 2-1 Important Properties of Elemental Mercury (Henke et al. 1993, Skoog et al. 1998)....5

Table 2-2 Properties of Selected Inorganic Mercury Compounds (Lide 1997 and Henke et al. 1993) ....................................................... 7

Table 2-3 Properties of Selected Organomercury Compounds................................................. 7

Table 2-4 Solubility Information for Selected Mercury Compounds at about $20^{\circ} \mathrm{C}\left(68^{\circ} \mathrm{F}\right)$ (Modified from Henke et al. 1993) ....................... 8

Table 2-5 Stability Constants of Complexes between Mercury and Various Inorganic and Organic Ligands (From Martell et al. 1998, Ravichandran 1999)....... 11

Table 2-6 Stability Constants of Mercury-DOC Complexes Reported in Literature (Modified from Ravichandran 1999).................................. 12

Table 2-7 Logarithms of Formation Constants for 18 Methylmercuric Complexes $\left(\mathrm{CH}_{3} \mathrm{HgX}\right)$ in Water (from Baugman et al. 1973) ................................ 13

Table 2-8 Degrees of Dissociation of 10 Organomercury Compounds in Aqueous Solution at $25^{\circ} \mathrm{C}$ (from Baugman et al. 1973) .................... 13

Table 2-9 Mercury Consumption by Use in USA (tonnes) (from Craig 1986) ........................ 14

Table 2-10 Use of Organomercury Compounds (from Craig 1986)....................................... 15

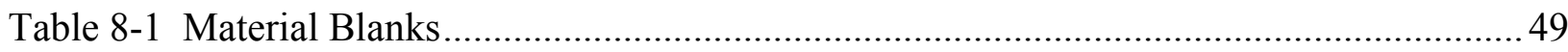

Table 8-2 Mercury Absorbed on Metal Squares and Tiles at Different Contamination Time Periods 49

Table 8-3 Percent Removal by Different Strippable Paints at Different Time Periods .............. 50

Table 8-4 Percent Removal by KI/I2 Solution............................................................ 51

Table 8-5 Percent Removal by SCF adsorbent .................................................................... 52 


\section{ACRONYMS}

BDAT Best Demonstrated Available Technology

BPHC Bicarbonate-treated Peanut Hull Carbon

DIW Deionized Water

DOE U.S. Department of Energy

CVAFS Cold Vapor Atomic Fluorescence Spectrometry

GAC Granular activated carbon

HDPE High Density Polyethylene

LDR Land Disposal Restrictions

MDPS Modified decontamination process strategies

MHBB Modified Hardwickia binata bark

MLLW Mixed low level waste

MWFA Mixed Waste Focus Area

ORR Oak Ridge Reservation

PAC Powdered activated carbon

PMET/MRS Pittsburgh Mineral \& Environmental Technology, Inc./Mercury Recovery Services

PTT Portable thermal treatment

RCRA Resource Conservation and Recovery Act

RMERC Retorting or roasting with recovery of mercury for reuse

SPC Sulfur polymer cement

SPSS Sulfur polymer stabilization/solidification

TCLP Toxicity Characteristic Leaching Procedure

UTS Universal Treatment Standard 


\section{EXECUTIVE SUMMARY}

Over the years mercury has been recognized as having serious impacts on human health and the environment. This recognition has led to numerous studies that deal with the properties of various mercury forms, the development of methods to quantify and speciate the forms, fate and transport, toxicology studies, and the development of site remediation and decontamination technologies. This report reviews several critical areas that will be used in developing technologies for cleaning mercury from mercury-contaminated surfaces of metals and porous materials found in many DOE facilities. The technologies used for decontamination of water and mixed wastes (solid) are specifically discussed. Many technologies that have recently appeared in the literature are included in the report. Current surface decontamination processes have been reviewed, and the limitations of these technologies for mercury decontamination are discussed. Based on the currently available technologies and the processes published recently in the literature, several processes, including strippable coatings, chemical cleaning with iodine/iodide lixiviant, chemisorbing surface wipes with forager sponge and grafted cotton, and surface/pore fixation through amalgamation or stabilization, have been identified as potential techniques for decontamination of mercury-contaminated metal and porous surfaces. Their potential merits and applicability are discussed. Finally, two processes, strippable coatings and chemical cleaning with iodine/iodide lixiviant, were experimentally investigated in Phase II of this project. 



\subsection{INTRODUCTION}

\subsection{BACKGROUND AND RATIONALE}

Elemental and speciated forms of mercury are present in many DOE waste streams, and over 38,000 cubic meters of low-level and transuranic waste containing mercury have been identified in the DOE complex. ${ }^{1}$ Statements of need addressing technology deficiencies for removing and treating mercury contamination have been expressed in both the D\&D and Mixed Waste Focus Areas, including the need for mercury removal from metal and porous surfaces and more effective mercury amalgamation processes. ${ }^{2}$ Three primary technology deficiencies associated with mercury and mercury-contaminated wastes have been identified:

- Amalgamation processes for immobilizing rad-contaminated, high concentration (>260 $\mathrm{mg} / \mathrm{k}$ ) or elemental mercury streams

- Stabilization processes for rad-contaminated, low concentration $(<260 \mathrm{mg} / \mathrm{k})$ mercury/mercury-contaminated streams

- Separation/removal processes for rad-contaminated, primarily liquid streams, e.g., off-gas scrubber solutions and other wastewaters.

To correct these deficiencies, DOE, EPA, and others have carried out treatability studies and have begun technology development with the assistance of commercial technology vendors. To date, a significant amount of bench-scale information has been gained regarding the disposition of mercury in a variety of solid and liquid waste matrices and mercury's behavior under various physical and chemical strategies for its removal or immobilization. To a large degree, these studies have pursued directly opposite ends: to enhance the mercury's solubilization and removal from a liquid or solid waste matrix or, oppositely, to strongly fix and immobilize it on the waste's surface or within the waste.

While these investigations pursue opposite ends, they have manipulated the same chemical and physical properties of mercury. Any incompleteness or ineffectiveness in manipulating the chemical or surface properties of the mercury in a treatment to one end may harbor information that could provide an enhancement to the other end. Thus, information from treatability studies with mercury wastes, especially their "failures," might therefore provide valuable information for mercury decontamination efforts. To illustrate this premise further, consider the following: A Hanford Site need addresses the need for a better method for treating MLLW mercury wastes, specifically high concentration wastes that are required by RCRA/LDR to be treated by amalgamation. Test results indicate, however, that $2 / 3$ of the existing amalgamated mercury does not pass the $0.025 \mathrm{mg} / 1$ TCLP limit, apparently due to some incompleteness of the process. At the same time, a DDFA need at the ORR requests a technology that can remove mercury from

11996 estimate.

2 For example, ORDD-08 (Mercury Removal from Metal and Porous Surfaces), and EMSPTFA9 (Demonstrate Process for Amalgamation of Mercury Which Results in a Nonhazardous Waste). 
metals (e.g., iron, nickel, aluminum, copper) and porous surfaces (e.g., concrete and clay tiles) to which it is strongly bound. Details from the ineffective amalgamation results of the Hanford wastes might provide physical, chemical, or processing details that could be applied to destabilize or reverse the binding of the mercury to the metal or porous surface and allow routine decon methods to be more effective.

A number of sources of waste mercury studies have been identified from the DOE Focus Areas and Laboratories, EPA, National Technical Work Group, and the online Mercury Network. FIUHCET has initiated a two-phase project. Phase I surveyed the available treatability studies regarding mercury wastes, selected those that appeared to be relevant to this project's objectives, and communicated with the investigators to identify physical, chemical, and process details of potential value in enhancing the effectiveness of mercury decontamination from metal and porous surfaces. As a result of Phase I, several modified decontamination process strategies (MDPS) with good potential for improving mercury decontamination effectiveness were identified. During Phase II of this project, these candidate MDPS will be evaluated at the bench scale in a treatability laboratory, under controlled conditions to confirm their feasibility.

\subsection{OBJECTIVES}

The overall objective of this project is to first identify technical information within current mercury waste treatability studies of potential usefulness in enhancing the effectiveness of mercury removal from metal and porous media using routine (albeit modified) decontamination methods and then if modified MDPS of sufficient potential are identified, to evaluate them under controlled test conditions.

The special objectives of this report are to

- Summarize the mercury-related issues that provide important background information for decontamination of mercury from mercury-contaminated surfaces of metals and porous materials found in DOE facilities. These include mercury chemistry and environmental issues.

- Review the currently available technologies in the industries and recently published processes in the literature for mercury decontamination in waters and mixed wastes.

- Identify existing and potential mercury decontamination technologies for contaminated metals and porous surfaces. Evaluate the potential merit of the modified decontamination process strategies.

- Provide recommendations for the further evaluation of the identified technologies in Phase II of this project.

The current (interim final) report presents all the Phase I findings as well as the experimental design and preliminary results from Phase II. A final report will be issued that will include the complete project findings, as anticipated in the interim final report.

\subsection{APPROACH}

The approach followed in this project has been to review recent technical literature regarding the chemistry of mercury and its use in mercury control techniques that have been developed for 
contaminated waters and mixed waste matrices. The information derived from this review was then reconsidered in light of potential modifications in decontamination strategies that might enhance current mercury control capabilities. With the completion of this Phase I work, several modified decontamination strategies with potential merit were developed for laboratory evaluation in Phase II of this project. 


\subsection{CHEMISTRY OF MERCURY AND ENVIRONMENTAL ISSUES}

\subsection{PROPERTIES OF MERCURY}

Elemental mercury $\left(\mathrm{Hg}^{0}\right)$, although it is a metal, is unique in that it is a liquid at normal temperatures. This property, plus its high specific gravity and electrical conductivity, has brought about its widespread use in industry and various types of laboratory equipment and instruments (Jones 1971, USEPA 1997). These applications include mercury-arc lamps, neon and fluorescent lamps, mercury boilers, electrodes in electrolysis, arc rectifiers, batteries, switches, thermometers, barometers, manometers, hydrometers, pyrometers, and related equipment. Except elemental mercury, other forms of mercury that have been widely used and found in the natural environment are inorganic mercury (II) compounds, such as mercury (II) hydroxide $\left(\mathrm{Hg}(\mathrm{OH})_{2}\right)$, mercury(II) sulfide ( $\mathrm{HgS})$, and mercury(II) chloride $\left(\mathrm{HgCl}_{2}\right)$; and organomercury forms, which include methylmercury species, such as monomethylmercury $\left(\mathrm{CH}_{3} \mathrm{HgX}\right.$, where $\mathrm{X}=$ inorganic counter ions, such as $\mathrm{Cl}$ and $\mathrm{OH}-)$ and dimethylmercury $\left(\left(\mathrm{CH}_{3}\right)_{2} \mathrm{Hg}\right)$ (Henke et al. 1993, USEPA 1997). Different mercury forms may exist at a contaminated site, and these compounds may also be transformed from one species to another under certain environmental conditions. Decontamination for different mercury forms may require different techniques. Therefore, a thorough understanding of the physical, chemical, hydrological, mineralogical, and biological processes that affect the transport and fate of mercury in the environment is a primary and key step for successful decontamination and remediation efforts. This understanding will provide the basis for the selection and/or development of effective and economical decontamination and remediation techniques (Stepan et al. 1993). Some basic physical, chemical, and biological properties are summarized here. More details can be found from literature (e.g., Henke et al. 1993, USEPA 1997).

\subsubsection{Properties of elemental mercury}

Table 2-1 lists the most important physical and chemical properties for elemental mercury. The physical properties of a substance refer to those characteristics that are determined without altering its chemical composition, such as odor, color, density, melting point, and boiling point (Henke et al. 1993). The elemental mercury metal is a heavy, silvery-white liquid at typical ambient temperatures and atmospheric pressures. The vapor pressure of mercury metal is strongly dependent on temperature, and it vaporizes readily under ambient conditions. The melting point of mercury is $-38.87{ }^{\circ} \mathrm{C}\left(-37.97{ }^{\circ} \mathrm{F}\right)$, and it has a boiling point of $357{ }^{\circ} \mathrm{C}\left(675^{\circ} \mathrm{F}\right)$. Elemental mercury is also extremely dense, being 13.5 times more dense than liquid water under ambient conditions. This high density, as well as the low saturation vapor pressure and high surface tension, control the immediate behavior of released elemental mercury on a land surface (Turner 1992, Henke et al. 1993). Most of the mercury encountered in the atmosphere is elemental mercury vapor.

The chemical properties refer to the characteristics of a substance that are intimately involved in chemical reactions with other substances. One of the most important chemical properties of different forms of mercury is the valance state (Henke et al. 1993). Mercury can exist in three oxidation states: $\mathrm{Hg}^{0}$ (metallic), $\mathrm{Hg}_{2}^{2+}$ (mercurous), and $\mathrm{Hg}^{2+}$ (mercuric). The properties and behavior of mercury depend on the oxidation state. The valance states of mercury have important 
implications in human health and safety, in understanding mercury transport and fate, and in developing effective remediation technologies. Most of the mercury in water, soil, sediments, or biota (i.e., all environmental media except the atmosphere) is in the form of inorganic mercury salts and organic forms of mercury. Solubility data on elemental mercury and mercury compounds, especially in water, are important in understanding mercury transport and fate. Compared to some mercury compounds, elemental mercury tends to be relatively insoluble in water (see also next section for mercury compounds). Redox potential is another key parameter in governing the biogeochemical cycling of mercury (USEPA 1997).

Table 2-1

Important Properties of Elemental Mercury (Henke et al. 1993, Skoog et al. 1998)

\begin{tabular}{|c|c|}
\hline Physical Properties & \\
\hline Atomic number & 80 \\
\hline Atomic radius & $1.5 \AA$ \\
\hline Atomic volume & $14.81 \mathrm{~cm}^{3} /$ g-atom \\
\hline Atomic weight & 200.59 \\
\hline Boiling point & $357.73^{\circ} \mathrm{C}\left(675^{\circ} \mathrm{F}\right)$ \\
\hline Boiling point/rise in pressure & $0.0746^{\circ} \mathrm{C} /$ torr \\
\hline Conductivity (heat) & $0.022 \mathrm{cal} / \mathrm{sec} / \mathrm{cm}^{3} .{ }^{\circ} \mathrm{C}$ \\
\hline Contact angle & 132 degrees \\
\hline Density & $13.546 \mathrm{~g} / \mathrm{cm}^{3}$ at $20^{\circ} \mathrm{C}\left(0.489 \mathrm{lb} / \mathrm{in}^{3}\right.$ at $\left.68^{\circ} \mathrm{F}\right)$ \\
\hline Diffusivity (in air) & $0.112 \mathrm{~cm}^{2} / \mathrm{sec}$ \\
\hline Electron configuration & {$[\mathrm{Xe}] 4 \mathrm{f}^{14} 5 \mathrm{~d}^{10} 6 \mathrm{~s}^{2}$} \\
\hline Heat capacity & $0.0332 \mathrm{cal} / \mathrm{g}$ at $20^{\circ} \mathrm{C}\left(0.060 \mathrm{Btu} / \mathrm{lb}\right.$ at $\left.68^{\circ} \mathrm{F}\right)$ \\
\hline Henry's law constant & $0.0114 \mathrm{~atm} \mathrm{~m}^{3} / \mathrm{mol}$ \\
\hline Interfacial tension $\left(\mathrm{Hg} / \mathrm{H}_{2} \mathrm{O}\right)$ & $375 \mathrm{dyn} / \mathrm{cm}$ at $20^{\circ} \mathrm{C}\left(68^{\circ} \mathrm{F}\right)$ \\
\hline Ionization potential (first) & $10.4375 \mathrm{ev}$ \\
\hline Ionization potential (second) & $18.751 \mathrm{ev}$ \\
\hline Isotope abundance & $\begin{array}{l}196(0.15), 198(9.97), 199(16.87), 200(23.1), 201 \\
(13.18), 202(29.86), 204(6.87)\end{array}$ \\
\hline Melting point & $-38.87^{\circ} \mathrm{C}\left(-37.97^{\circ} \mathrm{F}\right)$ \\
\hline Odor & None \\
\hline Reflectivity & $71.2 \%$ at $5500 \AA$ light \\
\hline Resistivity (heat) & $95.8 \times 10^{-6} \mathrm{ohm} / \mathrm{cm}$ at $20^{\circ} \mathrm{C}\left(68^{\circ} \mathrm{F}\right)$ \\
\hline Saturation vapor pressure & $0.16 \mathrm{~N} / \mathrm{m}^{2}$ (pascal) at $20^{\circ} \mathrm{C}\left(68^{\circ} \mathrm{F}\right)$ \\
\hline Specific gravity & 13.546 at $20^{\circ} \mathrm{C}\left(68^{\circ} \mathrm{F}\right)$ \\
\hline Surface tension (in air) & $436 \mathrm{dyn} / \mathrm{cm}$ at $20^{\circ} \mathrm{C}\left(68^{\circ} \mathrm{F}\right)$ \\
\hline Vaporization rate (still air) & $0.007 \mathrm{mg} / \mathrm{cm} 2$. hr.for $10.5 \mathrm{~cm} 2$ droplet at $20^{\circ} \mathrm{C}\left(68^{\circ} \mathrm{F}\right)$ \\
\hline
\end{tabular}




\begin{tabular}{ll}
\hline \multicolumn{1}{c}{ Physical Properties } \\
\hline Viscosity & $1.554 \mathrm{cp}$ at $20^{\circ} \mathrm{C}\left(68^{\circ} \mathrm{F}\right)$ \\
\multicolumn{1}{c}{ Chemical Properties } & \\
\hline & $0.854 \mathrm{~V}$ \\
$\mathrm{E}^{0}$ for $\mathrm{Hg}^{2+}+2 \mathrm{e}^{-}=\mathrm{Hg}(l)$ & $0.788 \mathrm{~V}$ \\
$\mathrm{E}^{0}$ for $\mathrm{Hg}_{2}{ }^{2+}+2 \mathrm{e}^{-}=2 \mathrm{Hg}(l)$ & $0.920 \mathrm{~V}$ \\
$\mathrm{E}^{0}$ for $2 \mathrm{Hg}^{2+}+2 \mathrm{e}^{-}=2 \mathrm{Hg}_{2}{ }^{2+}$ & $1.92($ Pauling scale $)$ \\
Electronegativity & In water: $60-80 \mu \mathrm{g} / \mathrm{L}$ at $20^{\circ} \mathrm{C}\left(68^{\circ} \mathrm{F}\right)$ \\
Solubility & In benzene: $2000 \mu \mathrm{gg} / \mathrm{L}$ at $20{ }^{\circ} \mathrm{C}\left(68{ }^{\circ} \mathrm{F}\right)$ \\
& In dioxane: $7000 \mu \mathrm{g} / \mathrm{L}$ at $20^{\circ} \mathrm{C}\left(68^{\circ} \mathrm{F}\right)$ \\
& In nitric acid: "soluble" \\
& \\
\hline
\end{tabular}

\subsubsection{Properties of some mercury compounds}

Tables 2-2 and 2-3 summarize some fundamental properties of selected inorganic mercury and organomercury compounds, respectively. Solubility information for some important mercury (organic and inorganic) compounds is listed in Table 2-4. Although water solubility values are available for elemental mercury and many inorganic mercury compounds, there is little quantitative information on the solubility of organomercury compounds in water (Henke et al. 1993). However, some qualitative information is available from literature (Environment Canada, 1984, Henke et al. 1993). Monomethylmercury compounds with highly electronegative inorganic anions, such as fluoride, nitrate, sulfate, or phosphate, tend to be more soluble in water and alcohol and less soluble in nonpolar solvent (for example, benzene), while the opposite is generally true for monomethylmercury compounds that contain hydroxide and less electronegative anions.

Solubility is also an essential parameter involved in the formation of amalgams between elemental mercury and various metals. Henke et al. (1993) summarized this information in their report to the U.S. Department of Energy. At ambient conditions, silver, gold, copper, zinc, and aluminum readily form amalgams in the presence of liquid or gaseous elemental mercury (Andren and Nriagu 1979). However, except for zinc, the solubility of these metals in elemental mercury is actually relatively low. Specifically, the solubility of zinc in mercury is $2.15 \mathrm{~g} / 100 \mathrm{~g}$ of mercury, while gold solubility in mercury is only $0.13 \mathrm{~g} / 100 \mathrm{~g}$ of mercury. Silver, copper, and aluminum have even lower solubilities than gold. Nevertheless, the solubility is sufficient so that only small amounts of liquid or gaseous elemental mercury can cause aluminum, certain steel and copper alloy pipes and valves to become corroded or embrittled. Galvanized metal, which 
contains zinc, is even more susceptible to corrosion from elemental mercury. In natural environments, the transport and fate of elemental mercury could also be affected by amalgamation with naturally occurring metallic minerals or metallic equipment that is at or near the mercury spill site (Henke et al. 1993).

Table 2-2

Properties of Selected Inorganic Mercury Compounds (Lide 1997 and Henke et al. 1993)

\begin{tabular}{lllll}
\hline & Mol. W & Boiling point $\left({ }^{\circ} \mathrm{C}\right)$ & $\begin{array}{l}\text { Density at about } \\
25^{\circ} \mathrm{C}\left(77^{\circ} \mathrm{F}\right), \mathrm{g} / \mathrm{cm}^{3}\end{array}$ & Melting point $\left({ }^{\circ} \mathrm{C}\right)$ \\
\hline $\mathrm{HgCl}_{2}$ & 271.50 & 304 & 5.6 & 276 \\
$\mathrm{Hg}\left(\mathrm{NO}_{3}\right)_{2}$ & 324.60 & & 4.3 & 79 \\
$\mathrm{HgO}$ & 216.59 & 11.1 & $\begin{array}{l}\text { Decomposes at } 500^{\circ} \mathrm{C} \\
\left(932^{\circ} \mathrm{F}\right)\end{array}$ \\
$\mathrm{HgS}$ (black) & 232.66 & 7.70 & $\begin{array}{l}\text { Sublimes at } 583.5^{\circ} \mathrm{C} \\
\left(1082^{\circ} \mathrm{F}\right)\end{array}$ \\
$\mathrm{HgS}$ & 232.66 & 8.17 & $\begin{array}{l}\text { Transfer to black } \mathrm{HgS} \\
\text { at } 386^{\circ} \mathrm{C}\end{array}$ \\
(red) & & & \\
\hline
\end{tabular}

Table 2-3

Properties of Selected Organomercury Compounds

\begin{tabular}{l|llll}
\hline & Mol. W & Boiling point $\left({ }^{\circ} \mathrm{C}\right)$ & $\begin{array}{l}\text { Density at about } \\
25^{\circ} \mathrm{C}\left(77^{\circ} \mathrm{F}\right), \mathrm{g} / \mathrm{cm}^{3}\end{array}$ & Melting point $\left({ }^{\circ} \mathrm{C}\right)$ \\
& & & 4.063 & 170 \\
\hline $\mathrm{CH}_{3} \mathrm{HgCl}$ & 251.09 & Volat. at 100 & 3.069 & \\
$\left(\mathrm{CH}_{3}\right)_{2} \mathrm{Hg}$ & 230.66 & 96 & liq. 2.444 & \\
$\left(\mathrm{C}_{2} \mathrm{H}_{5}\right)_{2} \mathrm{Hg}$ & 258.71 & 159 & & \\
\hline
\end{tabular}


Table 2-4

Solubility Information for Selected Mercury

Compounds at about $20^{\circ} \mathrm{C}\left(68^{\circ} \mathrm{F}\right)$ (Modified from Henke et al. 1993)

\begin{tabular}{|c|c|c|c|}
\hline Compound & Solvent & Solubility & Reference \\
\hline $\mathrm{Hg}^{0}$ & Water & $60-80 \mu \mathrm{g} / \mathrm{L}$ & Eichholz et al. 1988 \\
\hline $\mathrm{HgF}_{2}$ & Water & hydrolyzes & Cotton et al. 1999 \\
\hline $\mathrm{HgCl}_{2}$ & Water & $70,000,000 \mu \mathrm{g} / \mathrm{L}$ & Magos 1975 \\
\hline $\mathrm{Hg}_{2} \mathrm{Cl}_{2}$ & Water & $2,000 \mu \mathrm{g} / \mathrm{L}$ & Magos 1975 \\
\hline $\mathrm{HgBr}_{2}$ & Water & $6,205,000 \mu \mathrm{g} / \mathrm{L}$ & Cotton et al. 1999 \\
\hline $\mathrm{HgI}_{2}$ & Water & $58,060 \mu \mathrm{g} / \mathrm{L}$ & Cotton et al. 1999 \\
\hline $\mathrm{HgO}$ & Water & $53,000 \mu \mathrm{g} / \mathrm{L}$ & Kaiser and Tolg 1980 \\
\hline $\mathrm{Hg}_{2} \mathrm{O}$ & Water & "very low" & Kaiser and Tolg 1980 \\
\hline $\mathrm{HgS}$ & Water & $\sim 10 \mu \mathrm{g} / \mathrm{L}$ & Lide 1990 \\
\hline
\end{tabular}

\subsection{SOME IMPORTANT REACTIONS OF MERCURY}

\subsubsection{Reactions involving inorganic mercury}

Mercury is obtained from its principal ore, cinnabar $(\mathrm{HgS})$, by roasting to form $\mathrm{HgO}$ and then decomposing this at ca. $500^{\circ} \mathrm{C}$ (Cotton et al. 1999).

$$
\mathrm{HgO}(\mathrm{s}) \rightarrow \mathrm{Hg}(s)+1 / 2 \mathrm{O}_{2} \quad \Delta \mathrm{H}=160 \mathrm{~kJ} \mathrm{~mol}^{-1}
$$

Univalent Mercury (Mercurous, $\mathrm{Hg}_{2}{ }^{2+}$ ): $\quad$ As mentioned above, the $\mathrm{Hg}_{2}{ }^{2+}$ ion is a very important species of mercury. In aquatic solution the $\mathrm{Hg}_{2}{ }^{2+}$ ion is readily obtained by reduction of the $\mathrm{Hg}^{2+}$ ion. The transfer between different mercury species is often controlled by the potentials of a number of reduction/oxidation reactions. The following are some of the half reactions related to aqueous mercurous ion, $\mathrm{Hg}_{2}{ }^{2+}$ (Cotton et al. 1999):

$$
\begin{array}{ll}
\mathrm{Hg}_{2}^{2+}+2 \mathrm{e}^{-}=2 \mathrm{Hg}(l) & \mathrm{E}^{0}=0.7960 \mathrm{~V} \\
\mathrm{Hg}^{2+}+2 \mathrm{e}^{-}=\mathrm{Hg}_{2}^{2+} & \mathrm{E}^{0}=0.9110 \mathrm{~V} \\
\mathrm{Hg}^{2+}+2 \mathrm{e}^{-}=\mathrm{Hg}(l) & \mathrm{E}^{0}=0.8535 \mathrm{~V}
\end{array}
$$

From these, the potential of the following rapid, reversible reaction is then calculated:

$$
\mathrm{Hg}_{2}{ }^{2+}=\mathrm{Hg}^{2+}+\mathrm{Hg}(l) \quad \mathrm{E}^{0}=-0.115 \mathrm{~V}
$$

From this, the following equilibrium constant is obtained:

$$
\mathrm{K}=\left[\mathrm{Hg}^{2+}\right] /\left[\mathrm{Hg}_{2}{ }^{2+}\right]=1.14 \times 10^{-2}
$$

It follows, then, that when a solution containing $\mathrm{Hg}^{2+}$ is treated with an equimolar or greater quantity of elemental mercury, a solution of $\mathrm{Hg}_{2}{ }^{2+}$ is formed. This conclusion is obtained based on an assumption that only uncomplexed aqua ions are involved. In real aquatic environments, 
however, many anions exist. These anions tend to complex more strongly with $\mathrm{Hg}^{2+}$ than with $\mathrm{Hg}_{2}{ }^{2+}$, the marginal stability of the latter against disproportionation is easily altered and thus there are relatively few stable $\mathrm{Hg}_{2}{ }^{2+}$ compounds (Cotton et al. 1999). All anions or ligands such as $\mathrm{NH}_{3}$, amines, $\mathrm{OH}^{-}, \mathrm{CN}^{-}, \mathrm{SCN}^{-}, \mathrm{S}^{2-}$, and $\mathrm{acac}^{-}$that complex or precipitate $\mathrm{Hg}^{2+}$ promote the disproportionation of $\mathrm{Hg}_{2}{ }^{2+}$.

$$
\begin{aligned}
& \mathrm{Hg}_{2}{ }^{2+}+2 \mathrm{OH}^{-} \rightarrow \mathrm{Hg}(l)+\mathrm{HgO}(s)+\mathrm{H}_{2} \mathrm{O} \\
& \mathrm{Hg}_{2}{ }^{2+}+\mathrm{S}^{2-} \rightarrow \mathrm{Hg}(l)+\mathrm{HgS}(s) \\
& \mathrm{Hg}_{2}{ }^{2+}+2 \mathrm{CN}^{-} \rightarrow \mathrm{Hg}(l)+\mathrm{Hg}(\mathrm{CN})_{2}(a q)
\end{aligned}
$$

The rate-determining step in these disproportionations has been shown to be the cleavage of the $\mathrm{Hg}-\mathrm{Hg}$ bond.

The four halides, $\mathrm{Hg}_{2} \mathrm{X}_{2}$, all occur, the chloride, bromide, and iodide all being insoluble in water. $\mathrm{Hg}_{2} \mathrm{~F}_{2}$ is rapidly hydrolyzed to $\mathrm{HF}, \mathrm{Hg}(l)$, and $\mathrm{HgO} . \mathrm{Hg}_{2}\left(\mathrm{NO}_{3}\right)_{2} \cdot 2 \mathrm{H}_{2} \mathrm{O}$ and $\mathrm{Hg}_{2}\left(\mathrm{ClO}_{4}\right)_{2} \cdot 4 \mathrm{H}_{2} \mathrm{O}$ are very soluble in water to give stable solutions from which the insoluble halides can easily be precipitated. Other compounds that contain weakly coordinating anions, e.g., sulfate, chlorate, bromate, iodate, and acetate, also occur. In general, oxygen-donor ligands such as oxalate, succinate, $\mathrm{P}_{2} \mathrm{O}_{7}{ }^{4-}$, and $\mathrm{P}_{3} \mathrm{O}_{10}{ }^{5-}$, which do not form strong complexes with $\mathrm{Hg}^{2+}$, give stable complexes, such as $\left[\mathrm{Hg}_{2}\left(\mathrm{P}_{2} \mathrm{O}_{7}{ }^{4-}\right)_{2}\right]^{6-}$, with mercurous ion (Cotton et al. 1999).

Divalent Mercury: An important process by which mercury concentration in solution could increase is through the dissolution of mercury minerals. The most common mercury minerals are cinnabar (red HgS) and metacinnabar (black HgS). Cinnabar is most commonly found as an ore mineral, whereas metacinnabar is often found in anoxic, Hg-contaminated sediments (Barnett et al. 1997, Ravichandran 1999).

The addition of $\mathrm{H}_{2} \mathrm{~S}$ or alkali metal sulfides to aqueous $\mathrm{Hg}^{2+}$ precipitate the highly insoluble, black mercuric sulfide, $\mathrm{HgS}$.

$$
\mathrm{Hg}^{2+}+\mathrm{S}^{2-}=\mathrm{HgS}_{\text {black }} \quad \mathrm{Ksp}=10^{-53}
$$

This black solid when heated or treated in other ways is changed into a red form that is identical to the mineral cinnabar (Cotton et al. 1999). In this red form, $\mathrm{HgS}$ has a distorted $\mathrm{NaCl}$ structure in which the $(\mathrm{Hg}-\mathrm{S})_{\infty}$ chain can be recognized. Red cinnabar on irradiation in aqueous $\mathrm{KI}$ is converted to black cinnabar, which has the ZnS structure and also occurs in nature.

The addition of $\mathrm{OH}^{-}$to aqueous $\mathrm{Hg}^{2+}$ precipitates $\mathrm{HgO}$ as a yellow solid of fine particles. When prepared in other ways, e.g., by gentle thermolysis of $\mathrm{Hg}_{2}\left(\mathrm{NO}_{3}\right)_{2}$ or $\mathrm{Hg}\left(\mathrm{NO}_{3}\right)_{2}$, or by direct combination of $\mathrm{Hg}$ and $\mathrm{O}_{2}$, it is red.

All four halides, $\mathrm{HgX}_{2}$, are known. Mercury (II) fluoride has the fluorite structure and is not volatile. It is decomposed by water as might be expected since $\mathrm{HgO}$ and $\mathrm{HF}$ are both weakly dissociated. No fluoro complex is known (Cotton et al. 1999). The other three halides can all be vaporized as XHgX molecules, and such molecules can also occur in solution.

Salts of oxo anions, such as the nitrate, perchlorate, and sulfate, are appreciably dissociated in aqueous solution, but because of the weakness of mercuric oxide as a base, the solutions must be acidified to be stable (Cotton et al. 1999). An aqua ion, $\left[\mathrm{Hg}\left(\mathrm{H}_{2} \mathrm{O}\right)_{6}\right]^{2+}$, apparently exists, but this readily hydrolyzes to $\mathrm{Hg}(\mathrm{OH})^{+}$aq and then to $\mathrm{Hg}(\mathrm{OH})_{2(\text { aq })}$ in which there is a linear $\mathrm{HO}-\mathrm{Hg}-$ 
$\mathrm{OH}$ unit. The dissolved nitrate is mainly present as $\mathrm{Hg}\left(\mathrm{NO}_{3}\right)_{2}, \mathrm{Hg}\left(\mathrm{NO}_{3}\right)^{+}$and $\mathrm{Hg}^{2+}$, but in the presence of excess $\mathrm{NO}_{3}{ }^{-}$, the complexes $\mathrm{Hg}\left(\mathrm{NO}_{3}\right)_{3}{ }^{-}$and $\mathrm{Hg}\left(\mathrm{NO}_{3}\right)_{4}{ }^{2-}$ are formed.

Mercury (II) Complexes: Mercury is a distinctly "soft" cation, showing a strong preference for $\mathrm{Cl}, \mathrm{Br}, \mathrm{I}, \mathrm{P}, \mathrm{S}, \mathrm{Se}$, and certain N-type ligands. It displays coordination numbers of 2 through 6 , with a preference for the lower ones. Its marked preference for linear 2-coordination is a distinctive feature (Cotton et al. 1999). Several important mercury (II) complexes are shown below.

Halogen and pseudohalogen complexes are an important category. In aqueous solution, mercury forms complexes $\mathrm{HgX}_{\mathrm{n}}{ }^{-(\mathrm{n}-2)}$ for $\mathrm{n}=1-4$. At $10^{-1} \mathrm{M} \mathrm{Cl}^{-}$, for example, approximately equal amounts of $\mathrm{HgCl}_{2}, \mathrm{HgCl}_{3}{ }^{-}$, and $\mathrm{HgCl}_{4}{ }^{2-}$ are present, but at $1 \mathrm{M} \mathrm{Cl}^{-}$essentially only $\mathrm{HgCl}_{4}{ }^{2-}$ is present.

Mercury (II) has a great affinity for ligands with sulfur and the other chalcogenides as the ligating atom and forms more complexes with such ligands than with any other types (Cotton et al. 1999). Indeed, the name mercaptan for thiols arose from their affinity for mercury. In biological systems $\mathrm{Hg}$ (II) invariably binds to cysteine thiolate groups.

In aquatic environments, hydroxide, chloride, and sulfide are considered to control the speciation of mercury (Schuster 1991, Ravichandran 1999). At circum-neutral pH conditions, hydroxidemercury species $\left(\mathrm{Hg}(\mathrm{OH})_{2}, \mathrm{HgOH}^{+}\right)$are expected to be predominant in freshwater (Hudson et al. 1994, Stumm and Morgan 1995). Chloride-mercury complexes are expected to be important at low $\mathrm{pH}$ and/or high chloride concentrations found in real aquatic environment, such as marine and estuarine. For example, Leermakers et al. (1995) estimated that more than $90 \%$ of mercury would be found as $\mathrm{HgCl}_{2}$ at salinity greater than $25 \%$ In anoxic aquatic environments containing dissolved sulfide ( $\mathrm{HS}^{-}$), mercury is expected to combine with sulfide to form mercuric sulfide species such as $\mathrm{HgS}_{\text {solid }}$ and $\mathrm{Hg}(\mathrm{SH})_{2(\mathrm{aq})}$ (Dyrssen and Wedborg 1991 Hudson et al. 1994; Ravichandran 1999).

Dissolved organic matter (DOM), which is ubiquitous in aquatic environments, is known to bind trace metals strongly, affecting their speciation, solubility, mobility, and toxicity (Buffle 1988, Ravichandran 1999). Many metals in natural waters have solubilities much higher than expected from calculations based on complexation with inorganic ligands. The enhanced solubility is predominantly due to the complexation of these metals with DOM. There is increasing evidence that DOM plays an important role in the speciation of mercury in aquatic environments. This evidence is largely based on positive correlation observed between mercury and dissolved organic carbon (DOC) concentration in natural waters (Andren and Harriss 1975, Lindberg and Harriss 1975, Mierle and Ingram 1991, Driscoll et al. 1995 Watras et al. 1995, Varshal et al. 1996 Cai et al. 1999, Ravichandran 1999).

Knowledge of the complexes formed between mercury and different ligands (inorganic and organic) is very important in understanding mercury transport and fate and in developing effective remediation technologies. Some important stability constants of complexes between mercury and various inorganic and organic ligands and between mercury and DOC are summarized in Tables 2-5 and 2-6, respectively. 
Table 2-5

Stability Constants of Complexes between Mercury and Various Inorganic and Organic Ligands (From Martell et al. 1998, Ravichandran 1999)

\begin{tabular}{|c|c|c|c|c|c|}
\hline & & $\mathrm{HgL}$ & & $\mathrm{HgL}_{2}$ & \\
\hline Ligand $^{\mathrm{a}}$ & Formula & $\log K$ & $\begin{array}{l}\text { T }\left({ }^{\circ} \mathrm{C}\right), \\
\text { I (M) }\end{array}$ & $\log K$ & $\begin{array}{l}\mathrm{T}\left({ }^{\circ} \mathrm{C}\right), \\
\mathrm{I}(\mathrm{M})\end{array}$ \\
\hline Chloride & $\mathrm{Cl}^{-}$ & 7.3 & 25,0 & 14 & 25,0 \\
\hline Carbonate & $\mathrm{CO}_{3}{ }^{2-}$ & 11.0 & $25,0.5$ & -- & -- \\
\hline Hydroxide & $\mathrm{OH}^{-}$ & 10.6 & 25,0 & 21.8 & 25,0 \\
\hline Sulfate & $\mathrm{SO}_{4}{ }^{2-}$ & 1.3 & $25,0.5$ & -- & -- \\
\hline Bromide & $\mathrm{Br}^{-}$ & 9.1 & $25,0.5$ & 17.3 & $25,0.5$ \\
\hline Fluoride & $\mathrm{F}^{-}$ & 1.0 & $25,0.5$ & -- & -- \\
\hline Ammonia & $\mathrm{NH}_{3}$ & 8.8 & $22,2.0$ & 17.4 & $22,2.0$ \\
\hline Sulfide & $\mathrm{HS}^{-}$ & -- & -- & 37.7 & $20,1.0$ \\
\hline Phosphate & $\mathrm{PO}_{4}^{3-}$ & 9.5 & $25,3.0$ & -- & -- \\
\hline Acetic acid & $\mathrm{CH}_{3}(\mathrm{COOH})$ & 3.7 & $24,0.1$ & 8.4 & $25,3.0$ \\
\hline Citric acid ${ }^{3-}$ & $\mathrm{HOC}\left(\mathrm{CH}_{2}\right)_{2}(\mathrm{COOH})_{3}$ & 10.9 & $25,0.1$ & -- & -- \\
\hline Nitrilotriacetic acid ${ }^{3-}$ & $\mathrm{N}\left(\mathrm{CH}_{2} \mathrm{COOH}\right)_{3}$ & 14.3 & $25,0.1$ & -- & -- \\
\hline $\begin{array}{l}\text { Ethylenedinitrilo- } \\
\text { tetraacetic acid }\end{array}$ & $\left(\mathrm{HOOCCH}_{2}\right)_{4}\left(\mathrm{NCH}_{2}\right)_{2}$ & 21.5 & $25,0.1$ & -- & -- \\
\hline Cysteine $^{2-}$ & $\mathrm{HSCH}_{2} \mathrm{CH}\left(\mathrm{NH}_{2}\right) \mathrm{COOH}$ & 14.4 & $25,0.1$ & -- & -- \\
\hline Glycine $^{-}$ & $\mathrm{NH}_{2} \mathrm{CH}_{2} \mathrm{COOH}$ & 10.3 & $25,0.5$ & 19.2 & $20,0.5$ \\
\hline Thiourea $^{-}$ & $\mathrm{H}_{2} \mathrm{NCSNH}_{2}$ & 11.4 & $25,0.5$ & 22.1 & $25,0.5$ \\
\hline Thioglycolic acid ${ }^{2-}$ & $\mathrm{HSCH}_{2} \mathrm{COOH}$ & -- & -- & 43.8 & $25,1.0$ \\
\hline
\end{tabular}

${ }^{a}$ The superscripts in organic ligands are the charge on the ligand when they are fully ionized, for which the binding constants are given. 
Table 2-6

Stability Constants of Mercury-DOC Complexes Reported in Literature (Modified from Ravichandran 1999)

\begin{tabular}{|c|c|c|c|c|}
\hline Method & Type of organic matter & $\mathrm{pH}$ & $\log K$ & Reference \\
\hline Ion-exchange & $\begin{array}{l}\text { Marine sedimentary humic } \\
\text { acid, commercial humic } \\
\text { acid }\end{array}$ & 5.0 & 5.2 & $\begin{array}{l}\text { Strohal and Huljev } \\
\text { (1971) }\end{array}$ \\
\hline \multirow{2}{*}{$\begin{array}{l}\text { Iodide selective } \\
\text { electrode }\end{array}$} & \multirow[t]{2}{*}{ Soil fulvic acid } & 3.0 & 4.9 & \multirow{2}{*}{$\begin{array}{l}\text { Cheam and Gamble } \\
\text { (1974) }\end{array}$} \\
\hline & & 4.0 & 5.1 & \\
\hline $\begin{array}{l}\text { Iodide selective } \\
\text { electrode }\end{array}$ & Soil humic substances & 4.5 & 4.69 & Yin et al. (1997) \\
\hline Titration & $\begin{array}{l}\text { Bog water-concentrated } \\
\text { organic matter }\end{array}$ & 4.0 & 10.4 & $\begin{array}{l}\text { Lovgren and Sjoberg } \\
\text { (1989) }\end{array}$ \\
\hline $\begin{array}{l}\text { Gel Filtration } \\
\text { Chromatograph } \\
\text { y }\end{array}$ & $\begin{array}{l}\text { Lake and river humic } \\
\text { substances }\end{array}$ & 8.0 & $\begin{array}{l}18.4- \\
21.1\end{array}$ & $\begin{array}{l}\text { Mantoura and Riley } \\
\text { (1975) and Mantoura } \\
\text { et al. (1978) }\end{array}$ \\
\hline Ultrafiltration & $\begin{array}{l}\text { Surface water organic } \\
\text { matter }\end{array}$ & $7.0-7.6$ & $\begin{array}{l}4.85- \\
6.66\end{array}$ & Cai et al. (1999) \\
\hline
\end{tabular}

\subsubsection{Organomercury compounds}

The vast majority of organomercury compounds are of the $\mathrm{RHgX}$ or $\mathrm{R}_{2} \mathrm{Hg}$ types, in which the C $-\mathrm{Hg}-\mathrm{X}$ or $\mathrm{C}-\mathrm{Hg}-\mathrm{C}$ units are linear (Cotton et al. 1999). Among a number of organomercury compounds that have been synthesized over the years, the case of $\mathrm{R}=\mathrm{CH}_{3}$ is of special interest because of its presence in environmental and biological samples and its toxicity to animals and human beings. The $\mathrm{CH}_{3} \mathrm{Hg}^{+}$ion exists in aqueous solution in one or more of the following forms, depending on $\mathrm{pH}$ : $\mathrm{CH}_{3} \mathrm{Hg}\left(\mathrm{H}_{2} \mathrm{O}\right)^{+}, \mathrm{CH}_{3} \mathrm{HgOH},\left(\mathrm{CH}_{3} \mathrm{Hg}\right)_{2} \mathrm{O},\left(\mathrm{CH}_{3} \mathrm{Hg}\right)_{3} \mathrm{O}^{+}$. The $\mathrm{CH}_{3} \mathrm{Hg}^{+}$is very persistent and can form a great variety of $\mathrm{CH}_{3} \mathrm{HgX}$ compounds (Geiser and Gross 1989), where $\mathrm{X}$ may be a unidentate group or a polydentate one such as a tripod ligand, whereby a tetrahedral complex is formed (Ghilardi et al. 1992, Midollini et al. 1994). Formation constants for 18 methylmercuric complexes $\left(\mathrm{CH}_{3} \mathrm{HgX}\right)$ in water are summarized in Table 2-7 (Baugman et al. 1973), and degrees of dissociation of 10 organomercury compounds in aqueous solution at $25^{\circ} \mathrm{C}$ are listed in Table 2-8. Reactions of $\mathrm{CH}_{3} \mathrm{Hg}^{+}$with proteins, peptides, nucleotides, and other biological molecules are presumably the reason for its toxicity. The interactions between methylmercury and DOC in aquatic environments have been investigated recently (Hintelmann et al. 1997, Cai et al. 1999). Strong complexation between methylmercury and small molecular weight DOC fractions has been observed with distribution coefficients (log K) ranging from 3.85 to 5.28 (Cai et al. 1999). 
Table 2-7

Logarithms of Formation Constants for 18 Methylmercuric Complexes $\left(\mathrm{CH}_{3} \mathrm{HgX}\right)$ in Water (from Baugman et al. 1973)

\begin{tabular}{lll}
\hline Ligand $\mathrm{X}^{\mathrm{a}}$ & $\log \left[\mathrm{CH}_{3} \mathrm{HgX}\right] /\left[\mathrm{CH}_{3} \mathrm{Hg}^{+}\right]\left[\mathrm{X}^{-}\right]^{\mathrm{a}}$ & \\
\hline $\mathrm{F}^{-}$ & 9.37 & $(9.5)$ \\
$\mathrm{Cl}^{-}$ & 5.25 & $(5.45)$ \\
$\mathrm{Br}^{-}$ & 6.62 & $(6.7)$ \\
$\mathrm{I}^{-}$ & 8.60 & $(8.7)$ \\
$\mathrm{OH}^{-}$ & 9.37 & $(9.5)$ \\
$\mathrm{OC}_{6} \mathrm{H}_{5}^{-}$ & & $(\sim 6.5)$ \\
$\mathrm{OCOCH}_{3}^{-}$ & & $(\sim 3.6)$ \\
$\mathrm{HPO}_{4}^{2-}$ & 5.03 & \\
$\mathrm{HPO}_{3}^{2-}$ & 4.67 & \\
$\mathrm{~S}^{2-}$ & 21.2 & \\
$\mathrm{SCH}_{2} \mathrm{CH}_{2} \mathrm{OH}^{-}$ & 16.12 & $(15.7)$ \\
$\mathrm{SR}^{-}\left(\mathrm{cysteine}^{-}\right)$ & & \\
$\mathrm{SO}_{3}{ }^{2-}$ & 8.11 & \\
$\mathrm{~S}_{2} \mathrm{O}_{3}^{2-}$ & 10.90 & $(6.1)$ \\
$\mathrm{SCN}^{-2}$ & & $(8.4)$ \\
$\mathrm{NH}_{3}$ & 7.60 & \\
$\mathrm{NH}_{2} \mathrm{CH}_{2} \mathrm{CH}_{2} \mathrm{NH}_{2}$ & 8.25 & \\
$\mathrm{CN}^{-}$ & 14.2 & \\
& & \\
\hline
\end{tabular}

$\bar{a}$ Values in parentheses taken from Simpson (1961) (ionic strength $=0.5$, temperature $25{ }^{\circ} \mathrm{C}$; other values from Schwarzenbach and Schellenberg (1965) (ionic strength $=0.1$, temperature $20^{\circ} \mathrm{C}$ ).

Table 2-8

Degrees of Dissociation of 10 Organomercury Compounds in Aqueous Solution at $25^{\circ} \mathrm{C}$ (from Baugman et al. 1973)

\begin{tabular}{lccc}
\hline \multicolumn{1}{c}{ Compound } & \multicolumn{3}{c}{ Degree of dissociation (\%) at } \\
\cline { 2 - 4 } $\mathrm{C}_{6} \mathrm{H}_{5} \mathrm{HgOCOCH}$ & $10^{-4} \mathrm{M}$ & $10^{-7} \mathrm{M}$ & $10^{-10} \mathrm{M}$ \\
$\mathrm{C}_{6} \mathrm{H}_{5} \mathrm{HgSR}$ & 32 & $>99$ & $>99$ \\
$\mathrm{CH}_{3} \mathrm{HgCl}$ & $<0.1$ & $<0.1$ & $<0.1$ \\
$\mathrm{CH}_{3} \mathrm{HgBr}$ & 21 & 98 & $>99$ \\
$\mathrm{CH}_{3} \mathrm{HgI}$ & 4.8 & 75 & $>99$ \\
$\mathrm{CH}_{3} \mathrm{HgOCOCH}$ & 0.5 & 3.3 & 91 \\
$\mathrm{CH}_{3} \mathrm{HgHPO}_{4}^{-}$ & 76 & $>99$ & $>99$ \\
$\mathrm{CH}_{3} \mathrm{HgNH}_{2} \mathrm{R}^{+}$ & 26 & 99 & $>99$ \\
$\mathrm{CH}_{3} \mathrm{HgSR}$ & 1.6 & 39 & $>99$ \\
$\mathrm{CH}_{3} \mathrm{HgS}^{-}$ & $<0.1$ & $<0.1$ & $<0.1$ \\
\hline
\end{tabular}

\subsection{USES OF MERCURY}

Mercury is widely used because of its diverse properties (USEPA 1997). In very small quantities, mercury conducts electricity, responds to temperature and pressure changes, and forms alloys with almost all other metals. Mercury serves an important role as a process or product ingredient 
in several industrial sectors. In the electrical industry, mercury is used in components such as fluorescent lamps, wiring devices and switches (e.g., thermostats), and mercuric oxide batteries. Mercury also is used in navigational devices, instruments that measure temperature, and pressure and other related uses. It also is a component of dental amalgams used in repairing dental caries (cavities). In addition to specific products, mercury is used in numerous industrial processes. The largest quantity of mercury used in manufacturing in the U.S. is the production of chlorine and caustic soda by mercury cell chlor-alkali plants. Other processes include amalgamation, use in nuclear reactors, wood processing (as an antifungal agent), use as a solvent for reactive and precious metals, and use as a catalyst. Mercury compounds are also frequently added as a preservative to many pharmaceutical products. Table 2-9 summarizes inorganic mercury consumption in the USA. The commercial uses of organomercury compounds are given in Table 2-10. Note that many uses have been regulated (Craig 1986, USEPA 1997).

Table 2-9

Mercury Consumption by Use in USA (tonnes) (from Craig 1986)

\begin{tabular}{lllll}
\hline & 1959 & 1968 & 1978 & 1984 \\
\hline Agriculture & 110 & 118 & $21(1975)$ & - \\
Amalgamation & 9 & 9 & $<0.5(1975)$ & - \\
Catalytic & 33 & 66 & $29(1975)$ & 12 \\
Dental & 95 & 106 & 18 & 49 \\
Electrical/batteries & 426 & 677 & 619 & 1170 \\
Chlor-alkali & 201 & 602 & 385 & 253 \\
Laboratory & 38 & 69 & 14 & 7.5 \\
Instruments & 351 & 275 & 309 & 98 \\
Paint & 121 & 369 & 120 & 160 \\
Paper/pulp & 150 & 14 & $<0.5$ & - \\
Pharmaceuticals & 59 & 15 & $15(1975)$ & - \\
Metal for inventory/ other & 298 & 298 & 216 & 48 \\
\hline
\end{tabular}


Table 2-10

Use of Organomercury Compounds (from Craig 1986)

\begin{tabular}{|c|c|c|}
\hline Compound & Use & Comments \\
\hline $\mathrm{CH}_{3} \mathrm{HgX}$ & $\begin{array}{l}\text { Agricultural seed dressing, } \\
\text { fungicide }\end{array}$ & $\begin{array}{l}\text { Banned Sweden 1966, USA } 1970 \\
\text { as seed disinfectant. Not used } \\
\text { today in Europe or USA. Used in } \\
\text { laboratories. }\end{array}$ \\
\hline $\mathrm{C}_{2} \mathrm{H}_{5} \mathrm{HgX}$ & Cereal seed treatment & $\begin{array}{l}\text { Banned USA, Canada 1970, Used } \\
\text { in UK. }\end{array}$ \\
\hline $\mathrm{RHgX}$ & $\begin{array}{l}\text { Catalyst for urethane, vinyl } \\
\text { acetate production }\end{array}$ & \\
\hline $\mathrm{C}_{6} \mathrm{H}_{5} \mathrm{HgX}$ & $\begin{array}{l}\text { Seed dressings, fungicide, } \\
\text { slimicide, and general } \\
\text { bactericide. For pulp, paper, } \\
\text { paints }\end{array}$ & $\begin{array}{l}\text { Banned as slimicide USA } 1970 . \\
\text { Banned as rice seed dressing } \\
\text { Japan 1970. Used in UK. }\end{array}$ \\
\hline $\begin{array}{l}\text { p- } \\
\mathrm{CH}_{3} \mathrm{C}_{6} \mathrm{H}_{5} \mathrm{H} \\
\mathrm{gX}\end{array}$ & Spermicide & \\
\hline $\begin{array}{l}\mathrm{ROCH}_{2} \mathrm{CH}_{2} \\
\mathrm{HgX}\end{array}$ & Seed dressings, fungicides & Banned Japan 1968. Used in UK. \\
\hline $\begin{array}{l}\mathrm{ClCH}_{2} \mathrm{CH}( \\
\left.\mathrm{OCH}_{3}\right) \mathrm{CH}_{2} \\
\mathrm{HgX}\end{array}$ & Fungicide, pesticide, preservative & \\
\hline Thiomersal & Antiseptic, $\mathrm{C}_{2} \mathrm{H}_{5} \mathrm{Hg}$ derivative & \\
\hline $\begin{array}{l}\text { Mercurochr } \\
\text { ome }\end{array}$ & $\begin{array}{l}\text { Antiseptic, organomercury } \\
\text { fluorescein derivative }\end{array}$ & \\
\hline Mersalyl & $\begin{array}{l}\text { Diuretic, methoxyalkyl } \\
\text { derivative, } \\
\mathrm{RCH}_{2} \mathrm{CH}\left(\mathrm{OCH}_{3}\right) \mathrm{CH}_{2} \mathrm{HgX}\end{array}$ & \\
\hline $\begin{array}{l}\text { Chlormerod } \\
\text { rin }\end{array}$ & $\begin{array}{l}\text { Diuretic, methoxyalkyl } \\
\text { derivative, } \mathrm{NH}_{2} \mathrm{CONHCH} \\
\mathrm{CH}\left(\mathrm{OCH}_{3}\right) \mathrm{CH}_{2} \mathrm{HgX}\end{array}$ & \\
\hline $\begin{array}{l}\text { Mercarboli } \\
\text { de }\end{array}$ & $\mathrm{oHOC}_{6} \mathrm{H}_{4} \mathrm{HgCl}$ & O-chloromercuriphenol \\
\hline $\begin{array}{l}\text { Mercuroph } \\
\text { en }\end{array}$ & $\mathrm{oNO}_{2} \mathrm{pONaC}_{6} \mathrm{H}_{3} \mathrm{HgOH}$ & \\
\hline $\begin{array}{l}\text { Mercuroph } \\
\text { ylline }\end{array}$ & Diuretic & \\
\hline
\end{tabular}

\subsection{MERCURY IN THE ENVIRONMENT}

Both anthropogenic and natural processes emit mercury (USEPA 1997). Due to its chemical properties, environmental mercury is thought to move through various environmental matrices, possibly changing form and species during this process. Measured data and modeling results indicate that the amount of mercury mobilized and released into the biosphere has increased since the beginning of the industrial age. Several types of emission sources contribute to the total atmospheric loading of mercury. Once in the air, mercury can be widely dispersed and transported thousands of miles from likely emission sources. The distance of this transport and 
eventual deposition depends on the chemical and physical form of the mercury emitted. Studies indicate that the residence time of elemental mercury in the atmosphere may be on the order of a year, allowing its distribution over long distances, both regionally and globally, before being deposited to the earth. The residence time of oxidized mercury compounds in the atmosphere is uncertain but is generally believed to be on the order of a few days or less. Even after it deposits, mercury commonly is emitted back to the atmosphere either as a gas or in association with particulates to be re-deposited elsewhere. Mercury undergoes a series of complex chemical and physical transformations as it cycles among the atmosphere, land, and water. Elemental mercury may also oxidize in soils, sediment, water, or air. Once the elemental mercury has oxidized to mercury (II) ions forms, the ions may sorb onto organic matter and minerals; chemically precipitate as mercury (II) form, such as mercury sulfide (HgS); migrate to some extent in the subsurface; methylate; and be reduced back to the elemental form (Schuster 1991, Rogers 1992, Henke et al. 1993).

A number of reviews on the transport and fate of mercury in the environment can be found in the literature (e.g., Henke et al. 1993, USEPA 1993). Some of the transport and fate mechanisms have been widely studied and are partially understood (Henke et al., 1993, USEPA 1997). For example, inorganic, organic, and elemental mercury forms are known to have strong tendencies to sorb onto materials that are common in many soils and sediments, including natural organic matter, clays, and mineral oxides (Fang 1978 and 1981, Adriano 1986, Bodek et al. 1988, Andersson et al. 1990, Schuster 1991). These strong sorption tendencies may suggest that inorganic mercury would not be very mobile in subsurface soils and sediments. However, this suggestion is still uncertain, since local conditions, such as the presence of significant methylating agents, colloid materials, chloride-rich groundwater, may hinder mercury sorption or favor the desorption and mobilization of mercury in the surface.

Bacterial and abiotic chemical processes can methylate mercury (II) ions in both waters and geological materials (Stepan et al. 1995). Many animals and certain plants, such as algae, can readily uptake methylmercury. Compared to elemental mercury, methylmercury is more easily absorbed by fish and other aquatic fauna, either directly through the gills or by ingestion of contaminated aquatic plants and animals. Human exposure may result via three dominant pathways: inhalation, ingestion, and dermal absorption. The most widespread mercury-related health problem among humans involves the consumption of water fauna, such as fish, that have been contaminated with methylmercury (Stepan et al. 1995 USEPA 1997). 


\subsection{CONTROL TECHNIQUES FOR CONTAMINATED WATERS}

This part is summarized based on the EPA Capsule Report on Aqueous Mercury Treatment (USEPA 1997a).

\subsection{PRECIPITATION PROCESSES}

Many processes have been developed for removing mercury from wastewater. One of the most well-established approaches is the precipitation and coagulation/co-precipitation technology.

\subsubsection{Sulfide Precipitation}

As discussed in Section 2, mercury ions in solutions can be precipitated easily using hydrogen sulfide or alkali metal sulfide salts. This reaction provides the basic for one of the most commonly reported precipitation methods for removal of inorganic mercury from wastewater (USEPA 1997a). In this process, sulfide (e.g., as sodium sulfide or other sulfide salt) is added to the wastestream to convert the soluble mercury to the relatively insoluble mercury sulfide form:

$$
\mathrm{Hg}^{2+}+\mathrm{S}^{2-} \rightarrow \operatorname{HgS}_{(s)}
$$

A typical process flow diagram for sulfide precipitation is shown in Figure 3-1. As with other precipitation treatments, the process is usually combined with $\mathrm{pH}$ adjustment and flocculation, followed by solids separation (e.g., gravity settling, filtration). Generally, the sulfide precipitant is added to the wastewater in a stirred reaction vessel, where the soluble mercury is precipitated as mercury sulfide. The precipitated solids can then be removed by gravity settling in a clarifier as shown in Figure 3-1. Flocculation, with or without a chemical coagulant or settling aid, can be used to enhance the removal of precipitated solids.

It has been reported that for initial mercury levels in excess of $10 \mathrm{mg} / \mathrm{L}$, sulfide precipitation can achieve 99.9\% removal (Patterson 1985). The lowest achievable effluent mercury concentration appears to be approximately 10 to $100 \mu \mathrm{g} / \mathrm{L}$ for various initial concentrations even with polishing treatment such as filtration. The most effective precipitation, with regard to minimizing sulfide dosage, is reported to occur in the near neutral $\mathrm{pH}$ range. Precipitation efficiency declines significantly at $\mathrm{pH}$ above 9 (Patterson 1985). Sulfide precipitation appears to be the common practice for mercury control in many chlor-alkali plants. Removal efficiencies of 95 to $99.9 \%$ are reported for well-designed and managed mercury treatment systems (Perry 1974, USEPA 1974, USEPA, 1997a). Costs of using the sulfide process for the treatment of chlor-alkali wastewater were reported to be $\$ 0.79 / 1000$ gal (1987 basis), exclusive of sludge management. 


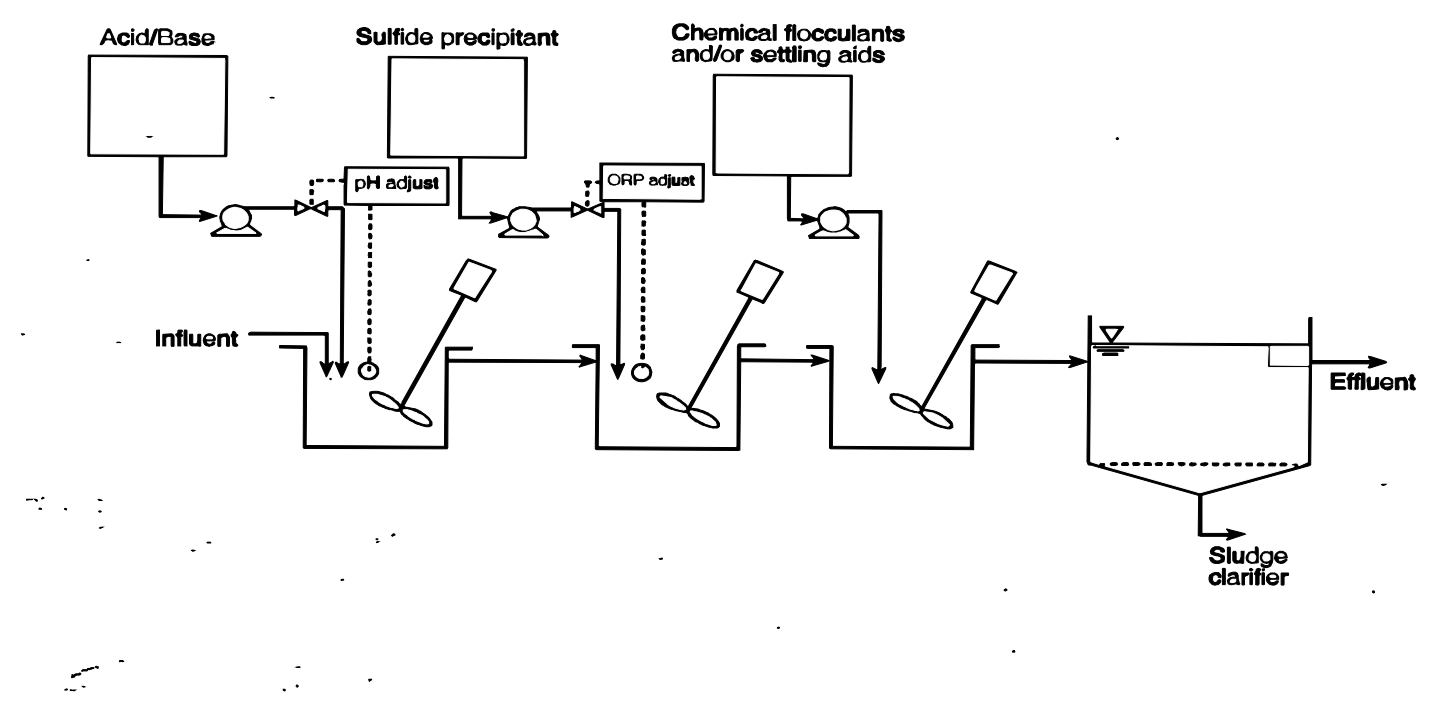

Figure 3-1 Sulfide Precipitation (USEPA 1997a).

Although the sulfide precipitation technology is the common technique for mercury treatment in water, a number of drawbacks exist (USEPA 1997a). One consequence of the application of sulfide precipitation technique is stockpiles of mercury-laden process sludges, which must be either disposed in an environmentally acceptable manner or processed for mercury recovery. Therefore, the sludge waste management approach chosen is a key factor in evaluating the sulfide process for treating such wastewater. Investigators have reported that mercury can resolubilize from sulfide sludge under conditions that can exist in landfills (Hansen and Stevens 1992). Note that this information implies that more comprehensive leaching testing should be conducted regarding the mercury remobilization in environmental conditions, especially the effects of microbials. Ignoring this potential transport of mercury may cause groundwater pollution in the landfill areas. In addition, the sulfide precipitation technique cannot reduce mercury concentration below 10 to $100 \mu \mathrm{g} / \mathrm{L}$.

\subsubsection{Coagulation/Co-precipitation}

Coagulation/co-precipitation is a common technique used in quantitative analysis of trace elements in aqueous solutions. It has also been used for removal of both inorganic and organic mercury from mercury-contaminated wastewater (Patterson 1985, USEPA 1997a). The major coagulants employed include aluminum sulfate (alum), iron salts, and lime. For alum and iron, the dominant mercury removal mechanism is most likely by adsorption co-precipitation (Patterson et al. 1992). Here, one ion is adsorbed into another bulk solid, formed, for example, by addition of alum and precipitation of aluminum hydroxide or by addition of an iron (ferrous or ferric) salt and precipitation of iron hydroxide. The adsorption process is isothermal, and treatment performance can be enhanced by optimal bulk solids formation and by $\mathrm{pH}$ manipulation to optimize bulk solid surface change and soluble mercury speciation (USEPA 1997a). 
Additional treatment, such as filtration, is generally required to achieve a better mercury removal. In studies on the treatment of inorganic mercury dosed to domestic sewage (Patterson 1985, USEPA 1997a), both alum and iron co-precipitation followed by filtration substantially reduced the initial mercury. The removal efficiency, however, is dependent on the concentration of coagulant dosage and the initial mercury concentration and species. For alum usage, more than $90 \%$ mercury removal is generally achieved at an initial concentration of mercury higher than $50 \mu \mathrm{g} / \mathrm{L}$ and coagulant dosage higher than $100 \mathrm{mg} / \mathrm{L}$. Similar results were found for iron. A much lower removal efficiency was found for organomercury compounds than for inorganic mercury (Patterson 1985). Lime usually has low removal efficiency compared to alum and iron.

It appears that the coagulation/co-precipitation technology also suffers similar limitations as for the sulfide precipitation process. Specifically, the retreatment and disposal of the mercury-laden process sludge must be carefully evaluated before conducting this treatment process.

\subsection{ADSORPTION PROCESSES}

Adsorption, another widely used process for mercury removal from wastewater, has the potential to achieve high efficiencies of mercury removal and/or low effluent mercury levels (USEPA 1997a). The predominated adsorption process utilizes activated carbon, but the use of other adsorbents also is reported in the literature. These include processed vegetable or mineral materials such as bicarbonate-treated peanut hull carbon (BPHC), modified Hardwickia binata bark (MHBB), coal fly ash, and the forager sponge (Namasivayam and Periasamy 1993, Sen and De 1987, Deshkar et al. 1990, USEPA 1994). An inherent advantage of adsorptive treatment, particularly when the adsorbent displays isothermal or quasi-isothermal behavior, is that increased treatment efficiency results from incremental adsorbent dosage. Variables other than adsorbent type and dosage can also affect adsorption efficiency. Common variables include wastewater $\mathrm{pH}$ and pollutant speciation.

\subsubsection{Activated Carbon Adsorption}

Granular activated carbon (GAC) is the most commonly used adsorption system for treating industrial waste (USDOE 1994). Some configurations of this process are shown in Figure 3-2. They can be upflow counter-current types with packed or expanded carbon beds, or upflow or downflow fixed-bed units with multiple columns in series. Mercury-contaminated water is passed through the columns until mercury is detected at a predetermined level in the effluent. When multiple columns are placed in series, the first column can be loaded to a greater capacity, while residual levels of the contaminant are removed in the downstream columns. The columns can be replaced or regenerated after being loaded to their capacity. An alternative method of carbon treatment involves use of powdered activated carbon (PAC). The PAC is typically added as slurry onto a contact reactor, and the PAC solids subsequently are removed in a solid separation stage. The PAC is normally not regenerated for reuse due to unfavorable economics including low recovery of the PAC (USEPA 1997a). 


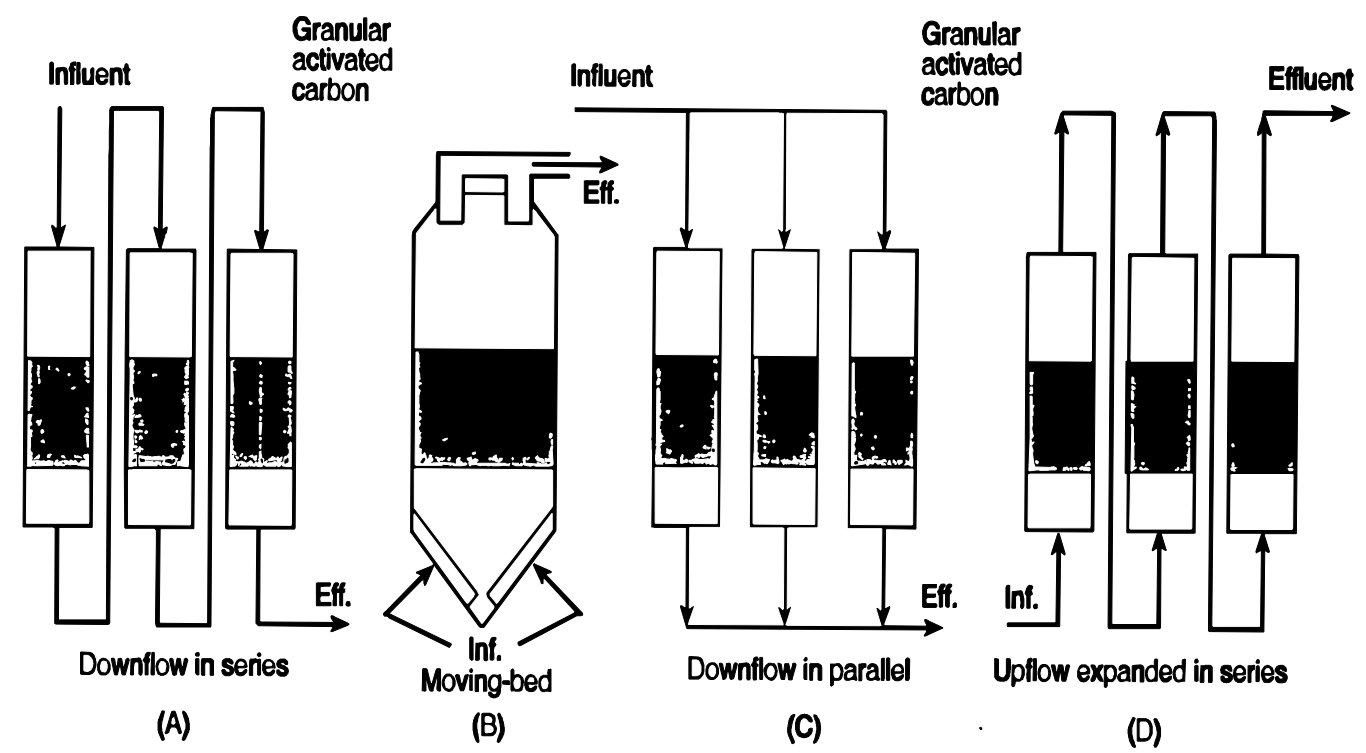

Figure 3-2 Types of GAC column design (USEPA 1997a)

A number of studies have been carried out for removal of mercury from water solutions using PAC and GAC. Thiem and colleagues (1976) tested PAC for mercury removal from potable water. Treating a spiked water solution containing $10 \mu \mathrm{g} / \mathrm{L}$ total mercury, they achieved approximately $80 \%$ removal at a $\mathrm{pH}$ of 7 and a PAC dosage of $100 \mathrm{mg} / \mathrm{L}$. Addition of chelating agents, such as ethylene diamine tetracetic acid (EDTA) or tannic acid, prior to contact with the PAC, was found to increase mercury removal efficiency. Huang and Blankenship (1984) studied the removal of mercury from synthetic wastes using 11 different brands of commercial activated carbon. Among the 11 different types of activated carbon, Nuchar SA and Nuchar SN exhibited a high percent ( $>99 \%$ ) mercury (II) removal over a wide $\mathrm{pH}$ range (2.5 to 11$)$. The other activated carbons studied displayed maximum total mercury (II) removal at $\mathrm{pH} 4$ to 5 , and the percent mercury (II) removal dropped markedly at $\mathrm{pH}$ values greater than and less than 4 to 5 (Huang and Blankenship 1984, USEPA 1997a). Pretreatment or modification of activated carbon with carbon disulfide solution before use has been shown to enhance mercury removal. With pretreated activated carbon, mercury was removed from an initial concentration of $10 \mathrm{mg} / \mathrm{L}$ down to $0.2 \mu \mathrm{g} / \mathrm{L}$, versus the $4 \mathrm{mg} / \mathrm{L}$ effluent value obtained without pretreatment (Humenick et al. 1974). The enhancement in mercury removal was clearly attributed to the strong affinity of sulfur to mercury, which results in chemisorption reactions during the process. The mercury removal mechanism proposed by Humenick et al. (1974) involves transport and diffusion to the carbon disulfide sites and subsequent formation of a chemical bond between a carbon disulfide molecule and the mercury ion.

Gates and colleagues (1995) conducted laboratory research to investigate the feasibility of using inexpensive sulfur-impregnated activated carbon beads, known as Mersob, for mercury removal from aqueous waste. These studies were conducted to evaluate the treatability of mercury- 
containing aqueous and solid mixed wastes stored at DOE sites, such as the Oak Ridge Y-12 site. Mersorb works better under neutral conditions than under acidic conditions ( $\mathrm{pH}$ of 2).

\subsubsection{Other Adsorption Processes}

Over the years, a variety of other adsorbent alternatives to activated carbon have been reported (USEPA 1997a). Several processes are summarized here.

\subsubsection{BPHC Adsorption}

Using a stock mercury solution feed of 10 to $20 \mathrm{mg} / \mathrm{L}$, Namisivayam and Periasamy (1993) reported that bicarbonate-treated peanut hull carbon (BPHC) is seven times more effective than GAC for mercury (II) removal in a bench-scale study. No full-scale data, however, were available on this material. The strong mercury removal capability of this material was attributed to the higher porosity plus moderate ion exchange capacity of BPHC as compared to GAC. The desorption capabilities of BPHC and GAC were also compared, and the former was found to be promising. Percent recoveries of mercury from $\mathrm{BPHC}$ and $\mathrm{GAC}$ using $0.6 \mathrm{M} \mathrm{HCl}$ were $47 \%$ and $13 \%$, respectively, $87 \%$ and $24 \%$, respectively, using $1.0 \% \mathrm{KI}$.

\subsubsection{MHBB Adsorption}

A modified Hardwickia Binata bark (MHBB) was studied at bench-scale for its adsorption on mercury (II) from water (Deshkar et al. 1990). Although the media were shown to be effective in removing mercury (II) from water, it was demonstrated that it is not as effective as GAC. The desorptive properties of the Hardwickia Binata bark were not reported.

\subsubsection{Coal Fly Ash Adsorption}

Coal fly ash, an industrial waste solid, was shown to adsorb mercury (II) (Sen and De 1987). It did not, however, perform as well as GAC. Maximum mercury adsorption by coal fly was observed in the $\mathrm{pH}$ range 3.5 to 4.5 .

\subsubsection{Forager Sponge Adsorption}

The forager sponge is an open-celled cellulose sponge with an amine-containing polymer that reportedly has a selective affinity for aqueous heavy metals in both cationic and anionic states (USEPA 1997a). The polymer is reported to form complexes with ions of transition-group heavy metals, providing ligand sites that surround the metal and form a coordination complex. The polymer's order of affinity for metals is reportedly influenced by solution parameters such as $\mathrm{pH}$, temperature, and total ionic content. Mercury is one of the metals claimed to be removed by the sponge. In general, the following affinity sequence for representative ions is expected (USEPA 1994):

$$
\begin{aligned}
\mathrm{Cd}^{2+}>\mathrm{Cu}^{2+}>\mathrm{Fe}^{3+}>\mathrm{Au}^{3+}>\mathrm{Mn}^{2+}>\mathrm{Zn}^{2+}>\mathrm{Ni}^{2+}>\mathrm{Co}^{2+}>\mathrm{Pb}^{2+}>\mathrm{Au}(\mathrm{CN})_{2}{ }^{+} \\
>\mathrm{SeO}_{4}{ }^{2-}>\mathrm{AsO}_{4}{ }^{3-}>\mathrm{Hg}^{2+}>\mathrm{CrO}_{4}{ }^{2-}>\mathrm{Ag}^{3+}>\mathrm{Ca}^{2+}>\mathrm{Mg}^{2+}
\end{aligned}
$$

The sponge can be used in different configurations such as in columns, fishnet-type enclosures, or rotating drums. Adsorbed ions can be eluted from the sponge using techniques typically 
employed to regenerate ion exchange resins and activated carbons. Following elution, the sponge can be reused in the next adsorption cycle. The number of useful cycles is reported to depend on the nature of the adsorbed ions and the elution technique used. Alternatively, the metal saturated sponge could be incinerated. Metal volatilization would be of concern. The sponge may be dried and reduced in volume to facilitate disposal.

\subsection{ION EXCHANGE TREATMENT}

Ion exchange techniques have been widely employed in water purification processes to clean up cations and anions. Their applications for mercury removal from aqueous solutions have also been reported. Resins containing the iminodiacetic group will exchange for cationic mercury selectively over calcium and magnesium, but copper and cobalt are also readily exchanged (USEPA 1997a). Mercury in the form of anionic complexes, such as $\mathrm{HgCl}_{3}{ }^{-}$, can be treated by anion exchange resins. The thiol resin, Duolite GT-73, is reported to be selective for mercury in any of its three oxidation states (Ritter and Bibler 1992).

Ion exchange processes are typically operated as packed column. Usually four operation steps are carried out in a complete ion exchange cycle: service, backwash, regeneration, and rinse (USEPA 1997a). In the service step, the water containing mercury to be removed is introduced into the packed column. After a target concentration of mercury in the column effluent is reached, the column is said to be spent. A backwash step is then initiated to expand the bed and to remove fines that may be clogging the packed bed. The spent resin is then regenerated by exposing it to a concentrated solution of the original exchange ion, so that a reverse change process occurs. The rinse step removes excess regeneration solution before the column is brought back online for the next service cycle. By using ion exchange treatment, extremely low effluent concentration of mercury is expected. However, this technique cannot typically be used for waters with a high total dissolved solid content.

When chloride content in the wastewater is high, such as that generated by a chlor-alkali plant, removal of inorganic mercury has been typically carried out using the ion exchange technology with anion resins since mercury presents in the negatively charged complex mercury chloride form in the high concentration of chloride (Sorg 1979). Cation exchange of mercury may be effective if the anion content of wastewater is low (Sorg 1979, USEPA 1997a). Certain cation exchange resins (Amberlite IR-120 and Dowex-50W-X8) are reported to be effective for ion exchange treatment of mercury present in industrial wastewater (Patterson 1985). The Duolite GT-73, a cationic resin, contains the thiol (-SH) group and reacts with ionic mercury. The thiol function group has a high selectivity for mercury (see section 2 of this report) as well as a strong tendency to bind certain other metal ions such as copper, silver, cadmium, and lead.

A full-scale ion exchange process at a defense processes facility has consistently removed mercury via ion exchange from 0.2 to $70 \mathrm{mg} / \mathrm{L}$ down to levels of 1 to $5 \mu \mathrm{g} / \mathrm{L}$, following $0.2 \mu \mathrm{m}$ prefiltration (Ritter and Bibler 1992). This system utilizes a macroporous, weakly acidic, polystyrene/divinylbenzene cation resin, with thiol (-SH) functional groups. High levels of mercury in a synthetic wastewater were removed to levels as low as $15 \mu \mathrm{g} / \mathrm{L}$ after 77 bed volumes of usage, and $35 \mu \mathrm{g} / \mathrm{L}$ after 157 bed volumes of usage (Becker and Eldrich 1993). This system utilized Amberlite IRC 718 in bench-scale testing. More applications have been summarized in the U. S. EPA report (1997a). 


\subsection{OTHER PROCESSES}

In addition to the three major technologies discussed above, the following processes are also reported to be applicable to remove mercury from wastewater: (1) chemical reduction, (2) membrane separation, (3) various emerging technologies.

\subsubsection{Chemical Reduction}

Ionic mercury can be reduced in solution by other metals higher in the electromotive series and then separated by filtration or other solids separation techniques. Reducing agents include aluminum, zinc, iron, hydrazine, stannous chloride, and sodium borohydride (USEPA 1997a). Although the literature includes much discussion of reducing processes, only limited actual treatment data are presented. The major disadvantage of this process is that the residual mercury concentration after reduction is too high, probably requiring second-stage polishing. In a study carried out by Sites and Oberholtzer (1992), residual mercury concentrations of 0.4 to $1.08 \mu \mathrm{g} / \mathrm{L}$ were reported by using a bimetallic oxidation/reduction compound, KDF, which consisted of a finely ground alloy of 55\% copper and $45 \%$ zinc. However, this process may be applicable only for exceptionally clean solutions.

\subsubsection{Membrane Separation}

Removal of mercury from wastewater has been carried out by several membrane processes, such as ultrafiltration, charged filtration, crossflow microfiltration, magnetic filtration, and reverse osmosis (USEPA 1997a). Ultrafiltration systems are pressure-driven membrane operations that use porous membrane for the removal of colloidal materials (Metcalf and Eddy 1991, Cai et al. 1999). Ultrafiltration is designed to removal colloidal materials and large molecules with molecular weight excess of 5000. It is, therefore, unlikely to remove dissolved mercury efficiently. To increase removal efficiency, mercury present in the water solution can be converted to large site of mercury-complex using chelating reactions (Kosarek 1981). Charged membrane ultrafiltration incorporates a noncellulosic, high flux membrane that is negatively charged as a result of dissociated subgroup within the membrane structure (USEPA 1997a). A beneficial aspect of the charged ultrafiltration membrane is that the negative polarization minimizes membrane fouling (Kosarek 1981). The crossflow microfiltration system is based on the concept of using a dynamic membrane to form a filtration medium. This process is a solidliquid separation process in which the feed suspension sweeps across the face of a filter membrane while pressure differences cause liquid phase to pass through the membrane, leaving the solids to be flushed away in the residual flow. By this means, the solids are concentrated up in the suspension flow, which is commonly recycled to the feed end. This contrast with the "barrier" filtration system, in which the solids build up on the filtering surface, gradually restricting the flow through the filter (Squires 1992). As with the regular ultrafiltration process, mercury in dissolved phased is not expected to be removed by crossflow microfiltration technique. Some pretreatment techniques such as co-precipitation have to first be employed (Broom et al. 1994).

Magnetic filtration of soluble species such as ionic metals is accomplished by forming a magnetic precipitate through coagulation and magnetic seed addition and then passing the wastewater through a filter made with ferromagnetic wires, which represent a magnetic field (USEPA 1997a). The magnetic precipitate can be rapidly and efficiently removed by magnetic 
filtration, even if the precipitate is quite fine (Terashima et al. 1986). Mercury removal has been studied in a bench-scale magnetic filtration unit fed gas-scrubbing wastewater from a municipal solid waste incineration plant. For an influent mercury concentration of $15.0 \mathrm{mg} / \mathrm{L}$, effluent mercury concentrations of 0.003 to $0.117 \mathrm{mg} / \mathrm{L}$ were achieved (Terashima et al. 1986).

Reverse osmosis is a physical separation technique whereby an applied pressure in excess of the inherent solution osmotic pressure forces water to permeate a semipermeable membrane, which rejects the bulk of the dissolved and suspended constituents. The reverse osmosis process has very strict feed water requirements, particularly related to the concentration of suspended solid and materials (e.g., oil or grease), which will foul the membrane surface (Kosarek 1981).

\subsubsection{Membrane Extraction}

Microemulsion liquid membrane extraction of mercury is an example of a liquid-liquid extraction technique (USEPA 1997a). Schematic representations of mercury extraction using an emulsion liquid membrane are shown in Figure 3-3. When oleic acid tetradecane, DNP-8 surfactant, and $6 \mathrm{~N}$ sulfuric acid are mixed, a microemulsion forms spontaneously. The microemulsion is then dispersed in the aqueous stream containing mercury. After extraction, the emulsion and aqueous phase are separated. The microemulsion is then demulsified to recover the internal aqueous phase, which is concentrated in mercury. During the extraction process, mercury ions react with the oleic acid at the surface of the emulsion droplet. The mercury/oleic complex diffuses to the interior of the emulsion until it encounters an internal droplet containing sulfuric acid. A hydrogen ion is exchanged for the mercury ion on the oleic acid molecule, which is then free to diffuse back to the surface of the emulsion and extract another mercury ion (Larson and Wiencek 1992). As a result, mercury can be pumped against its concentration gradient, with counter-transport of hydrogen ions.

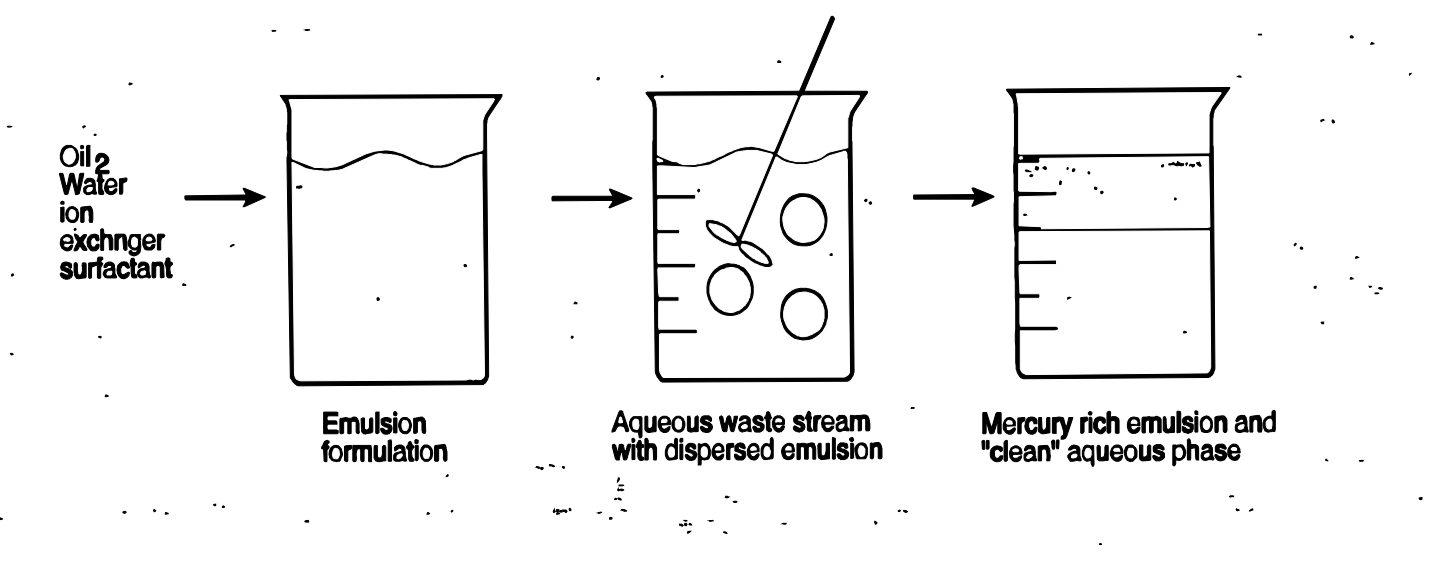

Figure 3-3 Schematic representation of mercury ion extraction with an emulsion liquid membrane (USEPA 1997a). 


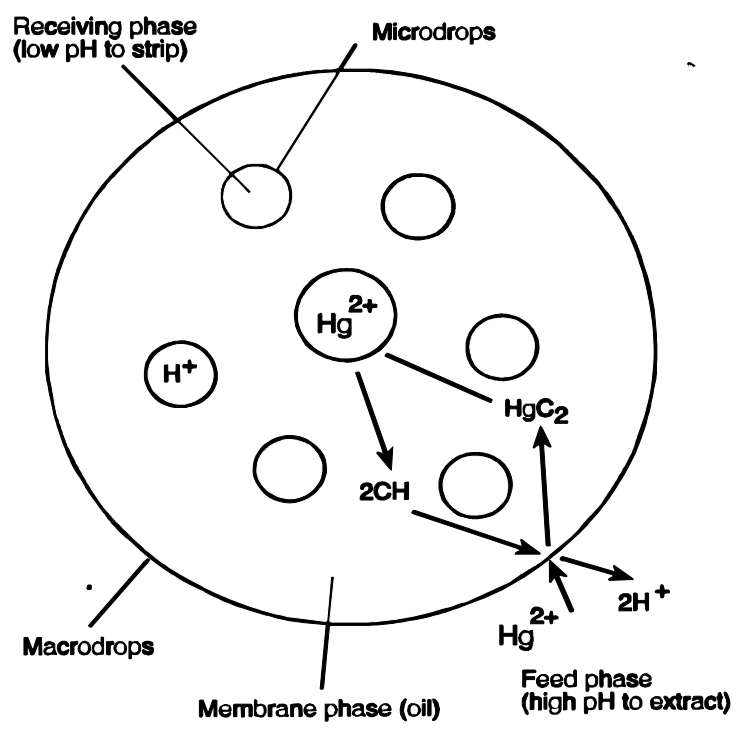

Figure 3-4 Schematic representation of mercury ion extraction with an emulsion liquid membrane (USEPA 1997a) mechanisms.

\subsection{RECENTLY PUBLISHED PROCESSES}

Several new technologies cited from technical literature are summarized here. Although these processes are still in the laboratory research stage, they may provide some possibilities for actual mercury treatment on a large scale in the near future.

\subsubsection{Self-Assembled Mercaptan on Mesoporous Silica (SAMMS)}

In order to remove mercury from a lixiviant consisting of an aqueous solution of potassium iodide/iodine, a novel adsorbent material consisting of self-assembled mercaptan groups on mesoporous silica (SAMMS) substrate has been developed at Pacific Northwest National Laboratory (Feng et al. 1997). This adsorbent has specifically designed functional groups that have very high specificity and adsorption capability for mercury and other soft cationic contaminants of concern. The pores in SAMMS have a very narrow, specifically tailored (15 to $400 \AA)$ pore-site distribution, resulting in a very high surface area $\left(>800 \mathrm{~m}^{2} / \mathrm{g}\right)$ (Mattigod et al. 1999).

The SAMMS adsorbent is synthesized by utilizing the principle of molecular self-assembly in which functional molecules are induced to aggregate on an active surface, resulting in an organized assembly with both order and orientation (Mattigod et al. 1999). During this process, bifunctional molecules containing hydrophilic and hydrophobic moieties adsorb onto an engineered substrate or interface as closely packed monolayers. Such a self-assembly of functional molecules is driven by both inter- and intramolecular forces. The hydrophobic and hydrophilic moieties of these functional molecules can be chemically modified to contain a 
specific functional group to promote covalent bonding between the functional organic molecules and the substrate on one end and molecular bonding between organic molecules and the metallic ions on the other end (Mattigod et al. 1999). By populating the outer surface with an optimum density of functional groups, an effective means for specifically binding certain metal ions can be established. The metal-loading capacity of such an assemblage is determined by the functional group density that, in turn, is controlled by the available surface area of the underlying inorganic engineered substrate (Mattigod et al. 1999).

In a recent study, Mattigod et al. (1999) demonstrated the effectiveness of the SAMMS adsorber in removing strongly complexed mercury (II) from spent KI lixiviant. The adsorption density measurements indicated that SAMMS material can adsorb from 26 to $270 \mathrm{mg} / \mathrm{g}$ of strongly complexed mercury (as $\mathrm{HgI}_{4}{ }^{2-}$ ) from potassium iodide/sulfate waste solutions. The adsorption density increased with decreasing iodide concentration. Dissolved mercury (II) has a higher affinity for thiol groups in SAMMS as compared to silanol groups in silica gel, affirming the nature of soft cation-soft base interaction expected between mercury and - SH groups. The kinetic data indicated that the adsorption reaction occurs very rapidly, independent of mercury (II) concentration and $\mathrm{pH}$.

\subsubsection{Graft Copolymer of Acrylamide onto Cellulose}

Polymers with ligands capable of coordinating with metal ions have been attracting great interest for cleanup of wastewater and recovery of noble metals. Current efforts are at the stage of developing selective chelating species. It has been reported that amide compounds are selective reagents for binding mercury (Bicak et al. 1999). The reaction is reasonably fast even at room temperature. The amide nitrogen forms a covalent bond with mercury (II) ions but not with other metal ions. Generally, the amide nitrogen atom lacks sufficient electron donating character due to the adjacent electron withdrawing carbonyl group and it cannot normally form a coordination bond with transition metal ions under regular conditions (Bicak et al. 1999). It has been demonstrated that crosslinked polyacrylamide is an extremely powerful sorbent for mercury uptake, sorbing as high as $3 \mathrm{~g}$ mercury (II) per gram of polymer (Bicak and Sherrington 1995). In a recent study, Bicak et al. (1999) reported the use of grafted polyacrylamide for mercury uptake. Acrylamide has been grafted onto cotton cellulose, and its mercury (II) adsorption characteristics have been investigated. The mercury uptake capability of the graft polymer is $3.55 \mathrm{mmol} / \mathrm{g}$. The mercury (II) sorption is selective, and no interferences have been observed in the presence of $\mathrm{Ni}(\mathrm{II}), \mathrm{Co}(\mathrm{II}), \mathrm{Cd}(\mathrm{II}), \mathrm{Fe}(\mathrm{III}), \mathrm{Zn}$ (II) ions in $0.1 \mathrm{M}$ concentration at pH 6 . Regeneration of the loaded polymer without losing its original activity can be achieved using hot acetic acid. The graft copolymer seems suitable for removal of mercury from wastewater. 


\subsection{CONTROL TECHNIQUES FOR MIXED WASTE MATRICES}

Mixed waste is waste that contains both hazardous chemical components, subject to the requirements of the Resource Conservation and Recovery Act (RCRA), and radioactive components, subject to the requirements of the Atomic Energy Act. The U.S. Department of Energy (DOE) Mixed Waste Focus Area (MWFA) is tasked with ensuring that solutions are available for the mixed waste treatment problems of the DOE complex (Perona and Brown 1993, Hulet et al. 1998, Kalb et al. 1999). DOE has classified individual mixed waste streams into broad categories, with mercury-containing wastes as one of these categories. DOE's diverse set of mercury-contaminated wastes comes from DOE-supported research, development, and manufacturing work in a variety of fields (Hulet et al. 1998). Some origins of the waste include medical isotope research, spill-cleanup residues, nuclear plant operational support equipment and waste, and weapons manufacturing secondary streams.

EPA classifies hazardous wastes as either wastewaters or nonwastewaters. Wastewaters are wastes that contain less than $1 \mathrm{wt} \%$ suspended solids and less than $1 \mathrm{wt} \%$ total organic carbon. Wastes not meeting this definition are nonwastewaters. Technologies for mercury-containing wastewaters have been summarized in section 3. The following review will be focusing on the nonwastewaters.

At many DOE sites, the mixed waste matrices are contaminated with mercury in many forms. If these mercury levels exceed $260 \mathrm{mg} / \mathrm{kg}(\mathrm{ppm})$, EPA regulations (40 CFR 268.40) require that the mercury be removed by separation technologies (retorting, roasting, or extraction). If sufficient organic material is present, mercury may be removed via incineration and captured in the off-gas (INEL 1997b). Mixed waste containing mercury at concentrations less than $260 \mathrm{mg} / \mathrm{kg}$ (ppm) are not required to undergo any mercury removal or separation steps. However, the final waste form must leach less than $0.2 \mathrm{mg} / \mathrm{L}$ of mercury as required by the Toxicity Characteristic Leaching Procedure (TCLP) of RCRA. This means that stabilization steps are frequently needed to meet this requirement. These EPA treatment standards were originally conceived for nonradiologically contaminated hazardous mercury. Separation of mercury from mixed waste soils results in generation of two waste streams for treatment/disposal. Recovered mercury would likely still be radiologically contaminated, prohibiting its recycle or reuse as elemental mercury. The elemental mercury would require further treatment prior to disposal (Kalb et al. 1999). Based on this information, EPA has agreed that the separation techniques such as retorting or roasting with recovery of mercury for reuse (RMERC) is not appropriate for this type of waste. Thus, several alternative treatment technologies that directly stabilize the mixed waste soil are being examined (Kalb et al. 1999).

A number of technologies have been developed either for mercury separation or stabilization. These technologies have been reviewed and summarized in a variety of documentation from government agencies and private institutes. Since this information is essential for identifying decontamination technologies that are useful for the project, these technologies are summarized briefly here. 


\subsection{SEPARATION/REMOVAL}

\subsubsection{Thermal Treatment Processes}

The U.S. EPA BDAT for the treatment of D009, high-mercury-contaminated materials, is thermal roasting or retorting (Stepan et al. 1993, Stepan et al. 1995). Thermal treatment is based on the vapor pressure of mercury and the low temperature at which mercury vaporizes. The vapor pressure of elemental mercury is relatively low at ambient temperature $\left(1.2 \times 10^{-3} \mathrm{mmHg}\right.$ at $20{ }^{\circ} \mathrm{C}$ (Dean 1985)). However, the vapor pressure increases rapidly, by orders of magnitude, with relatively small increases in temperature.

Thermal treatment of a mercury-contaminated material involves heating the contaminated materials, collecting and condensing evolved vapors, and recovering elemental mercury. The recovered mercury can be sold as a commodity product (Stepan et al. 1995).

The first step in a thermal retorting process is to purge the system of oxygen to prevent the oxidation of elemental mercury to mercuric oxide. At $300{ }^{\circ} \mathrm{C}\left(572{ }^{\circ} \mathrm{F}\right)$, mercuric oxide decomposes back into elemental mercury and oxygen. Therefore, to avoid oxidation, the mercury-contaminated materials are heated in either a nitrogen environment or in a vacuum, at temperatures up to $1200{ }^{\circ} \mathrm{C}\left(2192{ }^{\circ} \mathrm{F}\right)$. Under these conditions, mercury and other volatile compounds will vaporize. The vapors are collected and sent through a series of scrubbers and condensers to separate the various components, including elemental mercury (Stepan et al. 1993).

Numerous organizations are involved in thermal treatment of mercury-contaminated materials (Stepan et al. 1993, Weyand et al. 1994, Stepan et al. 1995). Figure 4-1 shows a schematic diagram of a portable thermal treatment (PTT) system developed by Pittsburgh Mineral \& Environmental Technology, Inc./Mercury Recovery Services (PMET/MRS). 


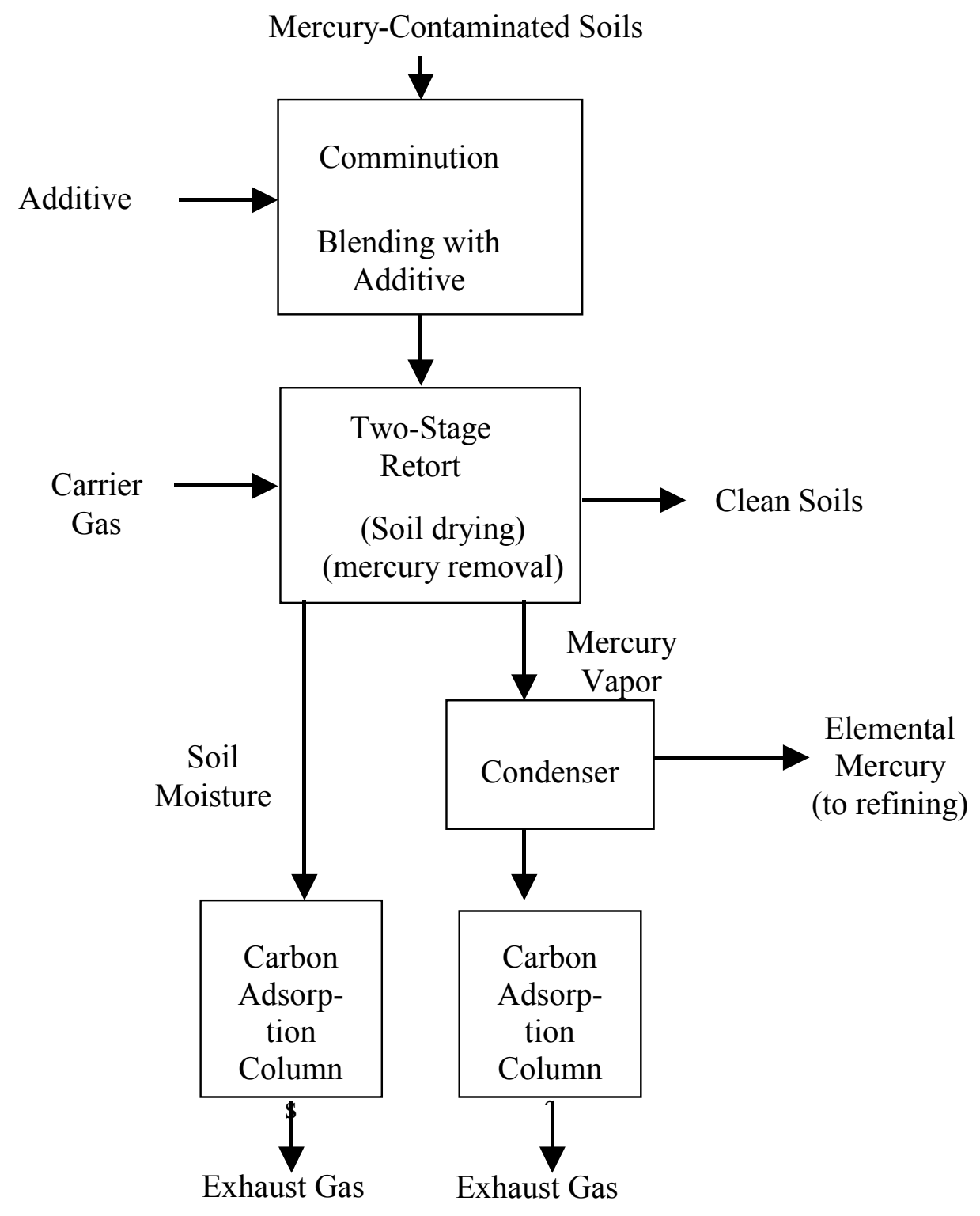

Figure 4-1 PEMT/MRS PTT schematic diagram (from Stepan et al. 1995).

Mercury-contaminated soils are mixed, split, and blended with a proprietary additive. The soils and additive are then heated at a low temperature in the furnace to remove soil moisture. The emissions, water vapor, and low concentration of mercury vapor generated during this drying process are passed through a set of three sulfur-impregnated, activated carbon columns in series (Stepan et al. 1995). After drying, the furnace temperature is increased to volatilize the remaining mercury. The mercury vapors are condensed, and the mercury is removed in a collection pot. The remaining vapors are passed through a second set of sulfur-impregnated activated carbon adsorption columns. Operation in this manner produces no waste streams. The recovered mercury is sent to a refinery for recycling, and the spent carbon is regenerated. 
The PTT system can process soils contaminated with elemental mercury as well as various mercury compounds (oxides, sulfides, organometallics) and amalgams. Bench-scale results conducted by PMET/MRS have shown removal efficiencies greater than $99.9 \%$ and final soil mercury concentration of less than $0.2 \mathrm{mg} / \mathrm{kg}$ (Stepan et al. 1995).

Thermal technologies are energy-intensive and may produce other contaminant condensates that will require subsequent treatment and disposal. If the process is located at a centralized site, transportation of the contaminated materials can be expensive. Additionally, the portable treatment systems are not designed to process large volumes of mercury-contaminated materials (Stepan et al. 1993).

\subsubsection{Chemical Leaching}

Chemical separation is based upon the reactivity of mercury and employs solution leaching of the mercury-contaminated materials. Solution leaching may be used to remove both elemental and inorganic forms of mercury. The most commonly used leaching solutions are oxidizing acids, such as nitric acid $\left(\mathrm{HNO}_{3}\right)$, hypochlorous acid $(\mathrm{HClO})$, and sulfuric acid $\left(\mathrm{H}_{2} \mathrm{SO}_{4}\right)$. These oxidizing acids are used because of their ability to readily dissolve elemental and inorganic mercury (Stepan et al. 1993). Foust (1993) has recently developed a process, which uses an $\mathrm{I}_{2} / \mathrm{I}^{-}$ lixiviant solution to solubilize mercury from contaminated solids.

Chemical leaching processes typically involve contacting the mercury-contaminated materials with the leaching solution, creating solubilized ionic mercury. The mercury-containing leachant is removed from the geologic materials, collected, and treated to convert the ionic mercury to elemental mercury for recovery. If acidic leachant solutions are used, the cleaned geologic materials may require neutralization prior to disposal in a landfill. Additionally, the spent leaching solutions will ultimately require further treatment for the removal of mercury prior to disposal (Stepan et al. 1995).

The approach of using a chemical separation process is fairly new compared to thermal treatment for the remediation of mercury-contaminated materials. Stepan et al. (1993 and 1995) reviewed this process and provided a detailed description for a technology demonstration conducted by COGNIS, Inc. (Santa Rosa, California). A process diagram for the COGNIS mercurycontaminated soil remediation process is shown in Figure 4-2. The overall process consists of physical soil washing and particle-size classification, oxidative leaching of mercury from soil matrices, and removal and recovery of dissolved mercury from the leachant via electrodeposition. 


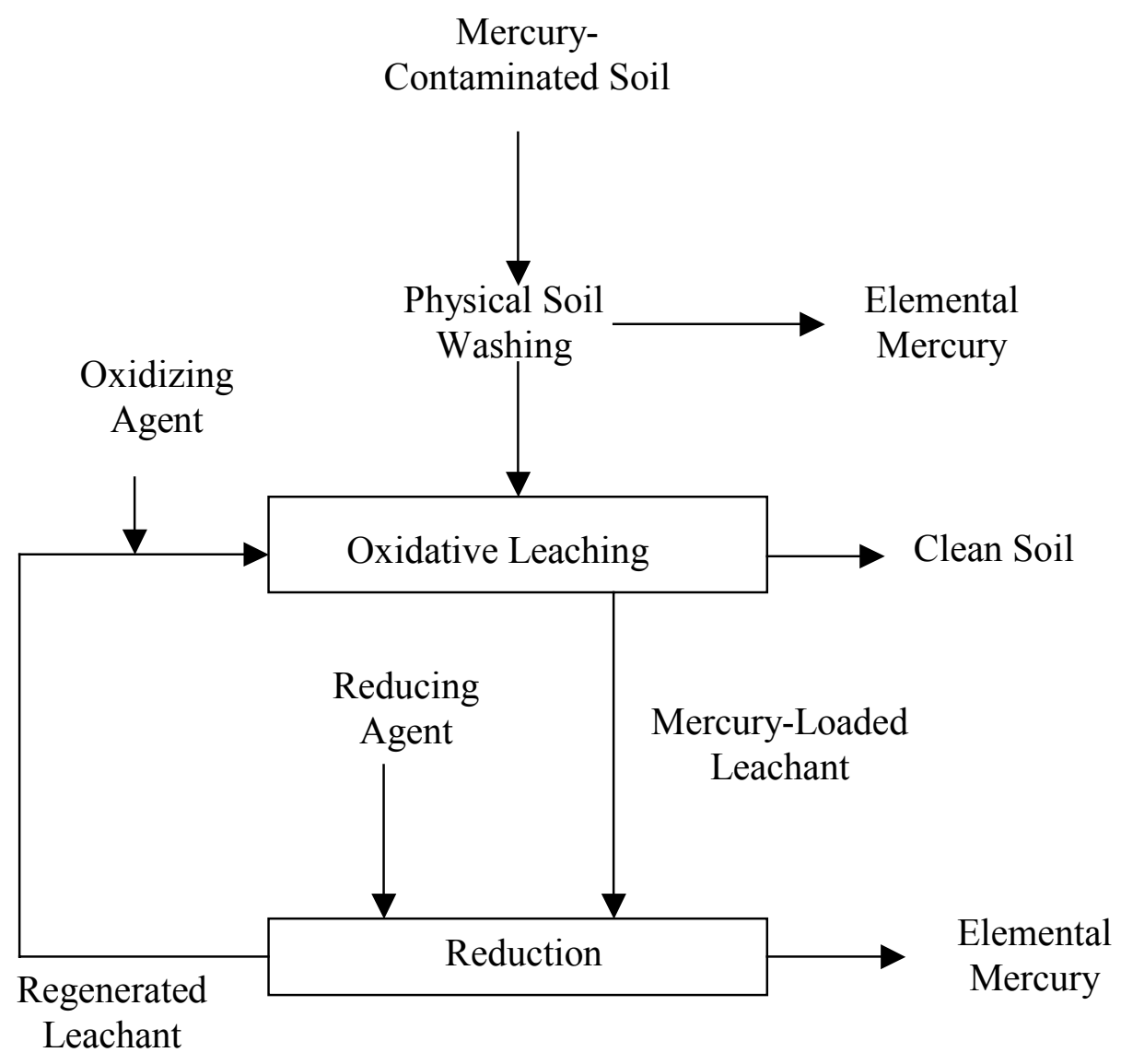

Figure 4-2 COGNIS, Inc., Mercury Remediation Process Schematic

This process was shown to remove mercury from two different types of soils, reaching a residual mercury concentration of $\leq 15 \mathrm{mg} / \mathrm{kg}$ and pass TCLP. Mercury in the sandy soil sample was reduced to $<5 \mathrm{mg} / \mathrm{kg}$, a removal of $99.7 \%$. The clayey soil was found to be more difficult to leach; however, the fine fraction and the coarse fraction were leached to $<15 \mathrm{mg} / \mathrm{kg}$ of residual mercury ( $>98 \%$ removal) and $<40 \mathrm{mg} / \mathrm{kg}$ of residual mercury, respectively (Stepan et al. 1995).

In the patented process developed by Foust (1993), mobilization/removal of mercury from solid wastes was conducted using a lixiviant consisting of an aqueous solution of potassium iodide/iodine $\left(\mathrm{KI} / \mathrm{I}_{2}\right)$. This process utilizes solutions consisting of $\mathrm{I}_{2}(0.001$ to $0.5 \mathrm{M})$ as the oxidizing agent and the iodide ion $(0.1$ to $1.0 \mathrm{M})$ as a complexing ligand. Mercury in contaminated solid wastes in the form of oxides, sulfides, elemental, and adsorbed phases is mobilized by the $\mathrm{KI} / \mathrm{I}_{2}$ lixiviant through oxidation and complex-forming reactions (Mattigod et al. 1999, Cox et al. 1996).

$$
\begin{aligned}
& \mathrm{HgS}+\mathrm{I}_{2}+2 \mathrm{I}^{-} \rightarrow \mathrm{HgI}_{4}{ }^{2-}+\mathrm{S}_{\text {oxidized }} \\
& \mathrm{Hg}(\mathrm{l})+\mathrm{I}_{2}+2 \mathrm{I}^{-} \rightarrow \mathrm{HgI}_{4}{ }^{2-} \\
& \mathrm{HgO}+\mathrm{I}_{2}+2 \mathrm{I}^{-} \rightarrow \mathrm{HgI}_{4}{ }^{2-}+\mathrm{O}^{2-}
\end{aligned}
$$


After such mobilization, the dissolved and strongly complexed mercury can be removed, and the lixiviant is recycled. Techniques have been developed to recover mercury from the spent lixiviant (Mattigod et al. 1999).

\subsubsection{Other Technologies}

\subsubsection{Physical Separation}

Physical separation technologies are based upon the high density of mercury relative to most other materials (Stepan et al. 1993 and 1995). These types of processes have historically been used in the mining industry to recover heavy metals or precious metals from less dense materials. Physical separation in a soil-water mixture removes and recovers elemental mercury and other heavy metals from the less dense soils through the use of a series of density-based separators. Although these processes are effective in removing the majority of the unbound elemental mercury from most contaminated materials, they are not capable of removing organic and inorganic mercury compounds or residual mercury that has been sorbed onto clays. So most often this process is combined with other cleanup technologies, such as chemical leaching or thermal treatment, for further treatment.

\subsubsection{Biological Treatment}

Biological treatment is based upon the ability of certain bacteria or plants to assimilate or accumulate mercury, or convert from one mercury form to another (Stepan et al. 1993, Meagher et al. 1999). These processes are generally inexpensive but are slow.

Many bacteria have a detoxification mechanism for converting soluble ionic mercury into elemental mercury. Certain bacteria utilize another detoxification mechanism to convert ionic mercury to methylmercury. The methylmercury can then be biologically converted to either demethylmercury or to elemental mercury and methane.

A new biotechnology was developed by a team led by David B. Wilson (Betts 1999) for mercury removal. The technology revolves around Escherichia coli bacteria that have been genetically engineered to take up mercury. Pilot tests of the bacteria's ability to take up metals in a hollowcore bioreactor showed that it is capable of consuming $99.75 \%$ of the mercury in a solution containing $2 \mathrm{mg} / \mathrm{L}$. If the reactor were placed in series, it is believed that mercury could be reduced down to $6.3 \mathrm{ng} / \mathrm{L}$ (Betts 1999).

Meagher et al. (1999) announced recently that it is possible to genetically engineer plants, in their example the common model plant, thale cress (Arabidopsis thaliana), so that they can remove organic groups from organomercurials, converting them back to far less labile molecules of ordinary mercury.

\subsubsection{Electrolyte Treatment}

Electrolytic processes are based on the conversion of heavy metal ions to stable metal oxides through the use of an applied electrical current. Electrolytic processes have been applied to the remediation of mercury-contaminated soils (Stepan et al. 1993, Cox et al. 1996). To be able to effectively use this technology, some forms of pretreatment of the matrices, such as chemical leaching, are required. Electrolytic processes are then used to remove dissolved mercury 
compounds from the liquid process streams. For maximum efficiency, the electrolytic technology should be used on contaminated liquids containing less than $3 \%$ to $5 \%$ solids.

In a recent study, enhanced electrokinetic remediation of $\mathrm{HgS}$-contaminated soils using $\mathrm{I}_{2} / \mathrm{I}^{-}$ lixiviant was investigated using bench-scale electrokinetic cells (Cox et al. 1996). The thermodynamic conditions under which the lixiviant could be effective were determined by constructing a $\mathrm{pE}-\mathrm{pH}$ diagram for the $\mathrm{Hg}-\mathrm{S}-\mathrm{I}$ system. The critical issues in determining the efficacy of the process are the oxidation of reduced $\mathrm{Hg}$ by $\mathrm{I}_{2}$ and $\mathrm{I}_{3}{ }^{-}$and the transport of the resulting $\mathrm{HgI}_{4}{ }^{2-}$ complex.

\subsection{IMMOBILIZATION}

As stated previously, EPA has allowed industry to use stabilization technologies only in the treatment of mercury wastes containing less than $260 \mathrm{mg} / \mathrm{kg}$ of total mercury. Separation processes are required to recover mercury in wastes with total mercury contents greater than or equal to $260 \mathrm{mg} / \mathrm{kg}$. In the literature on mercury decontamination, many terms regarding the immobilization process have been used. Different mercury immobilization technologies may be divided into the following two categories, stabilization and amalgamation. Their definitions and related technologies are discussed below.

\subsubsection{Stabilization}

Stabilization involves a chemical immobilization of hazardous constituent, through chemical bonds to an immobile matrix, or chemical conversion to an immobile species, thereby reducing vaporization or leaching to the environment (SAIC 1998).

Stabilization technologies for mercury-contaminate soils and other solid wastes involve several steps (Stepan et al. 1993). The first step usually involves breaking up large mercury globules, providing a greater surface area to react with an added reagent. The chemical reagent is added to produce either mercury oxides or mercury sulfides. After the reagent is sufficiently mixed throughout the contaminated materials, cement is added. The mercury oxides or sulfides are trapped in the cemented mass. The resulted dense and less permeable mass reduces the mobility of the mercury.

A potential advantage of using a stabilization technology is that it produces more stable and less leachable mercury compounds. Stabilization processes, however, do not reduce total mercury concentration but rather reduce the leachability of the mercury, yielding a product that may still require disposal in a landfill. There is also a resulting increase in the volume of the contaminated materials (Stepan et al. 1993).

A number of technologies have been developed in recent years, and the summary of some of those technologies appeared in the literature (Stepan et al. 1993, SAIC 1998). Funderburk \& Associates, Fairfield, Texas, has developed a soil stabilization process that includes a mechanical system for breaking the elemental mercury in soils and sediments into fine spherical particles called prills (Funderburk 1992). The mercury prills are reportedly much easier to manage, have more exposed surface area, and are more resistant to coalescence. After the elemental mercury is broken into prills, a chemical reagent is added until an oxidized film covers the surface of the prills, creating a barrier against coalescence. A binding agent is then added to the chemical reagent/mercury-contaminated material slurry. The oxidized surface of the mercury is chemically 
bonded to the surrounding water molecules in the binding agent or in the soil. The mercury becomes incorporated into a thick and very-low-permeability matrix, which reduces the mobility of the mercury.

Radian Corporation conducted bench scale treatability tests with Portland cement for stabilizing soil from the East Fork Poplar Creak (Oak Ridge, TN) area contaminated with $1000 \mathrm{mg} / \mathrm{kg}$ of mercury, mostly in the mercuric sulfide form (SAIC 1998). They used a $60 \%$ waste loading and $25 \%$ added water to prepare a 28-day cure stabilized sample with an unconfined compressive strength of 913 psi. They conducted an ASTM leaching test (ASTM Method D-2434) using deionized water as the leachant and detected $0.22 \mu \mathrm{g} / \mathrm{L}$ of mercury in the leachate.

\subsubsection{Amalgamation}

Amalgamation is a physical immobilization technology unique to elemental mercury, in which another metal forms a semisolid alloy with mercury (SAIC 1998). Mercury dissolves in the solid metal, forming a solid solution. Amalgamation does not involve a chemical reaction.

Historically, mercury amalgamation has been used to extract precious metals (i.e., gold, silver) from metal ore. For example, gold is amalgamated with mercury, and this amalgam is then extracted from the ore. The amalgam is then retorted to volatilize the mercury and recover the gold.

Several treatability studies and other development efforts have been performed throughout the DOE complex related to amalgamation of mercury wastes (INEL 1997). Tests have been conducted to evaluate the ability of several different materials to stabilize mercury, including tin, zinc, copper, sulfur, and sulfur polymer cement (SPC). Sulfur and SPC stabilization techniques actually involve a reaction that forms a chemical compound $(\mathrm{HgS})$, which significantly decreases the vapor pressure of the mercury. In contrast, amalgamation processes using zinc, tin, and copper form an alloy with mercury, and do not involve a chemical reaction. However, the RARA definition for amalgamation, found at 40 CFR 268.40, includes sulfur as an acceptable inorganic reagent. Therefore, mercury stabilization processes with sulfur and SPC are also being referred to as amalgamation.

Tin and zinc do not give an acceptable final waste form to meet DOE's need, but alloys of these two metals may (USDOE 1998). To improve on amalgamation alone, encapsulation of amalgamated mercury waste will further limit the volatilization and leaching of mercury. SPC can be used to convert mercury compounds to mercuric sulfide and encapsulate simultaneously (USDOE 1998, SAIC, 1998). However, the encapsulation process temperature can volatilize mercury, so the mercury vapor must be captured and recycled in the process. SPC processing temperatures are much lower than mercury retorting temperatures, so good control is much more feasible (SAIC 1998).

\subsubsection{Sulfur polymer stabilization/solidification (SPSS)}

A new sulfur polymer stabilization/solidification (SPSS) technology has been recently developed in Brookhaven National Laboratory (Colombo et al. 1997, Kalb et al. 1999). Sulfur polymer cement consists of $95 \mathrm{wt} \%$ elemental sulfur reacted with $5 \mathrm{wt} \%$ of an organic modifier to enhance mechanical integrity and long-term durability. SPSS mercury treatment is conducted in 
two stages (Kalb et al. 1999). The first step is a reaction between mercury and powered SPC, forming mercuric sulfide.

$\mathrm{Hg}+\mathrm{S} \rightarrow \mathrm{HgS}$

The reaction vessel is placed under inert gas atmosphere to prevent the formation of mercuric oxide (a water soluble and highly leachable compound), and a small quantity of additive is included to accelerate the reaction. The vessel is heated to $\sim 40{ }^{\circ} \mathrm{C}$ during the stabilization to accelerate the sulfide formation reaction, and the materials are mixed until the mercury is completely reacted with the sulfur. Once the mercury is chemically stabilized, additional SPC is added, and the mixture is heated at about $130{ }^{\circ} \mathrm{C}$ until a homogeneous molten mass is formed. It is then poured into a suitable mold where it cools to form a monolithic solid waste form.

Results for a pilot-scale treatment using SPSS has been reported (Kalb et al. 1999). Two 55-gal drums of mixed waste soil containing high concentrations of mercury were successfully treated. Waste loadings of $60 \mathrm{wt} \%$ soil were achieved without any increase in waste volume. Preliminary TCLP analysis indicates that the final waste forms pass current EPA allowable TCLP concentrations, as well as the more stringent proposed Universal Treatment Standards.

\subsubsection{Sodium sulfide nonahydrate in sulfur polymer cement}

Darnell (1996) described the use of SPC cement for stabilization and microencapsulation of mercuric oxide. Sodium sulfide nonahydrate $\left(\mathrm{Na}_{2} \mathrm{~S} .9 \mathrm{H}_{2} \mathrm{O}\right)$ was added at $7 \mathrm{wt} \%$ to the SPC mixture to enhance the conversion of mercuric oxide to mercuric sulfide. SPC melts at $115{ }^{\circ} \mathrm{C}$ and pours at $135{ }^{\circ} \mathrm{C}$; the recommended mixing temperature is $127-138{ }^{\circ} \mathrm{C}$. When a $5 \mathrm{wt} \%$ loading of mercuric oxide was stabilized in this SPC mixture, the final waste form leached less than the EPA TCLP limit of mercury (0.2 mg/L) (SAIC 1998).

SPC-stabilized waste achieves an unconfined compressive strength of about 4000 psi, immediately upon cooling. It contains no water and is resistant to acids and salts for years, under conditions that would deteriorate hydraulic concrete in weeks to months. It is generally less permeable than hydraulic concrete. It is less resistant to strong alkali (above $10 \%$ ), strong oxidizers (e.g., hot chromic acid, sodium chlorate-hypochlorite), hot organic solvents, and some metal slimes like copper (SAIC 1998). 


\subsection{EXISTING AND POTENTIAL MERCURY DECONTAMINATION TECHNIQUES FOR CONTAMINATED METALS AND POROUS SURFACES}

\subsection{REVIEW OF CURRENT SURFACE DECONTAMINATION PROCESSES ${ }^{3}$}

During facility decommissioning activities, decontamination can achieve several mutually useful objectives, including the reduction of the potential for release and uptake of radioactive contamination, the reduction of worker exposure, allowing the release of some materials for recycle and/or reuse, and potentially reducing the volume of decommissioned material requiring intensive waste management and ultimate disposal in licensed burial facilities. Typically, it is the floors, walls, and external structural surfaces that require decontamination, and these are primarily metal (e.g., I-beams, piping, plates, and posts) and porous (e.g., cement, brick, wooden) surfaces.

The range of decontamination methods currently used at DOE sites derives from cleaning methodologies originally developed for the chemical processing industry and are usually classified as either mechanical or chemical.

\subsubsection{Mechanical decontamination}

While mechanical decontamination has typically referred to manually applied, physical contaminant removal techniques, like wet or dry abrasive blasting, surface grinding, and spalling, it now includes such supplementary activities as washing, foaming, wet-wiping, or the application of removable or "tie-down" coatings. These techniques are applied to either clean surfaces of contamination or to remove the contaminated surface itself. When contaminants are located on or at near surface levels, surface cleaning is usually effective, depending upon the contaminants involved and the nature of the surface material. Contamination at deeper levels may require surface removal techniques and depending upon the type of surface material may be of limited practicality (e.g., activated metal structures).

The following is a list of mechanical decontamination methods, ranging from the mildest surface cleaning types to the most aggressive surface removal types:

- Flushing with water

- Dusting/Vacuuming/Wiping/Scrubbing

- Fixative/Stabilizer Coatings

- Turbulator (recirculating cleaning tank)

- Paint Removal (removal solvents, scraping, detergent scrubbing)

- Strippable Coatings

${ }^{3}$ The information for this discussion was derived from Decommissioning Handbook, DOE/EM1042P, March 1994, US DOE, Office of Environmental Restoration. 
- Steam Cleaning

- Sponge Blasting

- Carbon Dioxide Blasting

- Wet Ice Blasting

- Hydroblasting

- Ultrahigh-Pressure Water

- Shot Blasting

- Wet Abrasive Cleaning

- Grit Blasting

- Grinding

- Scarification

- Milling

- Drill and Spall

- Paving Breaker/Chipping Hammer

- Expansive Grout.

\subsubsection{Chemical decontamination}

In chemical decontamination, chemical reagents are applied to remove fixed contaminants from the surfaces of facility structures, fixtures, and equipment. This process can be carried out manually or remotely, reaching inaccessible surfaces, with few airborne hazards. Some disadvantages exist, however, including minimal effectiveness on porous surfaces, the generation of moderate volumes of secondary waste that require additional treatment, and corrosion and safety problems if carried out improperly.

Chemical decontamination may utilize dilute or concentrated reagents to chemically dislodge the contaminant. Typical chemical reaction sequences include the following:

- High-pH oxidation with dissolution

- High-pH oxidation followed by low-pH dissolution

- Low-pH oxidation with dissolution

- Low-pH oxidation followed by low-pH dissolution

- Low-pH dissolution

- Low-pH reduction with dissolution.

The following is a list of decontamination reagent systems typically applied separately or in sequence:

- Water/Steam 
- Strong Mineral Acids

- Acid Salts

- Organic/Weak Acids

- Alkaline Salts

- Complexing Agents

- Oxidizing and Reducing Agents

- Detergents and Surfactants

- Organic Solvents

- Alkaline Permanganate

- Chemical Foam

- Chemical Gel.

\subsection{DECONTAMINATION PROBLEMS SPECIFIC TO MERCURY-CONTAMINATED SURFACES}

Decontamination of mercury from mercury-contaminated surfaces of metals and porous materials deserves special considerations because of the unique properties of elemental mercury, which is supposed to be the main species in the mercury-containing contaminants. Elemental mercury is a liquid and is volatile at room temperature. It may transfer from one area to another very easily and quickly. Raising temperature will increase this relocation process dramatically. On the other hand, elemental mercury forms amalgams with many metals, such as copper, zinc, nickel, tin, cadmium, and gold. The formation of amalgams, instead of surface absorption makes the decontamination process more complicated. Elemental mercury has very low solubility in water and in many mineral acids. Procedures involving mobilization of mercury by washing with steam water are not appropriate and efficient techniques. Application of strong mineral acids directly on the surface of metals and porous materials is also a bad choice because of the low efficiency for removing elemental mercury and the potential damage of the surfaces.

\subsection{MODIFIED DECONTAMINATION PROCESS STRATEGIES OF POTENTIAL MERIT}

Taking the unique properties of mercury into consideration, several processes have been identified as potential techniques for decontamination of mercury-contaminated metal and porous surfaces. Their potential merits and applicability are summarized here.

\subsubsection{Reactive strippable coatings}

Strippable or temporary coatings are innovative technologies for decontamination that effectively reduce loose contamination at low cost (Ebadian et al. 1999). These coatings have become a viable option during the deactivation and decommissioning (D\&D) of both DOE and commercial nuclear facilities to remove or fix loose contamination on both vertical and horizontal surfaces. 
These technologies are thought to be suitable for removal of mercury from large or medium surfaces, such as mercury-contaminated equipment or laboratory walls. They are not appropriate, however, for treatment of small debris.

\subsubsection{Principle and process}

Strippable coatings are polymer mixtures, such as water-based organic polymers, that are applied to the surface by paintbrush, roller, or spray applicator (Ebadian et al. 1999). Upon applying to the surface, these polymers can absorb, attract, and chemically bind the contaminants. Then during the curing process, they mechanically lock the contaminants into the polymer matrix. Incorporating fiber reinforcement, such as a cotton scrim, into the coating may enhance the strength of these coatings. Once the coating dries, it can be stripped manually from the surface. In the case of auto-release coating, the mixture cracks, flakes, and is collected by vacuuming (Ebadian et al. 1999). Nevertheless, once the strippable coating is removed, the loose surface contaminants are removed with the coating, producing a dry and clean surface.

\subsubsection{Potential for mercury removal and immobilization}

Florida International University's Hemispheric Center for Environmental Technology (FIUHCET) recently conducted a comprehensive study to evaluate the physical properties of some commercially available coating materials. The capability of these coatings on removing contaminant elements, Cesium (Cs), Thorium (Th), and Uranium (U), from stainless steel disks was evaluated (Ebadian et al. 1999). The decontamination factors (DF = initial contamination/final contamination) calculated ranged from 1.53 to 4.35 , which reflects 34.8 to $77.0 \%$ removal. These results indicated the effective removal of contaminants could be achieved.

Mercury presented on the surface of metal and porous materials can exist in different forms depending on the sources of mercury and the environmental conditions, although elemental mercury is expected to be the major form. Elemental mercury may form alloy with metals, consequently prohibiting the removal by these strippable coating processes. However, mercury in other forms and free elemental mercury may be removed by appropriate coatings. Since mercury binds sulfur strongly, sulfur modified coating materials may be a good alternative. The commercial availability of such coatings, however, is not known. Surface pretreatment before applying coatings may also improve the mercury removal efficiency. Oxidation of elemental mercury to $\mathrm{Hg}^{2+}$ (see section 5.3.2) followed by strippable coating may significantly increase the efficiency of mercury removal.

\subsubsection{Properties and disposition of coating wastes}

The secondary wastes generated by the coating process are expected to be a relatively small amount. Since the coating materials are usually made of organic compounds, incineration/combustion would be a good choice to recover the mercury from the coatings. It is also possible, given the significant insolubility of any mercury sulfide compounds formed in the coating, that the coating wastes would pass the TCLP and thus LDR. 


\subsubsection{Chemical decontamination with iodine/iodide lixiviant}

\subsubsection{Principle and process}

Processes leaching or dissolving mercury species away from a solid matrix must contend with peculiar mercury chemistry (Perona and Brown 1993). Most mercuric salts are only moderately to slightly soluble in water. Elemental mercury is not soluble in water and many mineral acids. However, as discussed in the previous sections, mercuric halides form anionic soluble complexes, which are soluble in excess of the corresponding halide, $\mathrm{HgX}_{4}{ }^{2-}$.

The use of solutions containing "active" chlorine or "elemental" chlorine to produce soluble mercury chloride anionic complexes was established in two patents. In another patented process developed by Foust (1993), mobilization/removal of mercury from solid wastes was conducted using a lixiviant consisting of an aqueous solution of potassium iodide/iodine $\left(\mathrm{KI} / \mathrm{I}_{2}\right)$. This process utilizes solutions consisting of $\mathrm{I}_{2}(0.001$ to $0.5 \mathrm{M})$ as the oxidizing agent and the iodide ion $(0.1$ to $1.0 \mathrm{M})$ as a complexing ligand. Mercury in contaminated solid wastes in the form of oxides, sulfides, elemental, and adsorbed phases is mobilized by the $\mathrm{KI} / \mathrm{I}_{2}$ lixiviant through oxidation and complex-forming reactions (Foust 1993, Mattigod et al. 1999, Cox et al. 1996). Iodine, an oxidizing agent, is capable of oxidizing the various species of mercury, including elemental mercury, to mercuric iodide. Potassium iodide, a complexing agent or solubilizing agent, reacts with mercuric iodide to form a water-soluble compound having the formula $\mathrm{K}_{2} \mathrm{HgI}_{4}$. After such mobilization, the dissolved and strongly complexed mercury can be removed, and the lixiviant is recycled. Techniques have been developed to recover mercury from the spent lixiviant (Mattigod et al. 1999).

\subsubsection{Potential for mercury removal from metal and porous surfaces}

The potential mercury contaminated porous and metal surfaces found in the DOE sites are:

Porous

- $\quad$ Brick wall - uncoated

- Concrete floor, wall, or ceiling - uncoated

- Wood - scrap lumber

Metal/Nonporous

- Cable

- Carbon steel plate - coated and uncoated

- Chain link fencing

- Galvanized metal plate and posts

- I-beams - coated and uncoated

- Lead brick

- Stainless steel plate - coated and uncoated

- Plastic pipes and posts

- Wood, metal and glass debris 
Since chemical-cleaning processes, such as the iodine/iodide lixiviant, involve transfer of the mercury contaminant to a liquid phase, it is essential that the contaminated solid material be in a form suitable for washing. Liquid phase containing the decontamination reactants, are passed or percolated through the particulate solid materials, thereby contacting the contaminant, which is generally in solid form with the reactants. This process seems to be efficient for surface decontamination. Preferred oxidizing agents are those, which are characterized as being mild, and which do not strongly react with any of the varied components of the metal and porous materials to form oxidation products, which complicate the decontamination process. With this criteria in mind, iodine is the most preferred oxidant (Foust 1993).

\subsubsection{Treatment of the generated wastes}

In the same patented procedure, Foust (1993) reported an electrochemical procedure to recover the extracted mercury in the form of elemental mercury, which can be utilized and handled in accordance with established procedures and techniques. The electrochemical regeneration cell consists of an anode, a cathode separated by a cation exchange membrane. The cell is provided with a reference electrode, which controls the potential between the anode and cathode and prevents electrolysis of water at cathode. Mercury will deposit at the cathode, while iodine will be formed at the anode.

Separation of complexed mercury from a lixiviant consisting of an aqueous solution of potassium iodide/iodine has been carried out with a novel adsorbent material consisting of selfassembled mercaptan groups on mesoporous silica (SAMMS) substrate (Feng et al. 1997). This adsorbent has specifically designed functional groups that have very high specificity and adsorption capability for mercury and other soft cationic contaminants of concern. The pores in SAMMS have a very narrow, specifically tailored (15 to $400 \AA)$ pore-site distribution, resulting in a very high surface area $\left(>800 \mathrm{~m}^{2} / \mathrm{g}\right)$ (Mattigod et al. 1999).

Mattigod et al. (1999) demonstrated recently the effectiveness of the SAMMS adsorber in removing strongly complexed mercury (II) from spent KI lixiviant. The adsorption density measurements indicated that SAMMS material can adsorb from 26 to $270 \mathrm{mg} / \mathrm{g}$ of strongly complexed mercury (as $\mathrm{HgI}_{4}{ }^{2-}$ ) from potassium iodide/sulfate waste solutions. The adsorption density increased with decreasing iodide concentration. Dissolved mercury (II) has a higher affinity for thiol groups in SAMMS as compared to silanol groups in silica gel, affirming the nature of soft cation-soft base interaction expected between mercury and - SH groups. The kinetic data indicated that the adsorption reaction occurs very rapidly, independent of mercury (II) concentration and $\mathrm{pH}$.

\subsubsection{Chemisorbing surface wipes}

\subsubsection{Foraging sponge adsorption}

Details of using forager sponge adsorption for mercury decontamination from mercurycontaminated waters have been given in section 3.2.2.4. The sponge, an open-celled cellulose with an amine-containing polymer is reported to have a selective affinity for aqueous heavy metals, in both cationic and anionic states, including mercury ion $\left(\mathrm{Hg}^{2+}\right)$ (USEPA 1997a). The polymer is reported to form complexes with ions of heavy metals, providing ligand sites that surround the metal and form a coordination complex. The sponge can be used in different 
configurations such as in columns, fishnet-type enclosures, or rotating drums. Adsorbed ions can be eluted from the sponge using techniques typically employed to regenerate ion exchange resins and activated carbons. Following elution, the sponge can be reused in the next adsorption cycle. The number of useful cycles is reported to depend on the nature of the adsorbed ions and the elution technique used. Alternatively, the metal saturated sponge could be incinerated. Metal volatilization would be of concern. The sponge may be dried and reduced in volume to facilitate disposal.

It is important to note that a single technology may not be adequate to address all the decontamination needs of mercury-contaminated metal and porous materials. Rather, strategies will often be required that combine several technologies for removing the various forms of mercury from varying materials. Using forager sponge for cleaning mercury from the surfaces of metal and porous material requires pretreatment of the surfaces to convert different forms of mercury to "active" mercury ion $\left(\mathrm{Hg}^{2+}\right)$. The oxidation/complexing procedure using iodine/iodide lixiviant (Section 5.3.2) could be modified and used for this purpose. Once the different forms of mercury are converted to $\mathrm{Hg}^{2+}$, it could be wiped out from the surfaces with the forager sponge.

\subsubsection{Grafted cotton}

Sulfhydryl cotton fiber has been synthesized and used for mercury preconcentration from aqueous solutions (Lee and Mowrer 1989, Cai et al. 1996). The thiol (-SH) group introduced onto the cotton fiber has very strong capability for binding mercury ion $\left(\mathrm{Hg}^{2+}\right)$. The binding capability for elemental mercury has not been reported but is supposed to be weak. Again, an oxidation pretreatment would be first used to convert different forms of mercury to $\mathrm{Hg}^{2+}$. However, sulfhydryl cotton fiber is not stable in strong oxidative solution. The oxidation of the thiol group will dramatically reduce the absorption capability. Anyway, the possibility of using the grafted cotton for wiping out mercury from surfaces of the contaminated metal and porous material remains to be studied.

\subsubsection{Surface/Pore fixation through amalgamation or stabilization}

Stabilization technologies may be used for mercury-contaminated small debris with high porous surface. Mercury contained in these materials is not readily accessible to strippable coating, leaching agents, or thermal desorption. Mercury may be chemically bound to a matrix constituent or trapped in the matrix. Thus, it is more practical to stabilize mercury in those materials to comply with regulations rather than extracting or removing the mercury. These techniques have been summarized in previous sections. 


\subsection{CONCLUSIONS FOR PHASE I}

Over the years mercury has been recognized as having serous impacts on human health and the environment. This recognition has led to numerous studies that deal with the properties of various mercury forms, the development of methods to quantify and speciate the forms, fate and transport, toxicology studies, and the development of site remediation and decontamination technologies. This report reviews several critical areas, which will be used in developing technologies for cleaning mercury from mercury-contaminated surfaces of metals and porous materials found in many DOE facilities. The technologies used for decontamination of water and mixed wastes (solid) are specifically discussed. Many technologies recently published in the literature are included in the report. The current surface decontamination processes have been reviewed, and the limitations of these technologies for mercury decontamination are discussed. Based on the currently available technologies and the processes published recently in the literature, several processes, including strippable coatings, chemical cleaning with iodine/iodide lixiviant, chemisorbing surface wipes with forager sponge and grafted cotton, and surface/pore fixation through amalgamation or stabilization, have been identified as potential techniques for decontamination of mercury-contaminated metal and porous surfaces. Their potential merits and applicability are discussed. Finally, two processes, strippable coatings and chemical cleaning with iodine/iodide lixiviant, were included for experimental investigation in Phase II of this project. 


\subsection{RECOMMENDATIONS FOR PHASE II}

Based on the information gathered in Phase I of this project, two techniques, namely reactive strippable coating and iodine/iodide lixiviant, were recommended for further evaluation in Phase II of this project. The preliminary results obtained from the laboratory experiments in Phase II will be used to evaluate the potential of these processes for decontamination of mercury from mercury-contaminated metal and porous surfaces.

\subsection{REACTIVE STRIPPABLE COATING: DESIGN AND EVALUATION}

The following laboratory work/experiments carried out:

- Selection of four commercially available strippable coating products on five different solid materials for assessment.

- Development an effective method for contamination of the selected metal and porous materials.

- Evaluation of the efficiency of mercury removal from the metal surfaces.

- Evaluation of the possibility of using this technique for field application.

\subsection{CHEMICAL DECONTAMINATION WITH IODINE/IODIDE LIXIVIANT}

Based on the contamination procedure established in section 6.1, the metals selected for assessment were first contaminated with elemental mercury. Decontamination of these mercurycontaminated materials using iodine/iodide lixiviant was evaluated. The following experiments were also carried out:

- Optimize the concentrations of oxidation and complexing agents.

- Evaluate the efficiency of mercury removal from the metal surfaces. 


\subsection{PHASE II: EVALUATION OF THE RECOMMENDED TECHNIQUES}

\subsection{EXPERIMENTAL APPROACH}

\subsubsection{Apparatus}

All sample preparations were carried out inside a Model 4 MP Negative Pressure Isolator equipped with a mercury-specific SC-1 Gas \& Fume Extraction System (Germfree Laboratories, Miami, FL).

Total mercury concentration in analytical samples was determined by cold vapor atomic fluorescence spectrometry (CVAFS). A PS Analytical (PSA) 10.025 Millennium System and a PC-based data acquisition and analysis software (Avalon version 2.39) were used. The detection limit is $0.2 \mathrm{ng} / \mathrm{L}$ (ppt). Mercury vapor was measured by a Jerome Model 431-X gold-film mercury vapor analyzer from Arizona Instruments (Phoenix, Arizona).

\subsubsection{Materials and chemicals}

Copper, aluminum, stainless steel, and carbon steel shim stock (Precision Brand, Downers Grove, IL) of 0.01 " thickness were used for metal samples. They were cut into 1 "x 1 " coupons in the laboratory and used without further treatment. Ceramic and masonry tile samples were purchased from a local home supply store and scored with abrasive prior to using. Wide mouth glass jars $(500 \mathrm{ml})$ were need for vapor contamination of samples. Nitric acid and hydrochloric acid (Fisher) of trace metal grade were used throughout this study. All other chemicals used were of at least ACS grade.

The strippable coatings used in this study included ALARA ${ }^{\mathrm{TM}} 1146$ (Carboline and Williams Power Corporation) and Stripcoat TLC Free (BARTLETT Services, Inc.).

Mercury-free deionized water: Produced by filtering tap water through a Culligan system consisting of activated charcoal and two mixed bed ion exchange cartridges. The filtered water is piped to a mercury-free clean room, where it is delivered through a Barnstead Mega-ohm B Pure system.

0.2 M Potassium bromide ( $\mathrm{KBr}$ ): $11.900 \mathrm{~g}$ of $\mathrm{KBr}$ (certified ACS grade) were heated overnight in a glass scintillation vial (Kimble 74511) at $250{ }^{\circ} \mathrm{C}+/-20{ }^{\circ} \mathrm{C}$ in a furnace to remove any trace mercury. After cooling, the $\mathrm{KBr}$ was dissolved in $500 \mathrm{ml}$ of DIW and stored in a borosilicate bottle. It was prepared on a weekly basis.

0.1 M Potassium bromate $\left(\mathrm{KBrO}_{3}\right): 8.385 \mathrm{~g}$ of $\mathrm{KBrO}_{3}$ (certified ACS grade) were heated overnight in a glass scintillation vial (Kimble 74511) at $250{ }^{\circ} \mathrm{C}+/-20{ }^{\circ} \mathrm{C}$ in a furnace to remove any trace mercury. After cooling, the $\mathrm{KBrO}_{3}$ is dissolved in $500 \mathrm{ml}$ of DIW and stored in a borosilicate bottle. It is prepared on a weekly basis.

Mixed brominating reagent (0.05 M Potassium bromide $(\mathrm{KBr}): 0.1 \mathrm{M}$ Potassium bromate $\left.\left(\mathrm{KBrO}_{3}\right)\right)$ : Equal volumes $(100 \mathrm{ml})$ of potassium bromate and potassium bromide solutions were mixed in a $250 \mathrm{ml}$ borosilicate bottle with a Teflon cap. It was prepared on a weekly basis. 
$12 \%(w / v)$ Hydroxylamine hydrochloride $\left(\mathrm{NH}_{2} \mathrm{OH} \cdot \mathrm{HCl}\right): 6.0 \mathrm{~g}$ of $\mathrm{NH}_{2} \mathrm{OH} \cdot \mathrm{HCl}$ (certified ACS grade) was dissolved in $50 \mathrm{ml}$ of DIW in a $60 \mathrm{ml}$ Teflon bottle. It was prepared on a weekly basis.

$2 \%(w / v)$ Stannous chloride ( $\mathrm{SnCl}_{2}$ ): $50 \mathrm{ml}$ of $12 \mathrm{~N} \mathrm{HCl}$ were added to $40 \mathrm{~g}$ of $\mathrm{SnCl}_{2} \cdot 2 \mathrm{H}_{2} \mathrm{O}$ and the volume was then brought up to $2000 \mathrm{ml}$ using DIW. It was purged with argon for 20 minutes before running samples. It was prepared on a weekly basis.

$0.05 \mathrm{M}$ Potassium iodide (KI) / $0.005 \mathrm{M}$ iodine ( $\mathrm{I}_{2}$ ) mixture preparation: $4.150 \mathrm{~g}$ of KI (Certified ACS Grade) and $0.635 \mathrm{~g} \mathrm{I}_{2}$ (Certified ACS Grade) were placed in a $500 \mathrm{ml}$ volumetric flask and diluted to the mark with DIW. A magnetic stirrer was placed inside the flask and the solution allowed to stir until completely dissolved. The solution was stored in a $500 \mathrm{ml}$ glass bottle covered with aluminum foil.

Grout Mixture Preparation: The grout mixture was prepared following the suggested manufacture instructions. A shallow box was lined with paper and the mixture was poured into it. The grout was spread evenly with desired thickness of $2 \mathrm{~mm}$. The grout was allowed to dry for a few hours and then cut into 1" x 1" squares. The grout was further dried for two days. After drying, the grout was separated and used for the experiments.

Synthesis of sulfhydryl cotton fiber (SCF) adsorbent: This synthesis followed the procedure used by Lee and Mowrer (1989). A mixture was first prepared by adding the following reagents in sequence to a round bottom flask: $100 \mathrm{ml}$ thioglycolic acid, $60 \mathrm{ml}$ acetic anhydride, $40 \mathrm{ml}$ acetic acid (36\%) and $0.3 \mathrm{ml}$ concentrated sulfuric acid. The mixture was allowed to cool to $45^{\circ} \mathrm{C}$, and then $30 \mathrm{~g}$ cotton wool were added and allowed to soak thoroughly in the mixture. The reaction bottle was placed in an oven for 3 days at $40{ }^{\circ} \mathrm{C}$, then the product was placed in a filter-funnel with suction filtration and washed thoroughly with deionized water $(\sim 2.51)$ to remove traces of thioglycolic acid. The SCF obtained was dried at $40{ }^{\circ} \mathrm{C}$ for $24 \mathrm{hr}$ and stored in a dark brown bottle at room temperature.

Wash water: $150 \mathrm{ml}$ of concentrated $\mathrm{HCl}(12 \mathrm{~N}$, trace-metal free) was added to 15 liters of DIW in a 15 liter Teflon bottle (Nalgene).

Argon-Zero grade: The gas is passed through two gas purifiers (charcoal and gold).

Calibration Total Mercury Primary Standard (1000 ppm): Bought from Fisher and used until expiration date.

Second Source Primary Total Mercury Standard (1000 ppm): Bought from Spex and used until expiration date.

Calibration Total Mercury Secondary Standard (100 ppb): $100 \mu \mathrm{l}$ of Total Mercury Primary Standard was transferred to a $1000 \mathrm{ml}$ volumetric flask and the volume is completed with $10 \mathrm{ml}$ of $\mathrm{HCl}$ and DIW. It was prepared on a daily basis.

Second Source Total Mercury Secondary Standard (100 ppb):_100 $\mu 1$ of Second Source Total Mercury Primary Standard was transferred to a $1000 \mathrm{ml}$ volumetric flask and the volume is completed with $10 \mathrm{ml}$ of $\mathrm{HCl}$ and DIW. It was prepared on a daily basis.

Total Mercury Working Standards: The working standards were prepared in 500 or $1000 \mathrm{ml}$ FEP bottles depending on the standard concentration. 


\subsubsection{Experimental procedures}

\subsubsection{Contamination of the testing materials}

In order to evaluate the decontamination effectiveness of strippable paints, iodine/iodide lixiviant, and chemisorbing surface wipes methods, contamination of testing materials (metal/grout squares, and tiles) by elemental mercury was first investigated. Wide mouth glass jars $(500 \mathrm{ml})$ containing a glass beaker with liquid mercury in it were employed. Either metal/grout squares or tiles were placed within the glass jars. The jars were capped tightly after the metal/grout squares and tiles were placed in a circular pattern around the bottom, taking care to ensure full exposure of their entire surfaces ${ }^{4}$. After a predetermined time, five metal/grout squares or tiles were removed from the jars and were immediately placed in five $250 \mathrm{ml}$ HDPE bottles. Then $100 \mathrm{ml}$ of $1 \% \mathrm{HCl}$ were added. Digestion of the sample was carried out after $2.5 \mathrm{ml}$ of bromination reagent $\left(\mathrm{KBrO}_{3} / \mathrm{KBr}\right.$ mixture) were added. After one hour, $0.5 \mathrm{ml}$ of $12(\mathrm{w} / \mathrm{v})$ hydroxylamine hydrochloride were added to the HDPE bottles to inhibit any further reaction. Samples were allowed to settle for at least $10 \mathrm{~min}$ before analysis by CVAFS. Dilutions were made if concentrations were too high. Detailed analytical procedures can be found elsewhere (SERC SOP, 1999).

\subsubsection{Strippable coating}

Generally, metal squares and tiles were first contaminated with elemental mercury according to the procedure described in section 8.1.3.1. Ten metal squares or tiles were removed from the jars after a predetermined time. Five of them were immediately placed in five $250 \mathrm{ml}$ HDPE bottles. These samples were used to obtain the average amounts of mercury absorbed on the metal squares and tiles. Digestion and analytical procedures were the same as above (section 8.1.3.1). The other five squares were placed on a clean paper in a hood. About 0.4 to $0.5 \mathrm{~g}$ of ALARA ${ }^{\mathrm{TM}}$ 1146 or Stripcoat TLC Free were transferred to the surfaces of the squares and tiles with a polyethylene disposable pipet. The paints were evenly distributed on the surfaces with the same pipet. After they were allowed to dry overnight (ca. $24 \mathrm{hrs}$ ), paints were carefully removed from the squares and tiles and put into $125 \mathrm{ml} \mathrm{HDPE}$ bottles. Then $50 \mathrm{ml}$ of $1 \% \mathrm{HCl}$ were added. Digestion of the sample was carried out after $1.25 \mathrm{ml}$ of bromination reagent $(\mathrm{KBrO} 3 / \mathrm{KBr}$ mixture) was added. After one hour, $0.25 \mathrm{ml}$ of $12 \%(\mathrm{w} / \mathrm{v})$ hydroxylamine hydrochloride was added to the HDPE bottles to inhibit any further reaction. Procedures described above were followed for analysis.

\subsubsection{Iodine/iodide lixiviant}

The same contamination procedures as described in Section 8.1.3.1 were applied to the method of iodine/iodide lixiviant. Metal/grout squares were used in this test. Fifteen metal or ten grout squares were removed from the jars after a predetermined time. Five of them were used to obtain the average amounts of mercury absorbed on the metal squares while the rest were subjected to evaluating the decontamination effectiveness of the iodine/iodide lixiviant. After removal from the jars, the metal/grout squares were immediately placed in small plastic weighing boats, which

${ }^{4}$ Vapor measurement of the $\mathrm{Hg}$ in the sealed jars was found to average $13.9 \mathrm{mg} / \mathrm{M}^{3}$. 
contained $5 \mathrm{ml}$ (for metal squares) or $10 \mathrm{ml}$ (for grout squares) of iodine/iodide mixture. After being swirled in the reagent for a predetermined time (20 seconds and 2 min for metal squares, 2 min for grout squares), the metal/grout squares were removed from the weighing boats with a pair of stainless steel tweezers and rinsed thoroughly with DIW. Afterwards, they were placed in $125 \mathrm{ml}$ HDPE bottles. Digestion and analytical procedures described in section 8.1.3.2 were then followed. Two different concentrations of iodine/iodide solution were tested.

\subsubsection{Wipe with SCF adsorbent}

The same contamination procedures as described in Section 8.1.3.1 were also applied to this method. Only metal squares were used in this test. Ten metal squares were removed from the jars after a predetermined time. Five of them were used to obtain the average amounts of mercury absorbed on the grout squares while the rest were subjected to evaluating the decontamination effectiveness of the SCF adsorbent. After removal from the jars with stainless steel tweezers, the metal squares were immediately and thoroughly rinsed on both sides with deionized water. A small amount of SCF adsorbent was then dipped in deionized water. Holding the SCF adsorbent with stainless steel tweezers, the metal squares were thoroughly rubbed with the SCF. The metal squares were then thoroughly rinsed with deionized water on both sides and then placed in an individually labeled $125 \mathrm{ml}$ plastic bottle. Digestion and analytical procedures described in section 8.1.3.2 were then followed.

\subsection{RESULTS AND DISCUSSION}

\subsubsection{Material blanks}

Mercury blanks of the materials used in this study were first investigated. The results are listed in Table 8-1. Metal/grout square and tile blanks provide the amounts of mercury present in these materials without exposure to mercury vapor in the jars. Paint blanks are used to evaluate the procedural blanks, which include the paint itself and the effect of exposure to the air in the hood. Most metal/grout squares and tiles contain small amount of mercury ranging from 0.09 to 3.42 $\mathrm{ng} /$ square, while the steel used in this study exhibited a higher blank level with a much higher standard deviation compared to others. This indicates its high potential in adsorbing mercury.

The procedural blanks were generally low ranging from 0.2 (copper and aluminum) to 0.49 (steel) ng/square for ALARA TM 1146 and from 0.22 (copper) to 0.34 (stainless steel) ng/square for Stripcoat TLC Free, respectively. These blanks are relatively small compared to the mercury amounts absorbed during the experimental procedures. 
Table 8-1

Material Blanks

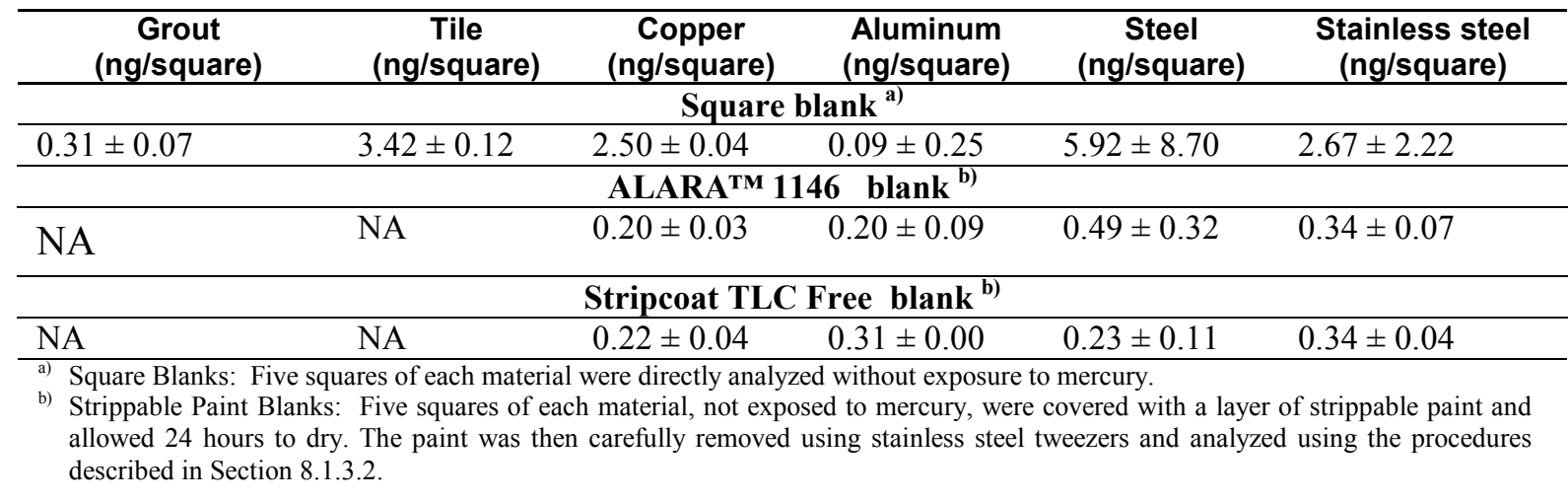

\subsubsection{Contamination of the testing materials}

In the first set of experiments (Table 8-2), only tile and copper were investigated for contamination with mercury in 9 and 14 day time periods. It seems that, compared to tiles, copper is more easily to be contaminated by mercury vapor. This is probably due to the formation of amalgam between copper and mercury. Large standard deviations were observed between individual squares and tiles and between the different treatment time periods. This could be attributed to several facts. First, since the temperature of the glove box was not controlled, small changes in room temperature may significantly affect the adsorption of mercury on the surface of testing materials. Second, homogeneity of the individual metal square, e.g. the differences in size and surface properties of the testing materials, may affect the mercury adsorption. The location of squares located at different positions in the jars may affect, to some extent, their exposure to mercury vapor. These potential effects need to be further investigated.

In the second set of experiments, four metal squares were treated in two time periods ( 2 and 5 days). Results are also summarized in Table 8-2. Among the four metals tested, steel is the one that adsorbs the most mercury with $289 \mathrm{ng} / \mathrm{square}$ for two-day treatment and $428 \mathrm{ng} / \mathrm{square}$ for five-day treatment. For the other three metals, the amounts of mercury absorbed ranged from 3 $\mathrm{ng} / \mathrm{square}$ (aluminum in 5 days) to $40 \mathrm{ng} /$ square (aluminum in 2 days). The effects of treatment time give no clear trend on the amount of mercury adsorption, indicating again the potential effect of temperature and homogeneity of the materials used. Two steps were taken to reduce this variability errors. First, squares for each decontamination experiment were removed at similar positions (height) from one jar. Second, five replicates were used for both contamination and decontamination procedures.

Table 8-2

Mercury Absorbed on Metal Squares and Tiles at Different Contamination Time Periods

\begin{tabular}{ccccc}
\hline & $\begin{array}{c}\text { 2 Days } \\
\text { ng/square }\end{array}$ & $\begin{array}{c}\mathbf{5} \text { Days } \\
\text { ng/square }\end{array}$ & $\begin{array}{c}\mathbf{9} \text { Days } \\
\text { ng/square }\end{array}$ & $\begin{array}{c}\text { 14 Days } \\
\text { ng/square }\end{array}$ \\
\hline Tile & NA & NA & $38.52 \pm 24.50$ & $8.10 \pm 0.82$ \\
Copper & $8.70 \pm 3.22$ & $24.74 \pm 13.54$ & $94.35 \pm 63.49$ & $82.21 \pm 10.83$ \\
Aluminum & $40.17 \pm 7.72$ & $2.98 \pm 0.35$ & NA & NA \\
Steel & $289.78 \pm 41.99$ & $428.25 \pm 115.28$ & NA & NA \\
Stainless Steel & $12.56 \pm 1.79$ & $35.30 \pm 18.30$ & NA & NA \\
Grout & NA & $266.4 \pm 28.0$ & NA & NA \\
\hline
\end{tabular}




\subsubsection{Mercury removal by strippable coating}

The percent removal of mercury by strippable ALARA ${ }^{\mathrm{TM}} 1146$ varies with the metals and time of treatment (contamination by mercury) (Table 8-3). Unreasonably high recoveries, 269\% for tile at 14 days, and $374 \%$ for copper at 2 days were closely related to the very low mercury concentrations found in the contaminated materials (see Table 8-2, 8.7 and $8.1 \mathrm{ng} / \mathrm{square}$ for copper and tile, respectively). These concentrations are only slightly higher than their blank levels (Table 8.1, 2.50 and $3.42 \mathrm{ng}$ /square for copper and tile, respectively). Although the reasons for the low mercury contamination levels found in these materials are not clear, it seems that these low concentrations may result in an incorrect calculation of the percent mercury removal. Another fact that could cause high standard deviation of the strippable coating procedure is that the metal squares were only coated on one side because of the operational difficulties for coating on both sides. This is especially true for ceramic tiles because the two surfaces of the tiles were clearly different with one side polished and other side not. Nevertheless, strippable coating seems a very simple method for removing a certain amount of mercury from the surfaces. More accurate contamination and coating procedures have to be developed for a more precise evaluation of the removal efficiency.

Stripcoat TLC Free was tested only for the four metals and for a 7-day time period. Compared to the ALARA ${ }^{\mathrm{TM}}$ 1146, lower removal efficiencies are observed for Stripcoat TLC Free for most metals, except copper. In addition, ALARA ${ }^{\mathrm{TM}} 1146$ has been found to be much easier removed in single piece from the surfaces tested than Stripcoat TLC Free. Other properties of these materials have also been evaluated by Ebadian et al. (1999) and the ALARA ${ }^{\text {TM }} 1146$ has been shown to be a better strippable coating material than the Stripcoat TLC Free.

Table 8-3

Percent Removal by Different Strippable Paints at Different Time Periods

\begin{tabular}{|c|c|c|c|c|c|}
\hline & \multicolumn{4}{|c|}{$\begin{array}{c}\text { ALARA }^{\mathrm{TM}} 1146 \\
\text { (\% Removed) }\end{array}$} & \multirow{2}{*}{$\begin{array}{c}\text { Stripcoat } \\
\begin{array}{c}\text { TLC Free } \\
\text { Removed) }\end{array} \\
7 \text { Days }\end{array}$} \\
\hline & 2 Days & 5 Days & 9 Days & 14 Days & \\
\hline Tile & NA & NA & $20.97 \pm 26.11$ & $269.23 \pm 59.36$ & NA \\
\hline Copper & $374.04 \pm 284.24$ & $47.19 \pm 34.08$ & $93.44 \pm 101.75$ & $9.99 \pm 2.48$ & $66.74 \pm 87.78$ \\
\hline Aluminum & $34.63 \pm 35.86$ & $42.77 \pm 11.91$ & NA & NA & $19.75 \pm 23.25$ \\
\hline Steel & $114.03 \pm 39.03$ & $75.69 \pm 51.78$ & NA & NA & $22.66 \pm 2.60$ \\
\hline Stainless Steel & $142.51 \pm 60.57$ & $39.14 \pm 22.95$ & NA & NA & $4.16 \pm 8.89$ \\
\hline
\end{tabular}

\subsubsection{Mercury removal by iodine/iodide lixiviant}

The materials used for testing iodine/iodide lixiviant were contaminated for 7 days before carrying out the cleaning procedure. The percent mercury removed by the lixiviant is summarized in Table 8-4. It should be pointed out that the standard deviations found for most materials, except for copper, in these tests are much smaller than those obtained in the strippable coating technique. Large standard deviations for copper are observed for both high and low iodine/iodide lixiviant solutions. The strong interferences found for copper treatment could be attributed to the following reactions (Skoog et al. 1998): 


$$
\begin{array}{ll}
\mathrm{Cu}^{2+}+2 \mathrm{e}^{-} \rightarrow \mathrm{Cu}(\mathrm{s}) & \mathrm{E}^{\mathrm{o}}=0.337 \mathrm{~V} \\
\mathrm{I}_{3}^{-}+2 \mathrm{e}^{-} \rightarrow 3 \mathrm{I}^{-} & \mathrm{E}^{\mathrm{o}}=0.536 \mathrm{~V}
\end{array}
$$

Oxidation of copper by iodine/iodide hampers the oxidation and complexing of mercury by iodine/iodide.

$$
\mathrm{I}_{3}^{-}+\mathrm{Cu}(\mathrm{s}) \rightarrow 3 \mathrm{I}^{-}+\mathrm{Cu}^{2+}
$$

For the rest of the metals, percent removal of mercury ranged from 76 to $89 \%$ for 20 sec, and from 87 to $96 \%$ for two min treatments when $0.05 \mathrm{M} \mathrm{KI} / 0.005 \mathrm{M} \mathrm{I}_{2}$ solutions were used. Increase in swirling time of metals in the lixiviant increased the removal of mercury.

For aluminum and steel, decrease in the concentration of the iodine/iodide lixiviant did not alter significantly the efficiency of mercury removal. About $90 \%$ of mercury can be removed by both solutions using a 2 min treatment time period. For stainless steel, $96.2 \pm 2.0 \%$ of mercury can be removed with $0.05 \mathrm{M} \mathrm{KI} / 0.005 \mathrm{M} \mathrm{I}_{2}$ solutions, whereas a lower removal $(63.2 \pm 18.0 \%)$ was observed with $0.01 \mathrm{M} \mathrm{KI} / 0.001 \mathrm{M} \mathrm{I}_{2}$ solutions. Generally lower mercury removal efficiencies from grout squares have been observed with $41.9 \pm 6.9 \%$ by $0.05 \mathrm{M} \mathrm{KI} / 0.005 \mathrm{M} \mathrm{I}_{2}$ and $21.7 \pm$ $17.8 \%$ by $0.01 \mathrm{M} \mathrm{KI} / 0.001 \mathrm{M} \mathrm{I}_{2}$, indicating a stronger bonding of mercury to the grout compared to the metals tested.

Overall, compared to strippable coating, chemical cleaning with iodine/iodide lixiviant seems to be a better method for mercury decontamination from most of the metal surfaces tested in terms of the decontamination effectiveness and the standard deviation. The mercury removal effectiveness is dependent on the concentrations of the iodine/iodide lixiviant solutions. The optimum concentrations of the lixiviant should be selected based on the individual target material. The cleaning process is simple and fast. It should be considered a potential decontamination technique for mercury contaminated metals and porous surfaces, which are not reactive to the iodine/iodide lixiviant. After such treatment, the dissolved and strongly complexed mercury, $\mathrm{HgI}_{4}{ }^{2-}$, can be removed and the lixiviant recycled. Techniques have been developed to recover mercury from the spent lixiviant (Mattigod et al., 1999).

Table 8-4

Percent Removal by KI/I2 Solution

\begin{tabular}{cc|c|c}
\hline & \multicolumn{2}{c}{$\mathbf{0 . 0 5 M ~ K I / 0 . 0 0 5} \mathbf{M ~ I}_{\mathbf{2}}$} & $\mathbf{0 . 0 1} \mathbf{M ~ K I / 0 . 0 0 1} \mathbf{M ~ I}_{\mathbf{2}}$ \\
\cline { 2 - 4 } & 20 Seconds & 2 Minutes & 2 Minutes \\
\hline Copper & $22.6 \pm 7.4 \%$ & $-34.6 \pm 71.6 \%$ & $17.5 \pm 66.31 \%$ \\
Aluminum & $81.5 \pm 5.1 \%$ & $87.34 \pm 6.5 \%$ & $91.4 \pm 6.8 \%$ \\
Steel & $75.9 \pm 16.5 \%$ & $92.9 \pm 5.1 \%$ & $96.1 \pm 3.5 \%$ \\
Stainless Steel & $89.0 \pm 6.0 \%$ & $96.2 \pm 2.0 \%$ & $63.2 \pm 18.0 \%$ \\
Grout & NA & $41.9 \pm 6.9 \%$ & $21.7 \pm 17.8 \%$ \\
\hline
\end{tabular}

\subsubsection{SCF adsorbent}

The percent removal of mercury from the metal squares with SCF adsorbent is listed in Table 85. Low percent removal ranged from only $0.4 \%$ for steel and $53 \%$ for stainless steel. The low 
mercury removal efficiencies together with modest standard deviations using SCF are not unexpected.

The SCF adsorbent was produced by introducing the sulfhydryl functional group into natural cotton fiber. The SCF adsorbent is similar to the several kind of ion-exchange/chelating resins used for mercury concentration from aqueous matrices (Cai et al. 1996). It is designed for concentrating ionic mercury species, especially monomethylmercury ion $\left(\mathrm{MeHg}^{+}\right)$. The mercury adsorbed on the surfaces of metals and porous materials in the DOE sites are expected to be mostly elemental mercury and/or mercury oxide $(\mathrm{HgO})$. These mercury species may not be readily available for the formation of mercury complexes with a sulfhydryl functional group. A pretreatment step, which converts these "nonreactive" mercury species to mercury ionic compounds, is necessary prior to cleaning with SCF adsorbent.

Table 8-5

Percent Removal by SCF adsorbent

\begin{tabular}{c|c}
\hline Metal square & Percent removal \\
\hline Copper & $23.3 \pm 39.5 \%$ \\
Aluminum & $35.4 \pm 17.0 \%$ \\
Steel & $0.4 \pm 23.5 \%$ \\
Stainless steel & $52.9 \pm 13.4 \%$ \\
\hline
\end{tabular}

\subsection{CONCLUSIONS}

Based on the experimental data gathered, the following conclusions can be drawn:

- Chemical cleaning with iodine/iodide lixiviant, a simple, fast and reliable method, seems to be a potential decontamination technique for mercury contaminated metals and porous surfaces. Since this is a chemical cleaning technique, the target treatment surfaces should not be reactive to the iodine/iodide lixiviant. The mercury removal effectiveness is dependent on the concentrations of the iodine/iodide lixiviant solutions. The optimum concentrations of the lixiviant should be selected based on the individual target material. The dissolved and strongly complexed mercury, $\mathrm{HgI}_{4}{ }^{2-}$ produced during the treatment process, can be removed and the lixiviant recycled. Techniques are available to recover mercury from the spent lixiviant.

- Decontamination with strippable coating is also a very simple and fast process. The ALARA $^{\text {TM }} 1146$ has been shown to be a better strippable coating material than the Stripcoat TLC Free. Although it is clear that a certain percent of mercury can be removed from different materials tested with this technique, the accurate and precise data regarding the removal effectiveness are not available from the current experiments. Further investigations are needed to improve the material contamination and coating processes.

- Direct use of SCF adsorbent for removal of mercury from the metal surfaces shows low removal effectiveness. Pretreatment may be necessary to convert "nonreactive" mercury species, such as elemental mercury and $\mathrm{HgO}$, to mercury ionic compounds, which form complexes with sulfhydryl functional group in the SCF adsorbent. 
- A single technique may not be adequate for decontamination of mercury from some of the metal and porous materials. Two or more methods may be necessary. In addition, one method is preferred for some materials while other methods may be good for other materials.

- A general decontamination strategy for mercury removal from metal and porous surfaces found in DOE sites is schematically illustrated in Figure 8-1.

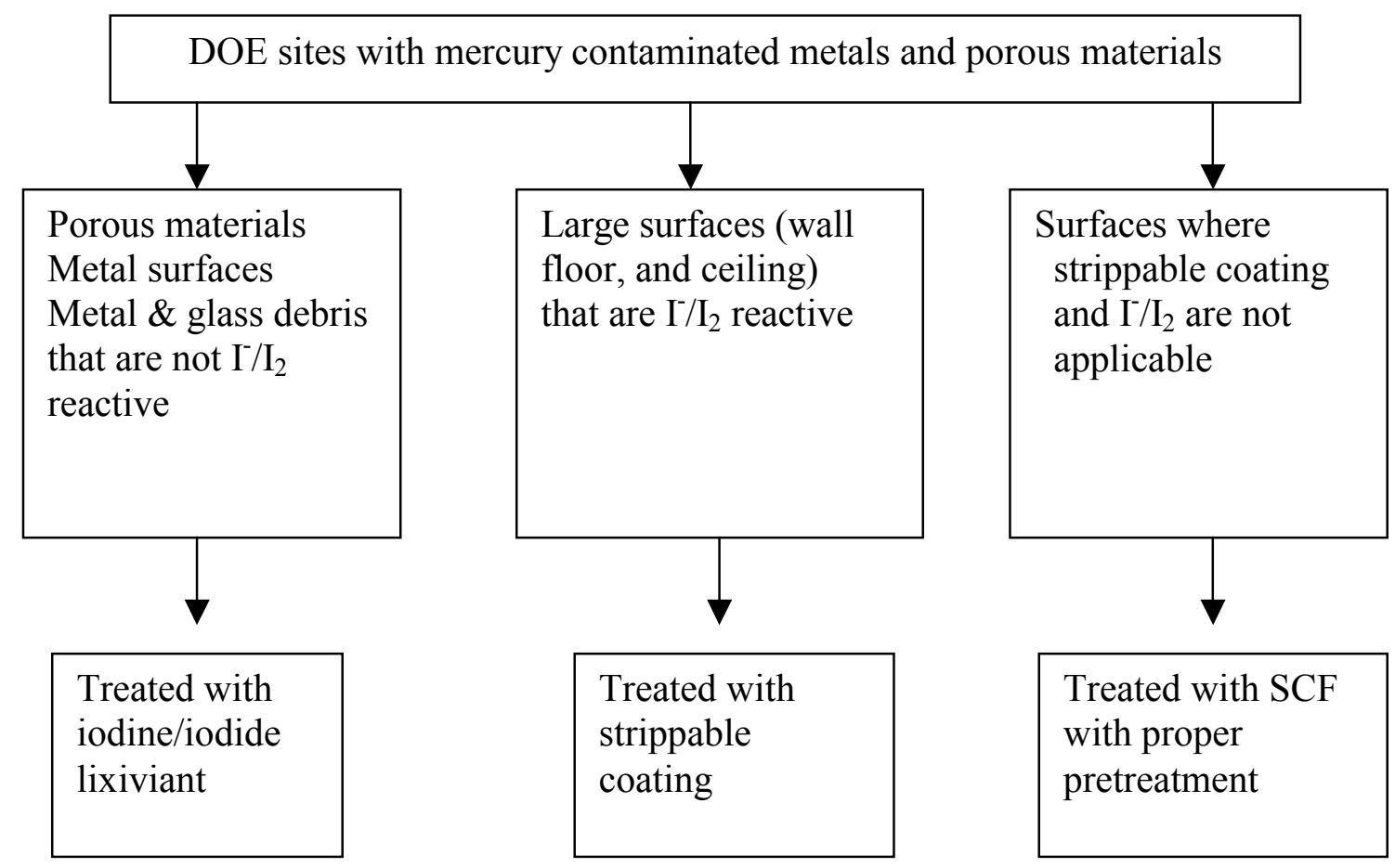

Figure 8-1 Decontamination strategy for mercury removal from metal and porous surfaces found in DOE sites

\subsection{FUTURE STUDIES}

\subsubsection{Testing more materials}

More surface material types that would be found at DOE sites need to be tested with regard to the mercury removal effectiveness since the percent removal of mercury by all the techniques tested so far varied with the specific materials used.

\subsubsection{Further tests on iodine/iodide lixiviant}

Iodine/iodide lixiviant seems to be a promising technique in removal of mercury from the metal and grout surfaces. The optimization of this method in terms of the concentrations of chemicals, contact time, kinds of materials that it can be applied to etc, need further investigation. 


\subsubsection{Development of more reliable contamination and strippable coating procedures}

Clearly the strippable coating is a very simple and fast technique for mercury removal from a variety of surfaces. However, the large standard deviation found in this study indicates that further research on contamination and coating processes has to be conducted in order to evaluate the technique more accurately and precisely.

\subsubsection{Development of alternative methods for evaluating mercury removal}

The processes used in this study might provide alternative bases for mercury removal from the contaminated surfaces. An alternative process might be designed to not only provide effective removal but also control the potential vapor emission of mercury left on the surfaces after treatment with the cleaning techniques.

\subsubsection{Bench testing with actual DOE site samples}

Using small samples of mercury contaminated metal and porous materials obtained from one or more DOE sites (e.g., the ORR), the effectiveness of individual and combined decontamination processes could be evaluated under controlled conditions. Removal efficiencies, contaminant residuals, and mercury vapor emissions before, during, and after treatment could be compared. The information gathered from this testing would further assist in the development of overall strategies for controlling mercury before, during, and after the D\&D of actual mercury contaminated facilities.

\subsubsection{Field demonstration}

The ultimate objective of these studies would be the development of strategies for controlling mercury throughout the D\&D of mercury contaminated facilities. Depending upon the availability and scale of mercury contaminated facilities at candidate DOE sites, the effectiveness of appropriate multi-step, multi-process mercury control strategies could be field tested. Figure 8-1 above is illustrative. 


\subsection{ACKNOWLEDGEMENTS}

The authors would like to thank Myron Georgiadis for his able technical and analytical assistance during this research. 


\subsection{REFERENCES}

Adriano, D.C., 1986, Trace Elements in the Terrestrial Environment, Springer-Verlag, New York, 533p.

Andersson, I., Parkman, H., and Jernolov, A., 1990, The role of sediments as sink or source for environmental contaminants - A case study of mercury and chlorinated organic compounds, Limnologia, 20, 347-360.

Andren, A.W., and Harriss, R.C., 1975, Observation on the association between mercury and organic matter dissolved in natural waters, Geochim. Cosmochim. Acta, 39, 1253-1257.

Andren, A.W., and Nriagu, J.O., 1979, The global cycling of mercury, in Nriagu, J.O., ed., The Biochemistry of Mercury in the Environment, Amsterdam, Elsevier/North-Holland Biomedical Press, V.3, 1-21.

Barnett, M.O., Harris, L.A., Turner, R.R., Stevenson, R.J., Henson, T.J., Melton, R.C., and Hoffman, D.P., 1997, Formation of mercuric sulfide in soil. Environ. Sci. Technol., 31, 3037-3043.

Baughman, G.L., Gordon, J.A., Wolfe, N.L., and Zepp, R.G., 1973, Chemistry of Organomercurials in Aquatic Systems, Ecological Research Series, National Environmental Research Center, U.S. Environmental Protection Agency, EPA-660/3-73012, September 1973.

Becker, N.S.C., and Eldrich, R.J., 1993, Selective recovery of mercury (II) from industrial wastewater, Reactive Polymers, 21, 5-14.

Betts, K., 1999, Bioengineered bacteria show promise in mercury removal, Environ. Sci. Technol., 33, 299A.

Bicak, N., and Sherrington, D., 1995, Reactive \& Functional Polymers, 27, 15.

Bicak, N., Sherrington, D., and Senkal, B.F., 1999, Graft copolymer of acrylamide onto cellulose as mercury selective sorbent, Reactive \& Functional Polymers, 41, 69-76.

Bodek, I., Lyman, W.J., Reehl, W.F., and Rosenblatt, D.H., 1988, Environmental Inorganic Chemistry Properties, Processes, and Estimation Methods, Pergamon Press, New York.

Broom, G.P., et al., 1994, The treatment of heavy metal effluents by crossflow microfiltration, J. Membrane Sci., 87, 219-230.

Cai, Y., Jaffe, R., Alli, A., and Jones, R.D., 1996, Determination of organomercury compounds in aqueous samples by capillary gas chromatography-atomic fluorescence spectrometry following solid-phase extraction, Anal. Chim. Acta, 334, 251-259.

Cai, Y., Jaffe, R., and Jones, R.D., 1999, Interactions between dissolved organic carbon and mercury species in surface waters of the Florida Everglades, Applied Geochemistry, 14, 395-407.

Carlson, G.A., 1974, U.S. Patent 3,785,942, January 15, 1974, assigned to PPG Industries, Inc. 
Charlton, D.S., Fraley, R.H., and Stepan, D.J., 1997, Commercial mercury remediation demonstrations: thermal retorting and physical separation/chemical leaching, Gas Research Institute Topical Report, GRI-96/0274, February 1997.

Colombo, P., Kalb, P.D., and Heiser, J.H., 1997, Process for the encapsulation and stabilization of radioactive, hazardous and mixed wastes, U.S. Patent 5,678,234, October 1997.

Cotton, F.A., Wilkinson, G., Murillo, C.A., and Bochmann, M., 1999, Advanced Inorganic Chemistry, Sixth Edition, Chapter 15.

Cox, C.D., Shoesmith, M.A., and Ghosh, M.M., 1996, Electrokinetic remediation of mercurycontaminated soils using iodine/iodide lixiviant, Environ. Sci. Technol., 30, 1933-1938.

Craig, P.J., 1986, Organomercury compounds in the environment, In Craig, P.J., ed., Organometallic Compounds in the Environment, John Wiley \& Sons, New York.

Darnell, G.S., 1996, Sulfur polymer cement, a final waste form for radioactive and hazardous wastes. Stabilization and solidification of hazardous, radioactive, and mixed wastes: 3rd Volume, ASTM STP 1240. American Society for Testing and Materials, West Conshohocken, PA, T. Michael Gilliam and C.C. Wiles, Eds.

Dean, J.A., 1985, Lange's handbook of chemistry, 13th ed., New York, McGraw Hill Book Company, Inc.

Deshkar, A.M., Bokade, S.S., and Dara, S.S., 1990, Modified Hardwickia Binata bark for adsorption of mercury (II) from water, Water Res., 24, 1011-1016.

Driscoll, C.T., Blette, V., Yan, C., Schofield, C.L., Munson, R., and Holsapple, J., 1995, The role of dissolved organic carbon in the chemistry and bioavailability of mercury in remote Adirondake Lakes, Water, Air, Soil Pollut., 80, 499-508.

Dyrssen D., and Wedborg, M., 1991, The sulfur-mercury (II) system in natural waters, Water, Soil, Soil Pollut., 56, 507-519.

Environment Canada, 1984, Mercury: Environmental and technical infromation for problem spills manual, Technical Services Branch, Environment Protection Program Directorate, Environmental Protection Service, Environment Canada, December 1984, 119 p.

Eichholz, G.G., Petelka, M.F., Kury, R.L., 1988, Migration of elemental mercury through soil from simulated burial sites, Water Research, 22, 15-20.

Fang, S.C., 1978, Sorption and transformation of mercury vapor by dry soil, Environ. Sci. Technol., 12, 285-288.

Fang, S.C., 1981, Studies on the sorption of elemental mercury vapor by soils, Archives of Environ. Contamination Toxicology, 10, 193-201.

Feng, X., Fryxell, G.E., Wang, L., Kim, A.Y., Liu, J., and Kemner, K.M., 1997, Functionalized monolayers on ordered mesoporous supports, Science, 276, 923-926.

Foust, D.F., 1993, Extraction of mercury and mercury compounds from contaminated material and solutions, US Patents 5,226,545.

Funderburk, R.E., 1992, Immobilization of elemental mercury: EmTech Environmental Services, Inc., Presentation at GRI Mercury Workshop, February 10-11, 1992. 
Gates, D.D. et al., 1995, Mercury removal from liquid and solid mixed wastes. Presented at 1995 Waste Management Conference, Tucson, Arizona (February 26 - March 2, 1995).

Geiser, G, and Gross, H., 1989, Inorg. Chim. Acta, 156, 91.

Ghilardi, C.A., Innocenti, P., Midollini, S, Orlandini, A., and Vacca, A., 1992, Synthesis, X-ray crystal structure and NMR characterization of a tetrahedral methylmercury complex with the tripod ligand N(CH2CH2PPh2)3, J. Chem. Soc., Chem. Commum., 1691.

Hansen, C.L., and Stevens, D.K., 1992, Biological and physiochemical remediation of mercurycontaminated hazardous waste, EPA/600/R-92/105, pp. 121-125.

Henke, K.R., et al., 1993, Critical Review of Mercury Contamination Issues Relevant to Manometers at Natural Gas Industry Sites, Gas Research Institute Topical Report, August 1993.

Hintelmann, H., Welbourn, P.M., and Evans, R.D., 1997, Measurement of complexation of methylmercury (II) compounds by freshwater humic substances using equilibrium dialysis, Environ. Sci. Technol., 31, 489-495.

Huang, C.P., and Blankenship, D.W., 1984, The removal of mercury (II) from dilute aqueous solution by activated carbon, Water Res., 18, 37-46.

Hudson, R.J.M., Gherini, S.A., Watras, C.J., and Porcella, D.B., 1994, Modeling the biogeochemical cycling of mercury in lakes: the mercury cycling model (MCM) and its application to MTL study lakes, In Mercury Pollution - Integration and Synthesis, Ed. By C.J. Watraas and J.W. Huckabee, CRC Press, pp 473-523.

Hulet, G.A., Conley, T.B., and Morris, M.I., 1998, Mixed waste focus area mercury contamination product line: an integrated approach to mercury waste treatment and disposal, INEEL/CON-98-00523.

Humenick, M.J., Jr., Asce, M., and Schnoor, J.L., 1974, Improving mercury (II) removal by activated carbon, ASCE J. Environ. Eng. Div., 100, 1250-1263.

INEL, 1997a, Mixed waste focus area technology development requirements document: Mercury amalgamation (INEL/EXT-97-00314, LMITCO Controlled Document, Rev 0). http/wastenot.inel.gov/mwfa/merdoc

INEL, 1997b, Mixed waste focus area technology development requirements document: Mercury stabilization (INEL/EXT-97-00316, LMITCO Controlled Document, Rev 0). http/wastenot.inel.gov/mwfa/merdoc

INEL, 1997, Mixed waste focus area technology development requirements document: Mercury removal/extraction (INEL/EXT-97-00317, LMITCO Controlled Document, Rev 0). http/wastenot.inel.gov/mwfa/merdoc

Izatt, R.M. et al., 1991, Heavy metal removal using bound macrocycles, Water Sci. Tech., 23, 301-308.

Jones, H.R., 1971, Mercury Pollution Control, Noyes Data Corporation, New Jersey.

Kaiser, G., and Tolg, G., 1980, Mercury, in Hutzinger, O., ed., Handbook of Environmental Chemistry: Anthropogenic Compounds: Berlin, Springer - Verlag, 1-58. 
Kalb, P.D., Adams, J.W., Milian, L.W., Penny, G., Brower, J., and Lockwood, A., 1999, Mercury bakeoff: technology comparison for the treatment of mixed waste mercury contaminated soils at BNL, Presented at Waste Management '99, Tucson, AZ, March 1999.

Kosarek, L.J., 1981, Removal of various toxic heavy metals and cyanide from water by membrane processes, In Chemistry in Waste Reuse, Chapter 12.

Larson, K.A., and Wiencek, J.M., 1992, Liquid ion exchange for mercury removal from water over a wide pH range, Ind. Eng. Chem. Res., 31, 2714-2722.

Lee, Y.H. and Mowrer, J., 1989, Anal. Chim. Acta, 221- 259.

Leermakers, M., Meuleman, C., and Baeyens, W., 1995, Mercury Speciation in the Scheldt Estuary, Water, Air, Soil Pollut., 80, 641-652.

Lide, D.R., Editor-in-Chief, Handbook of Chemistry and Physics, 77th Edition, 1996-1997, CRC.

Lide, D.R., 1990, CRC Handbook of Chemistry and Physics, 71st ed., Boca Raton, Florida, CRC Press, Inc.

Lindberg, S.E., and Harriss, R.C., 1975, Mercury-organic matter associations in estuarine sediments and interstitial waters. Environ. Sci. Technol., 8, 459-462.

Magos, L., 1975, Mercury and mercurials, British Medical Bulletin, 31, 241-245.

Martell, A.E., and Hancock, R.D., 1996, Metal Complexes in Aqueous Solutions, Plenum Press.

Martell, A.E., Smith, R.M., and Motekaitis, R.J., 1998, NIST Critically Selected Stability Constants of Metal Complexes Data Base, NIST Std. Ref. Database \# 46, Department of Commerce, Gaithersburg, MD.

Mattigod, S.V., Feng, X.D, Fryxell, G.E., Liu, J., and Gong, M.L., 1999, Separation of complexed mercury from aqueous wastes using self-assembled mercaptan on mesoporous silica, Separation Sci. Technology, 34, 2329-2345.

Meagher, R., 1999, Proceedings of the National Academy of Sciences, 8 June 1999.

Metcalf \& Eddy, Inc., 1991, Wastewater Engineering, 3rd ed., New York, McGraw-Hill, Inc.

Midollini, S., Barbaro, P., Cecconi, F., Ghilardi, C.A., Orlandini, A., Vacca, A., 1994, Metal coordination and $\mathrm{Hg}-\mathrm{C}$ bond protonolysis in organomercury(II) compounds synthesis, characterization, and reactivity of the tetrahedral complexes [(np3)HgR]-(CF3)SO3] \{np3 $=\mathrm{N}(\mathrm{CH} 2 \mathrm{CH} 2 \mathrm{PPh} 2) 3 ; \mathrm{R}=\mathrm{CH} 3, \mathrm{C} 2 \mathrm{H} 5, \mathrm{C} 6 \mathrm{H} 5\}$, Inorg. Chem., 33, 6163.

Mierle, G., and Ingram, R., 1991, The role of humic substances in the mobilization of mercury from watersheds, Water, Air, Soil Pollut., 56, 349-357.

Namasivayam, C., and Periasamy, K., 1993, Bicarbonate-treated peanut hull carbon for mercury (II) removal from aqueous solution, Water Research, 27, 1663-1668.

Patterson, J.W., 1985, Wastewater Treatment Technology, 2nd ed., Ann Arbor Science, Ann Arbor, Mi.

Patterson, J.W., et al., 1992, Toxicity reduction methodologies. In: Toxicity Reduction, Evaluation, and Control. Lancaster, PA, Technomic Publishing Co. 
Perona, J.J., and Brown, C.H., 1993, A technology assessment for mercury-contaminated mixed wastes, Mixed Waste Integrated Program, DOE/MWIP-9, March 1993.

Perry, R., 1974, Mercury Recovery from Contaminated Wastewater and Sludges, EPA/660/2$74 / 086$.

Ravichandran, M., 1999, Interactions between mercury and dissolved organic matter in the Florida Everglades, Ph.D Dissertation, University of Colorado.

Ritter, J.A., and Bibler, J.P., 1992, Removal of mercury from wastewater: Large-scale performance of an ion exchange process, Water Sci. Technol., 25, 165-172.

Rogers, R.D., 1992, Availability of metallic mercury in soil, In Charlton, D.S., and Harju, J.A., Eds., Workshop on mercury Contamination at Natural Gas Industry Sites, Chicago, Gas Research Institute, GRI-92/0214, p. 73-103

Schuster, E., 1991, The behavior of mercury in the soil with special emphasis on complexation and adsorption processes - a review of the literature. Water, Air, Soil Pollut., 56, 667680 .

Schwarzenbach, G., and Schellenberg, M., 1965, Die Komplexchemie des methylquecksilberkations, Helv. Chim. Acta, 48, 28.

Science Applications International Corporation (SAIC), 1998, Technologies for immobilizing high mercury subcategory wastes, SAIC Project No. 06-6312-08-5226-002. July 1998.

Sen, A.K., and De, A.K., 1987, Adsorption of mercury (II) by coal fly ash, Water Research, 21, $885-888$

Simpson, R.B., 1961, Association constants of methylmercury with sulfhydryl and other bases, J. Amer. Chem. Soc., 83, 4711.

Sites, A., and Oberholtzer, L., 1992, Mercury point-of-entry treatment study, New Jersey Department of Environmental Protection and Energy, September.

Skoog, D.A., Holler, F.J., and Nieman, T.A., 1998, Principles of Instrumental Analysis, Fifth Edition, Saunders College Publishing.

Sorg, T.J., 1979, Treatment technology to meet the interim primary drinking water regulation form organics: Part 4. J. AWWA, 71, 454-466.

Southeast Environmental Research Center (SERC) Standard Operation Procedures, \# 001-99, 1999 Determination of Total Mercury in Water samples, FIU-SERC.

Squires, R.C., 1992, Removal of heavy metals from industrial effluent by crossflow microfiltration. Water Sci. Tech., 25, 55-67.

Stepan, D.J., Fraley, R.H., Henke, K.R., Gust, H.M., Hassett, D.J., Charlton, D.S., Schmit, C.R., 1993, A Review of Remediation Technologies Applicable to Mercury Contamination at Natural Gas Industry Sites, Gas Research Institute Topical Report, September 1993.

Stepan, D.J., Fraley, R.H., and Charlton, D.S., 1995, Remediation of mercury-contaminated soils: development and testing of technologies, Gas Research Institute Topical Report, GRI-94/0402, May 1995.

Stumm, W., and Morgan, J.J., 1995, Aquatic Chemistry, 3rd ed., John \& Wiley. 
Terashima, Y., 1986, Removal of dissolved heavy metals by chemical coagulation, magnetic seeding, and high gradient magnetic filtration, Water Res., 20, 537-545.

Thiem, L., Badorek, D., and O'Conner, J.T., 1976, Removal of mercury from drinking water using activated carbon, J. AWWA, August, 447-451.

Turner, R.R., 1992, Elemental mercury in soil and the subsurface - transformations and environmental transport: arsenic and mercury: workshop on removal, recovery, treatment, and disposal: U.S. Environmental Protection Agency, EPA/600/R-92/105. p. 69.

U. S. DOE, 1994, Oak Ridge Y-12 plant remedial action technology logic diagram, Volume 3, Technology Evaluation Data Sheet (March).

U.S. DOE, 1998, Mixed Waste Focus Area Monthly Report: February. Technical Task RL37mw62 - Mercury Separation from Soils. pp. 31-33.

U.S. EPA, 1974, Development document for effluent limitations guidelines and new source performance standards for the major inorganic products segment of the inorganic chemicals manufacturing point source category, EPA/440/1-74/007-a.

U.S. EPA, 1993, Risk reduction engineering laboratory site technology profiles, 8th ed., (November).

U.S. EPA, 1997, Mercury Study Report to Congress, EAP-452/R-97-010, December 1997.

U.S. EPA, 1997a, Capsule Report, Aqueous Mercury Treatment, EPA/625/R-97/004, July 1997.

Varshal, G.M., Buachidez, N.S., Velyukhanova, T.K., and Chkhetia, D.N., 1996, The role of organic carbon in mercury cycle, In Global and Regional Mercury Cycles: Source, Fluxes, and Mass Balances, Ed., by W. Baeyens et al., Kluver Academic Publishers, pp 403-414.

Watras, C.J., Morrison, K.A., and Bloom, N.S., 1995, Chemical correlates of mercury and methylmercury in northern Wisconsin Lake waters under ice-cover, Water, Air, Soil Pollut., 84, 253-267.

Weyand, T.E., Rose, M.V., and Koshinski, C.J., 1994, Demonstration of thermal treatment technology for mercury-contaminated soils, Gas Research Institute, Final Report, June 1994.

Wygasch, E. and Weisss, G., 1973, U.S. Patent 3,755,110, August 28, 1973, assigned to Badische Anilin- \& Soda-Fabric AG, Germany. 